\title{
Konsumkritische Medienpraktiken als Schlüssel(-kategorie) für eine nachhaltige Gesellschaft und das "gute Leben"
}

Vor dem Hintergrund des Forschungsstandes zur Nachhaltigkeitskommunikation und dem Feld, das sich in der Kommunikations- und Medienwissenschaft mit dem ,guten Leben“ beschäftigt, wurde ein Forschungsdesiderat ausgearbeitet, das in Hinblick auf die Frage existiert, wie sich Individuen, Nichtregierungsorganisationen und Unternehmen Medien(-technologien) aneignen, um zu einer nachhaltigen Gesellschaft und einem ,guten Leben“ beizutragen. Wie im vorherigen Kapitel erläutert, wurde diese Forschungsfrage in einer vergleichenden qualitativen Studie am Beispiel dreier Fallstudien untersucht. Dabei wurde als zentrales theoretisches Konzept der Terminus der konsumkritischen Medienpraktiken entworfen. Die Ergebnisse der Studie präsentiere ich entlang der sechs theoretischen Dimensionen, die in der Analyse virulent wurden, und die die Dimensionen konsumkritischer Medienpraktiken ausmachen.

\subsection{Medienpraktiken und Materialität: Den Begriff der Medienpraktiken weit fassen}

Mit der Forschungsfrage des vorliegenden Buches, was Individuen, Organisationen und Unternehmen mit Medien machen, um zu einer nachhaltigen Gesellschaft und einem ,guten Leben“ beizutragen, stehen Medienpraktiken verschiedener Akteur*innen im Fokus dieser Arbeit. In Abschn. 3.2.1 wurde das Konzept der Medienpraktiken als eine der theoretischen Dimensionen skizziert, die für die Analyse relevant waren. Fokus dieser Medienpraktiken ist (auch) die Materialität digitaler Medientechnologien. In diesem Teilkapitel sollen daher anhand des Datenmaterials die Ergebnisse der hier diskutierten empirischen Studie präsentiert werden, welche in Hinblick auf die beiden theoretischen Dimensionen der Medienpraktiken sowie Materialität relevant sind.

(C) Der/die Autor(en) 2022

S. Kannengießer, Digitale Medien und Nachhaltigkeit,

Medien • Kultur • Kommunikation,

https://doi.org/10.1007/978-3-658-36167-9_4 
Im Folgenden werden zunächst die Medienpraktiken, die in den Fallstudien identifiziert werden konnten, beschrieben. Bereits hier wird deutlich, dass die Materialität digitaler Medientechnologien für die untersuchten Medienpraktiken von großer Bedeutung ist. Auf der Folie der hier präsentierten empirischen Studie argumentiere ich für ein weites Begriffsverständnis des Terminus' Medienpraktik, der diese sowohl in Relation zu Medieninhalten als auch zu Medientechnologien und ihrer Materialität umfasst. ${ }^{1}$ Außerdem wird in diesem Teilkapitel betont, dass die sozial-ökologischen Aspekte der Materialität digitaler Medientechnologien, welche durch die Akteur*innen der verschiedenen Fallstudien in diesen sichtbar werden und die Folie für die Medienpraktiken bilden, auch in der Kommunikations- und Medienwissenschaft intensiver diskutiert und weiter untersucht werden müssen. Damit kann das Fach seiner wissenschaftlichen Verantwortung nachkommen, aktuelle Herausforderungen digitaler Gesellschaften zu analysieren (s. zu dieser Argumentation detaillierter Abschn. 5.2).

Um die Medienpraktiken und die Aspekte der Materialität in den Fallstudien verstehen zu können, muss auch erläutert werden, wer die in den jeweiligen Fallstudien handelnden Akteur*innen sind. Nur durch eine solche Betrachtung wird verständlich, wer, wie und später warum (s. hierzu Abschn. 4.1) agiert. Neben den Akteur*innen sollen hier auch noch die Analyseerkenntnisse zu den Orten der exemplarisch untersuchten Repair Cafés dargelegt werden, da diese für die im Anschluss beschriebenen Medienpraktiken relevant sind (s. hierzu auch Kannengießer 2018c, S. 216 ff.).

In der Fallstudie zum Reparieren von Medientechnologien in Repair Cafés konnten verschiedene Akteur*innen identifiziert werden, die unterschiedliche Rollen erfüllen (siehe auch Kannengießer 2018e, S. 106 ff.). Neben den Organisator*innen der Veranstaltungen bieten Helfer*innen Unterstützung im Reparaturprozess an; Hilfesuchende suchen Rat beim Reparieren ihrer mitgebrachten, defekten Alltagsgegenstände, weitere Besucher*innen der Veranstaltungen beobachten hingegen das Geschehen und nehmen nur das in die Veranstaltungen integrierte Café-Angebot wahr. Die verschiedenen Akteursgruppen sind sehr heterogen: Menschen verschiedener Altersgruppen mit unterschiedlichen (Aus-)Bildungshintergründen und aus verschiedenen sozialen Klassen sowie Geschlechtergruppen sind an den Reparaturveranstaltungen beteiligt. So organisieren Frauen und Männer, Junge und Alte, Akademiker*innen und NichtAkademiker*innen aus verschiedenen Berufsfeldern die Repair Cafés. Es lässt

\footnotetext{
${ }^{1}$ Für diese Argumentation eines weiten Verständnisses des Terminus Medienpraktiken in Hinblick auf die auch hier genutzten Fallstudien siehe Kannengießer (2018e, S. 108 ff., 2020a); für die Relevanz von Materialität in den Fallstudien zum Repair Café und dem Fairphone siehe Kannengießer (2019).
} 
sich kein homogenes Bild der Veranstalter*innen zeichnen - Repair Cafés werden also von ganz verschiedenen Personen an sehr unterschiedlichen Orten organisiert. Auffällig ist jedoch bei der Gruppe der Helfer*innen - und diese Beobachtung teile ich mit Rosner (2013) -, dass diese eher traditionelle Geschlechterrollen in Hinblick auf ihre Reparaturkompetenz einnehmen: Während ich in den besuchten Veranstaltungen ausschließlich Männer beobachten konnte, die Hilfe bei der Instandsetzung elektronischer Geräte im Allgemeinen und Medientechnologien im Besonderen anboten, waren es ausschließlich Frauen, die beim Nähen kaputter Textilien halfen. Die Gruppe der Hilfesuchenden setzt sich wiederum sehr heterogen zusammen - Männer wie Frauen, jung und älter, mit unterschiedlichem Einkommen und Bildungshintergründen bringen ihre defekten Dinge mit und suchen Unterstützung beim Reparieren (s. auch Kannengießer 2020d).

Die Wahl der Veranstaltungsräume der Repair Cafés hängt von den Hintergründen der jeweiligen Organisator*innen und ihren Zielen ab (s. zu den Zielen detaillierter Abschn. 4.2). ${ }^{2}$ Manchmal ist der Veranstaltungsort auch Ergebnis pragmatischer Entscheidungen wie im Fall einer Künstlerin in Berlin, die das untersuchte Repair Café in ihrem Atelier in Kreuzberg anbietet, so dass kein weiterer Ort gesucht, finanziert oder umgebaut werden muss. Oftmals ist die Wahl für einen bestimmten Veranstaltungsraum oder -ort aber auch politisch motiviert. So organisiert die Rentnerin das Repair Café in Garbsen in Kooperation mit der Freiwilligenagentur der Stadt bewusst in einem Stadtteilzentrum eines Viertels, in dem viele Menschen mit Migrationshintergrund leben; sie erklärt im Interview:

\begin{abstract}
„Den haben wir extra gewählt, weil die Begegnungsstätte Auf der Horst sozusagen ein sozial schwieriges Umfeld ist, auf der einen Seite, und auf der anderen Seite ein sehr kommunikatives Umfeld, [...] einfach um zu sagen: Wir sind Teil einer Stadt und ihr seid Teil einer Stadt und wir gehören alle dazu, egal woher wir [her-]kommen und deswegen haben wir gesagt: mitten rein.“
\end{abstract}

Die Organisatorin differenziert hier zwischen ,uns“ und ,ihnen“ und konstruiert damit zwei Gruppen: Einmal die der Organisator*innen und Helfer*innen des Repair Cafés, die offenbar nicht zu diesem „,sozial schwierigen Umfeld“ gehören, und zudem eben dieses. Sie beschreibt, dass z. B. viele türkische Jugendliche oder Kinder mit ihren Fahrrädern kämen und findet das gut, ,weil die dann hier so eine Anbindung haben." Die Organisatorin verbindet also mit der Reparaturveranstaltung u. a. die Idee der Integration von Menschen verschiedener Nationalität

\footnotetext{
${ }^{2}$ Siehe zur Wahl der Orte und Räume auch Kannengießer (2018c, 216 ff.) Während der Covid-19-Pandemie fanden die Repair Cafés in Deutschland nicht in Präsenz statt, es gab aber Onlineveranstaltungen, die zum einen von der Anstiftung Ertomis organisiert wurden, zum anderen von einzelnen Reparaturinitiativen.
} 
oder kultureller Hintergründe (zu den Zielen s. u.). ${ }^{3}$ Die von mir durchgeführte Studie zeigte jedoch, dass an der Reparaturveranstaltung relativ wenige Menschen mit Migrationshintergrund teilnehmen.

Auch die Organisator*innen des Oldenburger Repair Cafés haben den Veranstaltungsort mit Bedacht ausgesucht. Zwar sind alle Organisator*innen Angestellte der Universität Oldenburg, sie haben aber dennoch außeruniversitäre Räume gewählt: Während das Repair Café nach der Gründung 2013 in der Kneipe Polyester in der Innenstadt Oldenburgs stattfand, wurde es aufgrund einer Kooperation mit dem Oldenburgischen Staatstheater in den Spielzeiten 2014 bis 2016 in einem vom Theater genutzten Ladenlokal in der Fußgängerzone Oldenburgs durchgeführt. ${ }^{4}$ Die Kooperation der Oldenburger Reparaturinitiative mit dem Oldenburgischen Staatstheater hat auch zu einer Erweiterung des Angebots der Reparaturveranstaltungen geführt. Der Reparaturbegriff wurde in diesem Rahmen breiter ausgelegt und nicht nur auf klassische Reparaturpraktiken, zum Erhalt oder Weiterverwendung von Technologien reduziert, um so mit deren Verschleiß und rückschrittlichen Veränderungen umzugehen (Rosner und Turner 2015, S. 59; s. Einleitung). Vielmehr regten die Organistor*innen auch an, kollektives Wissen zu „reparieren“, indem „alte“ Fertigkeiten wie etwa das Spinnen von Wolle unterrichtet und soziale Beziehungen durch eine Vermittlungsshow (s. u.) „repariert“ wurden. Darüber hinaus wurde das Thema Reparieren bzw. der Verfall von Gegenständen in einem „Museum für Konsumwahn“ vorgeführt, in dem defekte Alltagsgegenstände in sogenannten „Leichensäcken“ ausgestellt wurden. Der Raumwechsel des Repair Cafés war einerseits Ergebnis der Kooperation mit dem Oldenburgischen Staatstheater, andererseits aber auch nötig, da das Polyester für die wachsende Zahl der Veranstaltungsteilnehmer*innen zu klein geworden war. Bewusst wählten die Organisator*innen aber als neuen Ort keine Räume im Theater, sondern ein Gebäude in der Fußgängerzone. Eine der Organisator*innen erklärt im Interview, dass das vom Theater genutzte Gebäude in der Fußgängerzone ,niedrigschwelliger“ sei als die Theaterräume selbst. Des Weiteren verknüpft sie mit diesem Standort eine politische Aussage:

„Um uns 'rum passiert der Konsumwahn vom Feinsten und wir sind der Antikonsum.

[...] Im Prinzip ist es so, dass die Leute, die sich mit neuen Sachen eindecken um

\footnotetext{
${ }^{3}$ Einige Reparaturinitiativen entwickeln seit 2014 Konzepte für die Zusammenarbeit mit Geflüchteten, wie z. B. auch das hier untersuchte Oldenburger Repair Café oder eines in Recklinghausen (Recklinghauser Zeitung ohne Datum).

${ }^{4}$ Seit September 2016 findet das Reparaturcafé im Kunstforum Oldenburgs in Kooperation mit dem Werkschule e. V. statt und während der Covid-19-Pandemie auch online (https:// www.repaircafeoldenburg.org).
} 
uns rum, hier vielleicht durch Zufall in die Baumgartenstraße [Teil der Fußgängerzone, S. K.] kommen und sehen: ,Ah Reparaturcafé, ach ja, eigentlich hätte ich mir vielleicht keinen neuen Mixer kaufen müssen, sondern den alten reparieren lassen, ‘ und vielleicht dann umdenken, und die kommen nächste Woche mit einem kaputten Toaster und kaufen dann lieber eine Packung Toastbrot und keinen neuen Toaster.“

Sie sieht das Repair Café darüber hinaus auch als einen Ort der Entschleunigung, in dem Menschen zur Ruhe kommen können. Gleichzeitig beschreibt sie es als einen Raum der Kommunikation, ein Merkmal, welches sie ebenfalls als konträres Gegenstück zur umliegenden Fußgängerzone definiert: „Man kommt in jedem Fall irgendwie in Kontakt mit Menschen und das hat man beim ShoppenGehen draußen nicht so viel." Mit dieser Aussage tangiert die Organisatorin auch die zentralen Kommunikations- und Medienpraktiken, die für diese Fallstudie herausgearbeitet und näher untersucht wurden. ${ }^{5}$ Denn neben dem Reparieren ist Kommunikation eine der zentralen Handlungen in den Repair Cafés. So erklärt auch eine andere Organisatorin des Oldenburger Repair Cafés:

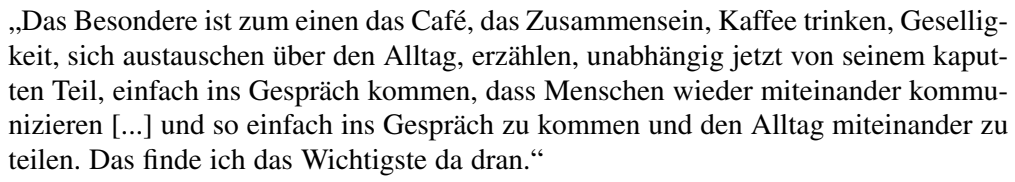

Die Relevanz der Kommunikation steckt bereits im Namen der Veranstaltungen: Es ist ein Repair Café und kein Reparatur ,-labor“, „-shop“ oder „-geschäft“. Manche Personen kommen alleinig zu den Veranstaltungen, um Kaffee und Kuchen zu genießen sowie sich zu unterhalten. So erklärt ein 27-jähriger Fahrradkurier, der das Oldenburger Repair Café besucht, beispielsweise:

\begin{abstract}
„Ja, also es ist halt ein Café. Also ich mach ja auch grad nichts, sitze hier nur rum und hänge $a b$ und habe gerade einen Kuchen gegessen. Das ist auch eine schöne Sache dabei und ja, dieses in Kontakt treten mit neuen Leuten oder mit anderen Leuten, mit denen man sonst nicht so viel zu tun hat.“
\end{abstract}

Die Kommunikation findet unter den beteiligten Akteur*innen jedoch nicht nur vis-à-vis während der Reparaturveranstaltungen statt, sondern auch medienvermittelt zwischen den Veranstaltungen. So nutzen die Organisator*innen der Repair Cafés E-Mailing-Listen, um die Helfer*innen anzufragen und zu koordinieren, aber auch um interessierte Hilfesuchende einzuladen. Damit ist die medienvermittelte Kommunikation neben der Koordination und Organisation auch wichtig für

\footnotetext{
${ }^{5}$ Siehe zur Analyse der Kommunikationsprozesse und Medienpraktiken in Repair Cafés auch Kannengießer (2018e, S. 108 ff., 2020a).
} 
die Öffentlichkeitsarbeit durch die Organisator*innen. Viele der in Deutschland organisierten Veranstaltungen pflegen dafür auch eigene Websites oder Profilseiten auf Facebook (s. Verweise auf den einzelnen Profilen verschiedener Repair Cafés auf www.reparatur-initiativen.de). Diese sowie auch Poster und Flyer, die in den jeweiligen Dörfern und Städten, in denen die Reparaturveranstaltungen stattfinden, verteilt werden, werden für die Öffentlichkeitsarbeit genutzt. Die visà-vis, aber auch die medienvermittelte Kommunikation ist darüber hinaus auch für Vergemeinschaftungsprozesse zentral, die in Abschn. 4.4 näher betrachtet werden.

Neben der Vis-à-vis-Kommunikation in den Reparaturveranstaltungen und der medienvermittelten Kommunikation zwischen den Veranstaltungen für die Öffentlichkeitsarbeit, die Organisation der Veranstaltungen und hier u. a. für die Vernetzung der Beteiligten, ist auch der Prozess des Reparierens selbst in den Repair Cafés oftmals ein kommunikativer: Die Hilfesuchenden und Helfer*innen kommen über die defekten Alltagsgegenstände miteinander ins Gespräch, indem die Hilfesuchenden beschreiben, welche Probleme sie mit den defekten Dingen haben und die Helfer*innen die von ihnen identifizierten Defekte erläutern. Im Prozess des Reparierens erklären die Helfer*innen dann, was sie tun, und geben ihr Reparaturwissen weiter. Dabei versuchen sie oftmals auch, die Hilfesuchenden konkret einzubinden und leiten den Reparaturprozess „nur“ an. Diese Einbindung hat jedoch v. a. bei elektrischen Geräten im Allgemeinen und Medientechnologien im Besonderen ihre Grenzen, da dessen Aufbau oftmals so kompliziert ist, dass die Reparatur Grundwissen über die Apparate erfordert, über welches die Hilfesuchenden selbst meist nicht verfügen (zur Komplexität digitaler Medientechnologien s. Kannengießer 2018b). Neueste Medientechnologien wie Tablets, Laptops und Smartphones sind zudem oftmals nicht mehr oder nur mit Spezialwerkzeug zu öffnen und damit auch nicht oder kaum zu reparieren (s. u.). So zeigen die Beobachtungen in den ausgewählten Repair Cafés, dass die Helfer*innen meistens die gesamte Reparatur für die Hilfesuchenden durchführen. Der Anspruch der Organisator*innen, mit den Repair Cafés Reparaturwissen zu verbreiten sowie die Hilfesuchenden in Hinblick auf ihre Alltagsgegenstände zu ermächtigen, wird damit oftmals nicht erfüllt (s. detaillierter Abschn. 4.2).

Dennoch ist das Reparieren ein kommunikativer Akt, der im Rahmen der Reparaturveranstaltungen vis-à-vis stattfindet. Die Kommunikation spielt sich dabei nicht nur zwischen den am Reparaturprozess beteiligten Personen ab, sondern auch zwischen den Menschen und den Medientechnologien selbst, da Reparieren mit Jackson und Kang (2014, S. 10) als ,communication with material objects" beschrieben werden kann. Das Reparieren von (digitalen) Medientechnologien definiere ich darüber hinaus aber auch als Medienpraktik. Versteht man 
eine Praxis als einen „Nexus von wissensabhängigen Verhaltensroutinen“ (Reckwitz 2003, S. 291; s. Abschn. 3.2.1) und im Gegensatz zu Handlungen als nicht punktuell und individuell, sondern als ein sozial geteiltes, routinisiertes und durch ein implizites und interpretatives Wissen gekennzeichnetes ,sozial ,verstehbares“ Bündel von Aktivitäten“ (ebd., S. 289), so ist das Reparieren von Medientechnologien in Repair Cafés als Praktik zu definieren, da es eine sozial geteilte Aktivität ist, die eine „kollektive Verhaltensweise“ (s. hierzu Reckwitz 2003, S. 289) darstellt, an welche Wissen gebunden ist. Dieses Wissen ist nicht nur ein solches über die Art und Weise des Reparierens u. a. digitaler Medientechnologien, über das v. a. die Helfer*innen verfügen, es ist auch ein Wissen über die prinzipiellen Möglichkeiten des Reparierens sowie die sozial-ökologischen Probleme der Produktion und Entsorgung digitaler Medientechnologien, die wiederum eine Folie für die Motivation des Reparierens darstellen (s. hierzu Abschn. 4.2) und über die die Teilnehmenden der Repair Cafés sich austauschen.

Als zentrale Frage für die Erforschung von Medienpraktiken formulierte Couldry (2004, S. 119): „What, quite simply, are people doing in relation to media across a whole range of situations and contexts?" Diese Frage kann für die Fallstudie zum Reparieren von Medientechnologien in Repair Cafés einfach beantwortet werden: Menschen reparieren Medientechnologien. Denn sind Medienpraktiken solche Praktiken, die in Relation zu Medien stattfinden, so ist das Reparieren von (digitalen) Medientechnologien auch eine Medienpraktik, da sich die Praktik des Reparierens auf Medientechnologien bezieht. Helfer*innen und Hilfesuchende öffnen und säubern die Medientechnologien, sie schrauben, kleben und löten. Wie bereits oben angemerkt, ist dabei ein Gefälle auszumachen, da v. a. bei der Reparatur digitaler Medientechnologien, die Helfer*innen oftmals für die Hilfesuchenden reparieren, auch wenn das gemeinsame Reparieren eines der Ziele der Veranstalter*innen ist (s. oben und Abschn. 4.2). Dennoch setzen sich die Helfer*innen und Hilfesuchenden durch die Medienpraktik des Reparierens mit der Materialität der Medientechnologien im Sinne einer Stofflichkeit und Beschaffenheit auseinander. Sie erfahren die Medientechnologie haptisch, begreifen die Beschaffenheit der Geräte, lernen die einzelnen Teile kennen, aus denen der jeweilige Apparat besteht, ferner die Art und Weise, wie diese Teile zusammengefügt sind, zudem die (Soll-)Bruchstellen der Medientechnologien und schließlich auch die der Materialität inhärenten Möglichkeiten (sowie Unmöglichkeiten) des Reparierens bzw. Repariertwerdens. Dabei stehen die Helfer*innen und Hilfesuchenden bei digitalen Medienapparaten wie Smartphones und Laptops vor der materiellen Herausforderung, dass diese nicht, sehr schwierig oder nur mit Spezialwerkzeug zu öffnen sind. So moniert ein Helfer im Berliner Repair Café in Hinblick auf die Beschaffenheit neuerer Medientechnologien: 
„Früher waren die [Medientechnologien, S. K.] hochwertiger anzufassen, da waren die Knöpfe, wo man sie angefasst hat, da hat man schon gemerkt, da hat man einen Widerstand. Also, das Hochwertige, das kann ich tausendmal an- und abschalten, das geht nicht kaputt. Heute ist alles, muss alles günstig produziert werden, das ist dann Kunststoff und bricht dann weg und dann ist es nicht mehr reparabel. Man kommt nicht mehr ran.“

Der Interviewpartner kritisiert hier zum einen die stoffliche Beschaffenheit neuerer Medientechnologien, die oftmals aus Kunststoff hergestellt sind, zum anderen den Aufbau der Geräte, an deren „Inneres“ er oft nicht mehr rankommt, da die Apparate nicht oder schwierig zu öffnen sind.

Über den Aufbau der Medientechnologien hinaus umfasst die Materialität hier aber auch noch eine zweite Dimension, die sich auf die in den Produktionsprozessen digitaler Medientechnologien verwendeten Ressourcen und des elektronischen Mülls bezieht (s. Abschn. 2.2.2). Das Wissen um die sozialökologischen Folgen der Produktion und Entsorgung digitaler Medientechnologien, welche sich in der Materialität der Medienapparate manifestieren, bildet die Hintergrundfolie für die Medienpraktik des Reparierens in Repair Cafés: Die Beteiligten der Repair Cafés wissen aus der massenmedialen Berichterstattung um die in Abschn. 2.2.2 erläuterten sozial-ökologischen Folgen der Produktion digitaler Medientechnologien. In den Interviews verweisen viele Befragte v. a. auf die menschenunwürdigen und umweltschädlichen Bedingungen der Ressourcengewinnung und hier insbesondere auf den Abbau des für digitale Medientechnologien benötigten Coltans, sowie auf die Problematik der unsachgemäßen Entsorgung elektronischen Mülls. So meint ein 42-jähriger Elektriker, der seine Reparaturhilfe im untersuchten Berliner Repair Café anbietet, etwas zynisch:

„Wegschmeißen ist nicht so sinnvoll, finde ich, und es sind in der Elektronik ja oft unglaublich wertvolle Rohstoffe verbaut, wie Coltan und Kupfer, Gold usw. und jeder Deutsche schmeißt davon im Schnitt jedes Jahr 15 Kilo weg. Und die landen dann in Afrika und werden dann am Strand verbrannt. Das ist nicht so richtig nett für die Umwelt und die Mitwelt und die Ressourcen. Insofern ist das [Reparieren, S. K.] wenigstens ein kleiner Schritt.“

Ein 70-jähriger ehemaliger Hauptschullehrer in Oldenburg, der Hilfe beim Reparieren elektrischer Geräte anbietet, argumentiert aufgrund der knappen für digitale Medientechnologien benötigten Ressourcen sogar konkret für eine gesellschaftliche Notwendigkeit des Reparierens:

„Also das sind ja immer Rohstoffe, die da drinstecken [in den Medientechnologien, S. K.]. Die verschiedenen Metalle und Materialien, die man speziell für die neuen 
elektronischen Handys und so weiter braucht, die sind inzwischen ziemlich knapp und werden immer teurer und man muss reparieren."

Auf die Ziele der Ressourcenschonung und Müllvermeidung durch das Reparieren digitaler Medientechnologien werde ich in Abschn. 4.2 näher eingehen. Hier sei in Hinblick auf die Relevanz der Medienpraktik des Reparierens digitaler Medientechnologien in Repair Cafés nochmals unterstrichen, dass diese eine doppelte Bedeutung hat: Zum einen ist es die Materialität der Beschaffenheit der (digitalen) Medientechnologien im Sinne des Aufbaus dieser, mit denen sich die Reparierenden auseinandersetzen, zum anderen sind es die Produktionsund Entsorgungsprozesse der (digitalen) Medientechnologien, welche sich in den Mediengeräten materialisieren, die die Reparierenden reflektieren. Ähnlich ist das Verhältnis von Medienpraktiken und Materialiät in der Studie zur Produktion und Aneignung des Fairphones zu beschreiben. Auch hier soll zunächst auf die Akteur*innen eingegangen werden, um anschließend die Medienpraktiken und ihre Auseinandersetzung mit der Materialität digitaler Medientechnologien verstehen zu können.

Wie bereits in Abschn. 3.1.2 erläutert, ist das Fairphone ein Smartphone, das unter fairen Bedingungen mit nachhaltigen Ressourcen hergestellt werden soll (s. zu den Zielen Abschn. 4.2). Das Fairphone startete als Projekt der Waag Society (www.waag.org) und wird seit der Gründung des gleichnamigen Unternehmens von diesem produziert und vertrieben (Fairphone 2015b, S. 1). Das niederländische Unternehmen sitzt in Amsterdam und mietet Produktionsstätten in China, um die Endgeräte zu produzieren (Fairphone 2015b, S. 7; mehr zum Produktionsprozess s. u.). Die zentrale Figur des Fairphone-Unternehmens ist der Gründer Bas von Abel, der international durch Interviews in traditionellen Massenmedien sehr präsent ist. Das Unternehmen selbst weist auf der seiner Plattform auf diese Präsenz in traditionellen Massenmedien hin (Fairphone 2019b).

Das Fairphone-Unternehmen beschreibt sich selbst als "social enterprise“ (Fairphone 2015b, S. 1) und wird auch als solches in der wissenschaftlichen Literatur bezeichnet, so benennen Lin-Hi und Blumberg (2015) das Unternehmen als "social entrepreneur" (s. auch Abschn. 3.1.2). Das Smartphone wird in einem „Crowdfunding“-Prozess produziert, d. h., dass Käufer*innen zunächst ihr Smartphone bestellen und erst bei einer entsprechend großen Anzahl von Vorbestellungen die Produktion der jeweiligen Fairphone-Generation beginnt. 2013 wurde es erstmalig produziert und insgesamt 60.000 Exemplare verkauft (Fairphone 2016e). Drei Jahre später wurde die zweite Fairphone-Generation ausgeliefert, für deren Produktion die Vorbestellung von 15.000 Exemplaren Grundlage war (Költzsch 2015; Pakalski 2013). Ab dem 27. August 2019 konnten Geräte der 
dritten Fairphone-Generation vorbestellt werden (Fairphone 2019g). Mittlerweile können sie nicht nur direkt über die Onlineplattform des Unternehmens, sondern auch bei ausgewählten Händler*innen und Telekommunikationsunternehmen erworben werden.

Mit Blick auf die Nutzer*innen zeigt sich allgemein, dass diese aus verschiedenen Ländern kommen und unterschiedlichen Alters- und Geschlechtergruppen angehören. Eine umfassende Studie zu den Fairphone-Käufer*innen liegt jedoch noch nicht vor. Wie in Abschn. 3.3.2 bereits erläutert wurde, ist am Sample meiner Interviewpartner*innen auffällig, dass diese zwar über unterschiedliches Einkommen verfügen, jedoch alle auf einen akademischen Hintergrund verweisen. Dies führte mich zu der Annahme, dass v. a. Akademiker*innen zu den Käufer*innen des Fairphones zählen, wobei dieser Umstand in Hinblick auf die von mir Interviewten auch mit meinem individuellen Rekrutierungsverfahren in Zusammenhang stehen könnte (s. Abschn. 3.3.2). Wie meine Studie zeigt zählen zu den Fairphone-Nutzer*innen technisch affine Personen sowie Menschen, die sich wenig mit Medientechnologien auseinandersetzen und auskennen und sich v. a. für den (vermeintlich) fairen Charakter des Smartphones begeistern.

Mit Blick auf die Relation von Medienpraktiken und Materialität lässt sich in dieser Fallstudie Folgendes festhalten: Das Fairphone-Unternehmen reflektiert die Materialität konventionell hergestellter Smartphones, nimmt die sozialökologischen Folgen der Abbauprozesse von für digitale Medientechnologien benötigten Ressourcen in den Blick und kritisiert sie. Eines der Kernanliegen des Unternehmens ist es, den Ressourcenabbau fairer zu gestalten: „We want to source materials that support local economies, not armed militias. We're starting with conflict-free minerals from the DR Congo." (Fairphone 2015b, S. 1; s. detaillierter Abschn. 4.2) Konfliktfreie Ressourcen sind solche, deren Kauf keine Konfliktgruppierungen unterstützen. Dies bezieht sich bei der SmartphoneProduktion u. a. auf Warlords in der Demokratischen Republik Kongo, welche mit dem Verkauf von Coltan aus ihren Minen, ihren Krieg finanzieren (s. hierzu Abschn. 2.2.2). Das Unternehmen reflektiert also die Materialität der Medientechnologien und die sich darin materialisierenden Abbauprozesse. Über ihre Onlineplattform erläutert es die Problematik der Materialiät von Smartphones wie folgt:

„Every smartphone contains over 30 different minerals. All minerals and metals enter the supply chain from the mining sector - a challenging industry in terms of environmental and social responsibility. From pollution and extremely dangerous working conditions to child labor, many mining-related practices desperately require improvement. Conflict minerals fund rebel groups, contributing to political and economic instability while neglecting workers' rights, safety and their ability to earn a fair 
wage. We want to source responsibly mined minerals and metals that support local economies, not militias.“ (Fairphone 2015b, S. 1)

Neben dieser Aufklärung über die Materialität von Smartphones schafft das Unternehmen über ihre Onlineplattform auch Transparenz über die eigenen Errungenschaften in Hinblick auf die Integration fair abgebauter Ressourcen in das Fairphone. Die Onlineplattform des Unternehmens, genau wie die vom Fairphone-Unternehmen gestalteten Profilseiten auf Facebook (https://de-de. facebook.com/Fairphone), Twitter (https://twitter.com/Fairphone) und Instagram (http://instagram.com/fairphone/), dienen also der Öffentlichkeitsarbeit, nicht nur um das Smartphone zu bewerben, sondern auch, um über die sozial-ökologischen Folgen der Produktion und Entsorgung von Medientechnologien aufzuklären sowie Transparenz über die Materialität des Fairphones zu schaffen. Denn bislang sind es die Ressourcen Zinn, Tantal, Wolfram und Gold, die fair und konfliktfrei abgebaut in die Fairphones integriert werden können (Fairphone 2015b, S. 1). Wird fairer Handel als ein solcher definiert, der auf ,auf Dialog, Transparenz und Respekt beruht und nach mehr Gerechtigkeit im internationalen Handel strebt (World Fair Trade Organization und Fairtrade Labelling Organizations 2009, 6; s. Abschn. 3.1.2), so ist das Fairphone-Unternehmen bestrebt, in den im Smartphone integrierten Ressourcen, aber auch im Herstellungsprozess der Endgeräte selbst, die Partnerunternehmen mit Respekt und gerecht zu behandeln (s. Fairphone 2015b).

Dennoch besteht mit den bislang nur wenige als fair klassifizierten Ressourcen lediglich ein kleiner Anteil des Smartphones aus fairen Stoffen - das Fairphone ist also mitnichten ein tatsächlich faires Smartphone. Das Unternehmen gibt in diesem Zusammenhang zu bedenken, dass ein ganzheitlich mit fair abgebauten Rohstoffen hergestelltes Fairphone derzeit nicht zu realisieren ist: „From the beginning, we knew it was unlikely, that the first edition of Fairphone would be truely 100\% fair" (Fairphone 2016g).

Die Transparenz in Hinblick auf die Materialität des Fairphones und dessen Produktionsprozesse ist etwas, das die Fairphone-Nutzer*innen besonders schätzen. So erklärt ein 33-jähriger Angestellter einer Umweltorganisation, dass er den Ansatz des Fairphone-Unternehmens gut findet:

„Einerseits [finde ich, S. K.] den Ansatz der Transparenz und auch der glaubwürdigen Kommunikation, dass man sagt, man weiß, es ist eine absolut komplexe Wertschöpfungskette, was dahintersteckt und man weiß okay, es gibt noch total Probleme, also wenn es um Beschaffung von unkritischen Rohstoffen geht, wenn es darum geht Arbeitsbedingungen zu verbessern und vor allem, dass man eine Kontrolle über seine 
Lieferkette hat und da fand ich, dass die Idee eigentlich vom Fairphone ziemlich gut $[\ldots]$ ist."

Dabei sind den Nutzer*innen die Grenzen in Hinblick auf eine faire Materialität des Fairphones durchaus bewusst. So äußert sich auch eine 33-jährige Dramaturgin:

„Ich habe auch gelesen, es ist nur ein gewisser Prozentsatz, den sie von Fair-TradeMaterialien benutzen können und es ist nicht hundert Prozent, aber die Perspektive, auch in etwas zu investieren, was dann immer mehr fair trade wird, und einfach in diese Idee zu investieren."

Die Hauptmotivation des Fairphone-Kaufs vieler Interviewpartner*innen ist also v. a. die Idee, die Entwicklung fairer Medientechnologien zu unterstützen. Denn die sozial-ökologischen negativen Folgen der Produktion des Fairphones zu minimieren, ist eines der postulierten Ziele des Unternehmens: „[We aim at further reducing, S. K.] our environmental impact with every version of the Fairphone we produce“" (Fairphone 2016b, zu den Zielen s. detaillierter Abschn. 4.2).

Neben der Materialität im Sinne einer Stofflichkeit, die sowohl das FairphoneUnternehmen als auch die Fairphone-Nutzer*innen reflektieren, ist es auch die Materialität im Sinne einer Beschaffenheit, die beide Akteursgruppen thematisieren. So ist das Fairphone als modulares Smartphone konzipiert, so dass leicht geöffnet und einzelne Teile ersetzt werden können. Das Fairphone-Unternehmen will damit ermöglichen, dass die Apparate reparierbar werden: „We're focusing on longevity and repairability to extend the phone's usable life and give buyers more control over their products." (Fairphone 2015b, S. 1). Das Unternehmen will also neben der Verwendung fairer und konfliktfreier Ressourcen auch ein Smartphone schaffen, das langlebig ist, und proklamiert: „Built to last.“ (Fairphone 2019a).

Dass der unternehmerische Anspruch nach einem reparablen Smartphone einer der Beweggründe für den Erwerb dieses Smartphones ist, zeigt das Interviewmaterial mit den Fairphone-Nutzer*innen. So erklärt der Mitarbeiter einer Umweltorganisation:

„Fairphone ist insofern super, weil, du kannst das jederzeit aufmachen. Es wird ja auch innen drin, also wenn du es dann geöffnet hast, so ein bisschen drauf hingewiesen: [...] 'This is your Battery.' Und wenn die halt leer ist, soll man das halt einschicken und dann kann man das auch austauschen."

„Change is in your hands“ steht als Wortspiel auf der zu erwerbenden Batterie (Fairphone 2019c). Damit lädt das Unternehmen zum einen ein, durch den 
Erwerb eines Ersatzakkus einen nicht mehr funktionierenden zu ersetzen. Zum anderen rekurriert das Unternehmen damit auf sein Anliegen, gesellschaftlichen Wandel durch die Produktion einer fairen Medientechnologie zu provozieren. Auch die Nutzer*innen wollen sich im Reparierprozess mit der Materialität im Sinne des Aufbaus ihres Smartphones auseinandersetzen, dieses verstehen und die Materialität durch das Reparieren selbst gestalten.

Zusammenfassend lässt sich festhalten, dass das Fairphone-Unternehmen sowie auch die Nutzer*innen die Materialität im Sinne der Stofflichkeit und Beschaffenheit des Smartphones nicht nur reflektieren, sondern diese verändern, fairer gestalten bzw. diese faire Gestaltung mit dem Erwerb des Fairphones unterstützen wollen (s. detaillierter zu den Zielen des Unternehmens und der Nutzer*innen Abschn. 4.2).

Die zentralen Medienpraktiken in der Fallstudie des Fairphones sind daher die Produktion und Nutzung des Fairphones. Sind Praktiken durch sozial geteiltes, routinisiertes, implizites und interpretatives Wissen gekennzeichnetes (s. o. und s. Abschn. 3.2.1), so motiviert das Wissen um die Materialität von Smartphones einerseits, sowie um die sozial-ökologischen Folgen des Abbaus von für digitale Medientechnologien benötigte Ressourcen und der Produktionsbedingungen dieser andererseits das Unternehmen und die Nutzer*innen zur Produktion bzw. zum Erwerb des Fairphones. Die von Couldry aufgeworfene Frage für Medienpraktiken (s. o.), kann auch in dieser Fallstudie einfach beantwortet werden: Das Unternehmen handelt in Relation zu Medien, hier als Medientechnologie, indem es diese unter fairen Bedingungen mit nachhaltigen Ressourcen produzieren will. In dieser Medienpraktik der Fairphone-Produktion ist die Materialität des Smartphones ein zentraler Aspekt, der reflektiert und verändert werden soll. Neben der Produktion wird in dieser Fallstudie der Erwerb sowie die Nutzung des Fairphones als Medienpraktik definiert, da die Nutzer*innen in Relation zu Medien (hier Medientechnologien) handeln. Dabei reflektieren sie auch die Materialität des Smartphones. Ziel ihrer Medienpraktik ist, die Entwicklung einer ,fairen Materialität" des Smartphones zu unterstützen. Des Weiteren sind in dieser Fallstudie auch die Herstellung von Medieninhalten für die Onlineplattform des Unternehmens sowie von diesen bespielte Profile in Onlinenetzwerken wie z. B. Facebook und Twitter Medienpraktiken.

Neben den Medienpraktiken sind in der Fairphone-Studie auch weitere kommunikative Praktiken zu identifizieren, so treffen sich Fairphone-Nutzer*innen auch vis-à-vis bzw. mit Mitarbeiter*innen des Unternehmens (s. detaillierter hierzu Abschn. 4.4).

Damit stehen in der Fallstudie des Reparierens von Medientechnologien in Repair Cafés und in der Fallstudie zum Fairphone digitale Medientechnologien 
im Zentrum der Akteur*innen. Beide Fallstudien sind damit Beispiele für das in Abschn. 3.2.1. beschriebene Konzept des ,acting on media“ (Kannengießer und Kubitschko 2017), da hier Medientechnologien in den Fokus der Medienpraktiken gestellt werden, die die Akteur*innen verändern und dadurch auch eine Transformation der Gesellschaft herbeiführen wollen. Kern dieser Veränderung ist die Reflektion der Materialität im Sinne einer Stofflichkeit und Beschaffenheit, mit der sich die Akteur*innen in ihrem Handeln auseinandersetzen und die sie gestalten wollen. In diesen Fallstudien sind also „material encounters between actors and objects“ (Hutchby 2001, S. 27) vorzufinden: Die Akteur*innen „,begegnen“ den Medientechnologien, setzen sich im Sinne eines ,acting on media“ bewusst mit diesen auseinander. So zeigt sich, dass digitale Medientechnologien mitnichten immateriell oder transparent (Jansson 2014, S. 281) sind, in Aneignungsprozessen weder ,verschwinden“ noch „untergehen“ (Mersch o. J., S. 3). Vielmehr zeigen die Fallstudien, dass sich die Nutzer*innen der Materialität digitaler Medientechnologien und ihrer sozial-ökologischen Folgen durchaus bewusst sind, diese reflektieren und kritisieren und sich in ihrem Medienhandeln nicht nur mit der Materialität digitaler Medienapparate auseinandersetzen, sondern Alternativen in der Materialität selbst (Fairphone) und im Umgang mit ihr (Reparieren) entwickeln. Der für die Herstellung von Onlineinhalten durch Nutzer*innen entwickelte Begriff des „ProdUsers“ (Bruns 2008) kann in Hinblick auf die Fallstudien des Reparierens und des Fairphones also nochmal anders gedacht werden: Nutzer*innen werden auch in Hinblick auf ihre Medientechnologien selbst zu Produzent*innen, indem sie sich mit der Materialität dieser auseinandersetzen und diese reparieren. Durch die Gestaltung der Medientechnologien wollen die Akteur*innen der Fallstudien schließlich auch auf aktuelle Digitalisierungsprozesse einwirken und diese verändern. Die genauen Ziele dieser Veränderung werden in Abschn. 4.5 näher betrachtet. Hier sei in Hinblick auf die untersuchten Medienpraktiken festgehalten, dass diese aktivistische Medienpraktiken sind, da sie politische Anliegen verfolgen, mit denen sie Gesellschaft gestalten wollen (s. Abschn. 4.5).

Etwas anders gelagert sind die Medienpraktiken der Fallstudie, die sich mit der Onlineplattform Utopia.de auseinandergesetzt hat. Die hier vorzufindenden Medienpraktiken stellen überwiegend nicht Medientechnologien in den Fokus des Handelns. Vielmehr beziehen sich die Medienpraktiken hier in einem traditionell kommunikations- und medienwissenschaftlichen Begriffsverständnis auf die Medieninhalte, welche in dem Onlinemagazin der Plattform Utopia.de und den hier integrierten Onlineforen sowie auf den durch die Utopia GmbH bespielten Onlinenetzwerken wie Facebook und Twitter präsentiert werden. Bevor ich das 
Zusammenspiel der Medienpraktiken und Materialität in dieser Fallstudie näher beschreibe, gehe ich näher auf die Akteur*innen ein.

Wie bereits in der Einleitung und in Abschn. 2.2.3 kurz angeführt, ist Utopia.de eine deutschsprachige Onlineplattform, die von der Utopia GmbH mit Sitz in München betrieben wird. Die Utopia AG mit der Onlineplattform wurde 2007 von der Unternehmerin Claudia Lange gegründet (Hauck 2010). 2014 kaufte Tivola Ventures, die Teil der Medienbeteiligungsgesellschaft Deutsche Druckund Verlagsgesellschaft (DDVG) ist, welche wiederum zu $100 \%$ im Besitz der SPD ist (Meyer 2014), die Utopia GmbH. Diese Parteinähe wird auf der Onlineplattform Utopia.de nicht transparent gemacht. Aufgrund der SPD-Nähe kann aber die Aussage „Utopia - Die grüne Mitte“ (Utopia 2015b, S. 3) nochmal anders interpretiert werden als es die Utopia GmbH selber macht mit der Deutung, nachhaltiger Konsum sei von der Nische in den Mainstream gelangt (ebd.). Vielmehr sind die politischen Ansätze der Utopia GmbH aufgrund der SPD-Nähe wohl auch inhaltlich in der ,politischen Mitte“ zu verorten.

Dass nachhaltiger Konsum (so er denn als ein solcher bezeichnet werden kann, s. Abschn. 4.2) jedoch auch durch die Onlineplattform Utopia.de an Popularität gewonnen hat, zeigen die Nutzer*innenzahlen: Nach eigenen Angaben hat die Onlineplattform 6,8 Mio. Besucher im Monat sowie 63.000 NewsletterAbonnement*innen (Utopia 2019a, S. 3). Unter der Überschrift „Die Lust am nachhaltigen Konsum" beschreibt die Utopia $\mathrm{GmbH}$ in ihren Mediadaten die die Plattform nutzenden Verbraucher*innen für die auf der Onlineplattform Werbung schaltenden Unternehmen: „Bewusste Konsumenten sind keine Konsummuffel. Im Gegenteil. Sie zeigen sich als online affin, konsumfreudig und offen für Produktneuheiten, die einen nachhaltigen Mehrwert bieten. Und sie lassen sich gerne durch Werbung inspirieren." (Utopia GmbH 2019a, S. 6) Hier zeigt sich, dass die Utopia GmbH bzw. ihrer Einschätzung nach deren Nutzer*innen, nachhaltigen Konsum nicht als Konsumverzicht interpretieren, sondern dass eine bestimmte Art von Konsum beworben bzw. praktiziert werden soll, der als nachhaltig bewertet wird. Kritisch zu hinterfragen ist an dieser Stelle jedoch, ob „Konsumfreude“ mit Nachhaltigkeit einhergehen kann - benötigt doch auch (vermeintlich) nachhaltiger Konsum Ressourcen und führt zu Kohlenstoffdioxidproduktion.

Dem eigenen Selbstverständnis nach will die Utopia $\mathrm{GmbH}$

„Millionen Verbraucher informieren und inspirieren, ihr Konsumverhalten und ihren Lebensstil nachhaltig zu verändern. Wir sind davon überzeugt, dass nachhaltiger Konsum sich nur dann auf breiter gesellschaftlicher Basis durchsetzen wird, wenn die Angebote attraktiv - und damit massen(markt)tauglich - sind. Wir glauben: Bewusster Konsum kann die Welt verändern. Deshalb wollen wir es unseren Nutzern so leicht 
und so attraktiv wie möglich machen, sich bei Produkten und Dienstleistungen für nachhaltigere Alternativen zu entscheiden." (Utopia 2019c)

Wenngleich die Ziele in Abschn. 4.2 noch einmal näher betrachtet werden, zeigt das angeführte Zitat ganz allgemein, dass die Utopia GmbH primär Kaufempfehlung und -beratung auf ihrer Onlineplattform ausspricht. D. h., es werden neben der Suche nach Produkt-Tester*innen v. a. Informationen über von der Utopia $\mathrm{GmbH}$ als nachhaltig eingestufte Produkte (z. B. auch Medientechnologien, s. Utopia 2015a) und Unternehmen verbreitet. Utopia.de ist insofern insbesondere eine Werbeplattform. Für die Erstellung der Inhalte existiert eine Vielzahl von Kooperationen mit Unternehmen, durch deren Finanzierung als nachhaltig eingestufte Produkte beworben werden. Dabei bestehen auch Kooperationen mit weniger für ihre Nachhaltigkeit bekannten Unternehmen wie Tchibo oder Penny. Die Utopia GmbH ermöglicht es Unternehmen, nicht nur durch Bannerwerbung oder Newsletter-Teaser direkt Werbung zu schalten, sondern durch Gewinnspiele, Produkttests, Themensponsoring oder „Green Shopping“ (also durch die Vorstellung eines ,nachhaltigen“ Shops oder Produktes) für sich und ihre Produkte zu werben (Utopia 2019a). Neben dieser Produkt- und Unternehmenswerbung werden im Onlinemagazin konsumkritische Do-It-Yourself-Praktiken vorgestellt, wie z. B. das Reparieren, Kochen oder Basteln. In die Plattform integriert sind des Weiteren Onlineforen, in denen Nutzer*innen ihre Meinung über Produkte oder Tipps für nachhaltigen Konsum äußern und sich vernetzen.

In einer von der Utopia $\mathrm{GmbH}$ beauftragten Studie wird für die Intentionen der Plattformnutzung festgehalten:

„Die große Mehrheit sucht hier praktische Tipps für den Alltag (86,1 Prozent) und allgemeine Informationen zum Thema Nachhaltigkeit (79,2 Prozent). Bei mehr als der Hälfte der User hilft Utopia bei Kaufentscheidungen (56,2 Prozent), knapp die Hälfte sucht konkrete Produktempfehlungen (45,9 Prozent).“ (Utopia 2015b, S. 3)

Damit findet der Zweck der Utopia GmbH eine Entsprechung bei ihren Nutzer*innen. Auf die sogenannten Utopist*innen der Onlineplattform werde ich in Abschn. 4.4 noch näher eingehen, hier sollen die Medienpraktiken und die Materialität der (digitalen) Medientechnologien im Fokus stehen.

Die von Couldry aufgeworfene Frage, was Menschen mit Medien machen, kann für die Onlineplattform Utopia.de wie folgt zusammenfassend beantwortet werden: Die Utopia $\mathrm{GmbH}$ erstellt die Medieninhalte des Onlinemagazins der Plattform, welche sich im weitesten Sinne mit Konsum und Nachhaltigkeit befassen. D. h., dass Produkte beworben und Praktiken beschrieben werden, die die Utopia $\mathrm{GmbH}$ als nachhaltig einstuft. Inwiefern der Konsum neuer Produkte 
tatsächlich nachhaltig sein kann, da zumindest für die Produktion neuwertiger Konsumobjekte zwangsläufig Ressourcen verbraucht werden, problematisiert das Unternehmen z. T. selbst (s. u.). Durch die Kooperation mit Unternehmen sind viele der Produktbesprechungen letztendlich Werbung.

Die Erstellung der Medieninhalte erfolgt durch das Unternehmen nicht nur im Onlinemagazin der Plattform, sondern auch über den E-Mail-Newsletter sowie Onlinenetzwerke wie Facebook (https://de-de.facebook.com/utopia.de) und Instagram (https://instagram.com/utopia.de/) und den Mikrobloggingdienst Twitter (https://twitter.com/utopia). Auf Facebook hat das Profil der Utopia GmbH ca. 288.000 Follower, auf Twitter 28.800 und auf Instagram 80.000 (Stand 20. Juni 2021). Über Facebook findet schließlich auch eine Vernetzung der Nutzer*innen statt, die in ihren Posts Beiträge der Utopia GmbH kommentieren oder sich in sieben thematisch unterschiedlichen Facebook-Gruppen vernetzen können. ${ }^{6}$ In einer der Gruppen werden auch „Medientipps“ geteilt, indem auf als nachhaltig eingestufte Filme, Bücher o. ä. hingewiesen wird. ${ }^{7}$ Die Nutzer*innen der Onlineplattform gestalten des Weiteren die Inhalte dieser in den 27 thematisch unterschiedlichen Gruppen, in denen sie sich auch vernetzen können (s. für eine Übersicht der Gruppen Utopia 2019b). Die Foren nutzen können nur Personen, die sich auf der Onlineplattform registriert haben. Anfänglich hatte die Utopia $\mathrm{GmbH}$ ein Onlinenetzwerk integriert, für das sich „Utopist*innen“ registrieren und in diesem vernetzen konnten (Utopia 2015c). Diese Vernetzung findet nun öffentlich in den Onlineforen statt (s. hierzu Abschn. 4.4).

Das Erstellen von Medieninhalten erfolgt auf der Onlineplattform selbst sowie auf weiteren Internetmedien wie Facebook, Twitter und Instagram, also nicht nur durch die Utopia GmbH alleine, sondern auch durch die „Utopist*innen“, die damit zu ProdUser*innen (Bruns 2008, s. o.) werden und sich über die Onlineangebote artikulieren und vernetzen können. Die Medienpraktik im Couldry'schen Sinne ist also hier die Herstellung von Medieninhalten. Die Materialität digitaler Medientechnologien wird dabei auch in den Inhalten thematisiert. Unter Überschriften wie z. B. ,, Katastrophe“ - was Smartphones wirklich anrichten“ (Utopia 2016b) oder „Handy - Krieg und Verwüstung in der Hosentasche“ (Utopia 2013) werden die sozial-ökologischen Folgen der Produktion von Smartphones thematisiert. Auch über geplante Obsoleszenz wird in Hinblick auf Medientechnologien berichtet (Utopia 2016c). Auf der Onlineplattform findet man des Weiteren eine

\footnotetext{
${ }^{6}$ Siehe für die verschiedenen Facebook-Gruppen: https://www.facebook.com/pg/utopia.de/ groups/?ref=page_internal.

${ }^{7}$ Siehe die Facebook-Gruppe unter dem Link: https://www.facebook.com/groups/152723 655414630/?ref=pages_profile_groups_tab\&source_id=194397797261882.
} 
Beratung für den Kauf von Medientechnologien, welche auf der Grundlage einer Auseinandersetzung mit den negativen Auswirkungen der Produktion und Entsorgung digitaler Medientechnologien gegeben wird. So formuliert Winterer (2015a) in einem Onlineartikel auf der Plattform die folgenden Ratschläge:

\begin{abstract}
„Das nachhaltigste Gerät ist das, das nicht gekauft wird.
Jedes Gerät verbessert seine Ökobilanz dadurch, dass man es möglichst lange verwendet. Sinnvoll ist also, Smartphones und Tablets so lange wie möglich zu benutzen und schonend zu behandeln.

Wer ein Gerät benötigt, sollte auch dem Gebrauchtmarkt eine Chance geben, über den sich die Lebensdauer aller Geräte verlängern lässt - siehe unsere Bestenliste Gebrauchtkauf-Portale.

Steht ein Handy-Neukauf an, ist das Fairphone 2 wegen seiner Langlebigkeit und Reparierbarkeit eine interessante Option.

Wenn ein Gerät das Ende seiner Lebenszeit erreicht hat, bemühe dich um eine fachgerechte Entsorgung (siehe Elektroschrott).

Übrigens auch gut für die Umwelt: Den Stromanbieter wechseln - natürlich zu einem Ökostromanbieter.“
\end{abstract}

In den Fokus genommen werden in diesem Artikelabschnitt die Medienpraktiken der Nutzer*innen und die Materialität digitaler Medientechnologien in Hinblick auf diese Medienpraktiken. Vor dem Hintergrund der Diskussion der sozial-ökologischen Folgen der Produktion und Entsorgung digitaler Medientechnologien wird zu bestimmten Medienpraktiken geraten, nämlich dem Konsumverzicht („Das nachhaltigste Gerät ist das, das nicht gekauft wird.“), dem Erwerb gebrauchter Geräte (,Wer ein Gerät benötigt, sollte auch dem Gebrauchtmarkt eine Chance geben"). Auch das Fairphone ist ein wiederholtes Objekt in Onlineartikeln auf der Plattform (s. z. B. Haderer 2015; Winterer 2015b). Es wird für seine Langlebigkeit und Reparierbarkeit gelobt (Winterer 2015b).

Medientechnologien geraten selbst in den Fokus weiterer Medienpraktiken der Utopia GmbH. So betreibt das Unternehmen die Server mit Ökostrom und klimaneutralisiert den Verbrauch (Utopia 2019c). Damit reflektieren sie die ökologischen Effekte der Nutzung von Internetmedien. Medienpraktiken sind in dieser Fallstudie also nicht nur das Produzieren von Medieninhalten durch die Utopia $\mathrm{GmbH}$ und die Nutzer*innen für die Onlineplattform und hier integrierte Foren sowie Onlinenetzwerke wie Facebook, Instagram oder den Mikrobloggingdienst Twitter, sondern auch die Medienpraktik der Servernutzung - welche nachhaltig durch Öko-Strom sein soll. Für den Stromverbrauch gilt aber, was für jeglichen Konsum gelten kann: Kein Verbrauch ist im Sinne der Nachhaltigkeit besser als Verbrauch; eine Klimaneutralisierung ist nur der Versuch, an anderer 
Stelle Kohlenstoffdioxid einzusparen, aber sicherlich nicht die Möglichkeit, die Kohlenstoffdioxidemissionen ungeschehen zu machen.

Zusammenfassend lässt sich für die Fallstudie zu der Onlineplattform Utopia.de festhalten, dass die Medienpraktiken hier überwiegend das Erstellen der Medieninhalte auf den Webseiten der Onlineplattform und den in diese integrierten Onlineforen sowie auf den jeweiligen Profilseiten auf Facebook, Instagram und Twitter sind. Die Materialität digitaler Medientechnologien wird u. a. in Hinblick auf die sozial-ökologischen Folgen der Produktion und Entsorgung der Endgeräte in Beiträgen des Onlinemagazins thematisiert. Weiterhin sind aber auch das Betreiben der für die Onlineplattform benötigten Server mit Ökostrom sowie der Versuch der Klimaneutralisierung dieses Betriebs eine Medienpraktik, welche die Materialität digitaler Medientechnologien, hier die für das Betreiben der Server benötigte Energie, reflektiert.

Die drei Fallstudien vergleichend, stellt die folgende Tab. 4.1 eine Übersicht über die bis hierher erläuterten kommunikativen und Medienpraktiken dar (s. für

Tab.4.1 Medienpraktiken und kommunikative Praktiken in den Fallstudien

\begin{tabular}{|c|c|c|c|}
\hline Praktiken & $\begin{array}{l}\text { Reparieren von } \\
\text { Medientechnologien } \\
\text { in Repair Cafés }\end{array}$ & $\begin{array}{l}\text { Produktion und } \\
\text { Aneignung des } \\
\text { Fairphones }\end{array}$ & $\begin{array}{l}\text { Onlineplattform } \\
\text { Utopia.de }\end{array}$ \\
\hline \multirow[t]{2}{*}{ Medienpraktiken } & $\begin{array}{l}\text { Öffentliches und } \\
\text { gemeinsames } \\
\text { Reparieren von } \\
\text { Medientechnologien }\end{array}$ & $\begin{array}{l}\text { Produktion und } \\
\text { Erwerb/Nutzung } \\
\text { eines ,fairen“ } \\
\text { Smartphones }\end{array}$ & $\begin{array}{l}\text { Erstellen der } \\
\text { Inhalte des } \\
\text { Onlinemagazins, } \\
\text { der Onlineforen } \\
\text { und } \\
\text { Onlinenetzwerke }\end{array}$ \\
\hline & $\begin{array}{l}\text { Erstellen der Inhalte } \\
\text { der Onlineplattform } \\
\text { und } \\
\text { Onlinenetzwerke }\end{array}$ & $\begin{array}{l}\text { Erstellen der Inhalte } \\
\text { der Onlineplattform } \\
\text { und } \\
\text { Onlinenetzwerke }\end{array}$ & $\begin{array}{l}\text { Nutzung von } \\
\text { Ökostrom für } \\
\text { von der Utopia } \\
\text { GmbH bespielte } \\
\text { Server }\end{array}$ \\
\hline Vis-à-vis-Kommunikation & In Repair Cafés & $\begin{array}{l}\text { In lokalen } \\
\text { Veranstaltungen der } \\
\text { Nutzer*innen sowie } \\
\text { in einem jährlichen } \\
\text { Treffen der } \\
\text { Mitarbeiterer*innen } \\
\text { des Unternehmens } \\
\text { und der } \\
\text { Nutzer*innen }\end{array}$ & \\
\hline
\end{tabular}


eine detailliertere Analyse der kommunikativen Praktiken zur Vergemeinschaftung Abschn. 4.4).

Wie bis hierher herausgearbeitet wurde, ist die Materialität digitaler Medientechnologien zentral für diese hier untersuchten Medienpraktiken, welche Materialität im Sinne einer Stofflichkeit und Beschaffenheit reflektieren, sich mit diesen auseinandersetzen und die Materialität verändern wollen. Im Sinne Silverstones (1990) lässt sich in den Fallstudien also eine doppelte Artikulation ausmachen, denn Medien werden hier nicht nur als Inhalte relevant, sondern auch in ihrer Materialität. Solche Medienpraktiken, die Medientechnologien selbst in den Fokus des Handelns setzen, wurden mit dem Konzept des ,acting on media" (Kannengießer und Kubitschko 2017) erfasst. Ein zentrales theoretisches Argument dieses Buches ist es daher, anhand der untersuchten Medienpraktiken den kommunikations- und medienwissenschaftlichen Begriff der Medienpraktik weit zu fassen - als Praktiken, welche sich auf Medieninhalte aber auch Medientechnologien und Medienorganisationen beziehen. Die Materialität digitaler Medientechnologien spielt, wie gezeigt wurde, bei diesen Medienpraktiken eine entscheidende Rolle.

Versteht man das Reparieren von Medientechnologien in Repair Cafés, die Produktion und Aneignung des Fairphones sowie das Erstellen der Inhalte der Onlineplattform als Medienpraktiken, so kann durch die Analyse dieser Medienpraktiken nicht nur rekonstruiert werden, was Individuen, Nichtregierungsorganisationen und Unternehmen mit Medien(-technologien) in verschiedenen Kontexten machen, sondern es kann auch untersucht werden, warum die verschiedenen Akteur*innen auf diese unterschiedlichen Arten und Weisen mit Medien(-technologien) handeln sowie welche Bedeutung sie diesem Handeln jeweils zuschreiben. Im Folgenden sollen daher die Ziele der in den drei untersuchten Fallstudien handelnden Akteur*innen rekonstruiert und ihre Bedeutungszuschreibungen an ihre jeweiligen Medienpraktiken aufgearbeitet werden.

\subsection{Ziele konsumkritischer Medienpraktiken}

Wurden bislang die für die hier präsentierte Studie untersuchten Medienpraktiken und ihr Zusammenhang mit Materialität herausgearbeitet, so sollen im Folgenden die Ziele und Motive der Akteur*innen dieser Fallstudien näher betrachtet werden. Die Auswertung des unterschiedlichen Datenmaterials der verschiedenen Fallstudien zeigt, dass vier dominante Ziele bzw. Motive der Akteur*innen über die Fallstudien hinweg ausgemacht werden konnten: 1) Müllvermeidung, 
2) Ressourcenschonung, 3) Wissensverbreitung bzw. Lernen sowie 4) Wertzuschreibung. Dabei spreche ich von Zielen, wenn die Akteur*innen ein bestimmtes Vorhaben durch ihre Praktiken erreichen wollen (Ressourcen schonen, Müll vermeiden, Wissen weitergeben und erlernen), und von Motiven, wenn die Ursache des Handelns eher intrinsisch motiviert ist, hier, indem die Akteur*innen Medientechnologien einen Wert zuschreiben bzw. mit ihren Medienpraktiken bestimmte Werte verfolgen.

Es sind diese Ziele und Motive, welche als dominant in den Fallstudien herausgearbeitet wurden, die die Medienpraktiken der Akteur*innen in den Fallstudien zu konsumkritischen machen. So kann nach der Erläuterung der Ziele und Motive zum Abschluss dieses Teilkapitels das in der Einleitung dieses Buches eingeführte Konzept der konsumkritischen Medienpraktiken detaillierter erläutert werden. ${ }^{8}$ Dabei sind die Ziele nicht in allen drei Fallstudien in gleichem Maße vorzufinden, doch machen sie den Charakter der hier untersuchten Medienpraktiken aus. Auch wenn die Ziele in einem direkten Zusammenhang stehen, was im letzten Teil des Kapitels erläutert wird, so werden sie im Folgenden getrennt voneinander besprochen. Dabei arbeite ich auch Gemeinsamkeiten und Unterschiede sowie Paradoxien in den Zielsetzungen der verschiedenen Akteur*innen der unterschiedlichen Fallstudien heraus. ${ }^{9}$

\section{Ressourcenschonung}

Ressourcenschonung ist eines der dominanten Ziele der Akteur*innen, die in den hier diskutierten Fallstudien handeln. Im vorherigen Kapitel wurde bereits in Hinblick auf die Materialität digitaler Medientechnologien erläutert, dass die an den Repair Cafés beteiligten Akteur*innen der drei unterschiedlichen Gruppen (Organisator*innen, Helfer*innen und Hilfesuchende) die sozial-ökologischen Folgen des Abbaus der Ressourcen reflektieren. Ist die Ressourcenschonung eines der Ziele, das die Akteur*innen durch die Reparatur unterschiedlicher Konsumgüter in den Repair Cafés verfolgen, so wird der Reparatur und der damit einhergehenden Nutzungsdauerverlängerung von Medientechnologien eine besondere Bedeutung zugeschrieben, um die für digitale Medientechnologien benötigten Ressourcen zu schonen: „Wegschmeißen ist nicht so sinnvoll, finde ich, und es sind in der Elektronik ja oft unglaublich wertvolle Rohstoffe verbaut, wie Coltan und Kupfer, Gold

\footnotetext{
${ }^{8}$ Siehe zum Konzept der konsumkritischen Medienpraktiken auch Kannengießer (2016, 2018a, 2020a); zu den Zielen der Akteur*innen der Repair Cafés u. a. Kannengießer (2018c, d, e), zu den Zielen des Fairphone-Unternehmens und der Fairphone-Nutzer*innen Kannengießer 2020c).

${ }^{9}$ Siehe zu den Paradoxien konsumkritischer Medienpraktiken auch Kannengießer (2018a, S. 227 f., 2020a).
} 
usw., und jeder Deutsche schmeißt davon im Schnitt jedes Jahr 15 Kilo weg, " meint ein 42-jähriger Elektriker, der seine Hilfe bei der Reparatur von Medientechnologien in dem von mir untersuchten Berliner Repair Café anbietet. Das Reparieren ist für ihn ein ,kleiner Schritt“, mit dem er zur Ressourcenschonung und damit zum ,Schutz der Umwelt“" beitragen will, um darüber auch die Nachfrage nach neu produzierten Geräten zu senken. Die Organisator*innen, Helfer*Innen und Hilfesuchenden in den Repair Cafés knüpfen also an das Reparieren die Hoffnung einer Reduktion der Nachfrage neuwertiger Medientechnologien und der Schonung der für diese Technologien benötigten Ressourcen. Die Relevanz dieser Schonung begründet ein 70-jähriger Helfer im Oldenburger Repair Café mit der Knappheit der Ressourcen: „Die verschiedenen Metalle und Materialien, die man speziell für die neuen elektronischen Handys und so weiter braucht, die sind inzwischen ziemlich knapp und werden immer teurer und man muss reparieren." An die Relevanz der Ressourcenschonung knüpft er die Notwendigkeit des Reparierens. Für den 47jährigen Betreiber der Kneipe, in dem das für die hier präsentierte Studie untersuchte Oldenburger Repair Café zunächst ausgerichtet wurde, ist die Ressourcenschonung in heutigen Gesellschaften sogar eine Selbstverständlichkeit: „Man muss Ressourcen schonen, das ist einfach so." Neben den Helfer*innen, unterstreicht auch er die Relevanz der Reparatur digitaler Medientechnologien:

„Gerade diese Computer-Geschichte [die Reparatur von Computern, S. K.] [ist] sehr wichtig, weil da natürlich die Rohstoffe drin sind, wofür die anderen Menschen in anderen Ländern für sterben und wir das einfach so wegschmeißen und uns ein neues iPhone holen. Also das ist schon für mich unheimlich wichtig, dass es Leute gibt, die so was reparieren können und dass es auch Leute gibt, die sagen: ,Ich will es auch reparieren"."

Er rekurriert hier auf die sozial-ökologischen Folgen der Produktion digitaler Medientechnologien. Auch eine der beiden Organisatorinnen des Berliner Repair Cafés beschreibt Ressourcenschonung als eines der zentralen Ziele ihrer Veranstaltungen:

„Wir versuchen, die Ressourcen, die wir haben, auch weiter zu nutzen, also nicht verschwenden und deswegen auch eben das Repair Café, weil man schmeißt eben so viele Sachen weg und da sagen wir, das muss nicht sein. Wir müssen mit den Ressourcen, die wir haben, einfach irgendwie auskommen."

Ein 31-jähriger Musiker, der im Oldenburger Repair Café den Verstärker seiner ca. 30 Jahre alten Musikanlage reparieren (lassen, s. u.) möchte, bezieht sich auf den Diskurs der Postwachstumsökonomie (s. Abschn. 2.2.3): „Das ist uns allen, glaube ich, klar, dass die Ressourcen endlich sind und dass der Standard, auf dem 
wir leben, auf Dauer nicht funktioniert, wenn das alles nur auf Wachstum basiert.“ Die Notwendigkeit der Ressourcenschonung liegt für ihn also in der Endlichkeit der Rohstoffe begründet.

In Hinblick auf das Ziel des Ressourcenschutzes ist die Einbeziehung der Angaben der Repair-Cafés-Beteiligten zu ihren Medienrepertoires besonders interessant. Definieren Hasebrink und Domeyer (2012, S. 758) ein Medienrepertoire als die Gesamtheit der Medien, die der*die Nutzer*in regelmäßig verwendet, so verstehe ich ein Medienrepertoire hier als die Gesamtheit der Medientechnologien, die der*die Nutzer*in regelmäßig verwendet (s. Abschn. 3.3.2). Das Interviewmaterial der an den Repair-Cafés-Beteiligten, für die Ressourcenschonung ein Ziel der Reparaturprozesse ist, zeigt, dass einige der Personen wenige Medientechnologien besitzen, diese sehr lange nutzen oder gebraucht erwerben, andere jedoch über durchaus komplexe Medienrepertoires, also eine große Anzahl von Medientechnologien, verfügen und aufgrund technischer Innovationen regelmäßig neue digitale Endgeräte erwerben. Hier lässt sich eine Paradoxie im Handeln der Akteur*innen ausmachen, die einerseits mit dem Reparieren defekter Medientechnologien die Nutzungsdauer dieser verlängern wollen, auch um Ressourcen zu schonen, dass aber andererseits die Ressourcenschonung aufgrund technologischer Innovationen und der möglichen Komplexität von Medienrepertoires durch die große Anzahl verschiedener Medientechnologien nicht zwingend konsequent gelebt wird.

Dennoch zeigt sich in der Fallstudie, dass die Akteur*innen die ökologische und soziale Dimension von Nachhaltigkeit in Hinblick auf Ressourcenschonung thematisieren, da nicht nur der Schutz der Natur, sondern auch die Arbeitsbedingungen der Menschen, die Medientechnologien bzw. für diese benötigten Mineralien abbauen, verfolgt wird.

Ein nachhaltiger Umgang mit für digitale Endgeräte benötigte Ressourcen ist auch eines der Ziele des Fairphone-Unternehmens. Wie bereits im vorherigen Kapitel in Hinblick auf die Materialität digitaler Medientechnologien erläutert, erklärt das Fairphone-Unternehmen sowohl konfliktfreie Ressourcen zu verwenden, als auch zunehmend recycelte und wiederverwendbare Ressourcen sowie solche, die weniger gefährlich und giftig sind (Fairphone 2016a). Damit will das Unternehmen den negativen Umwelteinfluss der konventionellen Smartphone-Produktion minimieren und beschreibt somit eines seiner Kernziele: „[We aim at further reducing, S. K.] our environmental impact with every version of the Fairphone we produce“ (Fairphone 2016b). Gleichzeitig weist das Fairphone-Unternehmen aber auch darauf hin, dass bislang nur eine sehr begrenzte Anzahl der verwendeten Ressourcen tatsächlich unter fairen Bedingungen abgebaut werden kann. Denn bislang sind es die Ressourcen Zinn, Tantal, Wolfram und Gold, die fair und konfliktfrei abgebaut in die Smartphones integriert werden können (Fairphone 2015b, S. 1). 
Neben einem nachhaltigeren Abbau der für die Smartphone-Produktion benötigten Ressourcen, versucht das Fairphone-Unternehmen auch die Geräte unter menschenwürdigeren Bedingungen herstellen zu lassen und rekurriert dabei auf die desaströsen Bedingungen, unter denen konventionelle Smartphones (und andere digitale [Medien-]Technologien) hergestellt werden:

„The majority of the world's smartphones are manufactured in China, but the country's fast, affordable production comes at the cost of workers. We want to improve working conditions in the heart of the electronics sector, including health and safety, worker representation and working hours." (Fairphone 2019f.)

Das Fairphone-Unternehmen lässt seine Smartphones in chinesischen Produktionsstätten herstellen und arbeitet dort mit lokalen Partnerorganisationen zusammen, um die Arbeitsbedingungen in der Smartphone-Produktion zu verbessern und die Rechte der Arbeiter*innen zu stärken (ebd.).

Neben der Verwendung nachhaltig gewonnener Ressourcen und der Umsetzung menschenwürdiger Arbeitsbedingungen ruft das Fairphone-Unternehmen außerdem auf, defekte oder ungenutzte Mobilfunkgeräte und Smartphones einzusenden, damit ihre Partnerorganisation diese recyceln und aus ihnen notwendige Ressourcen für die Produktion neuer Medientechnologien gewinnen kann (Fairphone 2019e): „We're also encouraging consumers to send back their old phones, plus supporting the collection of scrap phones in Africa for safe recycling." (Fairphone 2019d).

Auch durch diese Recyclingprozesse will das Fairphone-Unternehmen Ressourcen schonen, wenngleich das Verfahren mit Blick auf seine Nachhaltigkeit als sehr energieaufwendiges Verfahren nicht unumstritten ist (s. für Solarenergie u. a. Peng et al. 2013). Außerdem regt das Fairphone-Unternehmen mit der Einladung zur Einsendung existierender Endgeräte und dem Recycling-Versprechen zum Kauf neuer Endgeräte an, indem es einen Rabatt von $45 €$ beim Neukauf eines Fairphones anbietet (Fairphone 2019e). Durch diese Anregung zum Kauf neuer Endgeräte, bleibt das Ziel der Ressourcenschonung zumindest dann fragwürdig, wenn existierende Smartphones zwar noch nutzbar sind, den Käufer*innen jedoch über das Recycling, gekoppelt an den Neukauf des Fairphones, ein reines Gewissen suggeriert wird. So erklärt ein 34-jähriger Sozialarbeiter im Interview, er habe sich das Fairphone mit dem Gefühl gekauft, ein weniger schlechtes Gewissen haben zu müssen als beim Kauf eines konventionellen Smartphones. Ein anderer Nutzer erzählt, er habe bis zum Kauf des Fairphones ein altes Mobilfunkgerät verwendet und dieses nur aufgrund der Möglichkeit des Erwerbs eines fair produzierten Smartphones ersetzt. Das Fairphone wurde hier durch das Versprechen eine ,gute Alternative“ auf dem Smartphone-Markt zu sein, also zum „Eintritt“ in den Smartphone-Markt. 
Ein nachhaltigerer Abbau der für Smartphones benötigten Ressourcen ist ein zentrales Argument vieler Fairphone-Käufer*innen. Sie führen das Bestreben des Unternehmens, das Fairphone (nach Möglichkeit) unter fairen Arbeitsbedingungen mit nachhaltigen Ressourcen herzustellen, als den zentralen Grund für den Erwerb des Fairphones an. In den Interviews zeigt sich, dass die Fairphone-Nutzer*innen um die sozial-ökologischen Folgen der Smartphone-Produktion wissen und im Fairphone eine Alternative sehen mit der sie nachhaltiger in ihren Medienpraktiken handeln können. So erklärt ein 42-jährige technische Angestellte: „Ich habe mich damals für eine Alternative zu den bestehenden Telefonen interessiert, die halt ja nicht sehr umweltfreundlich und fair produziert werden." Im Mittelpunkt der von ihm problematisierten Smartphone-Produktion sieht er besonders die menschenunwürdigen Bedingungen:

„In China wird halt unter unmenschlichen Bedingungen produziert und wenn ich dann im Fernsehen sehe, dass da die Angestellten aus dem Fenster springen, weil sie einfach keine andere Lösung mehr finden, weil sie einfach komplett überarbeitet sind oder dann [in, S. K.] irgendwelchen unmenschlichen Schlafkammern in der Fabrik übernachten müssen oder so was, das finde ich halt nicht in Ordnung. Da versuche ich halt dann was zu finden, ja, also Produkte zu finden die anders produziert werden, fairer."

Auch eine 70-jährige Fairphone-Nutzerin, die für eine FrauenNichtregierungsorganisation arbeitet, erklärt:

„Ich finde, dass wir in einer Welt leben, in der man nicht mehr einfach irgendwas machen kann, was Auswirkungen auf Menschen in anderen Teilen der Welt haben, die sich irgendwie nicht wehren können [...]. Also die da zu beschissensten, sorry, Arbeitsbedingungen tätig sind, wenig Geld verdienen und aber geknebelt sind bis zum geht nicht mehr, das geht für mich gar nicht.“

Sie rekurriert hier auf die Arbeitsbedingungen der Menschen, die im Abbau der für digitale Medientechnologien benötigten Ressourcen einerseits und in den Herstellungsprozessen der Technologien andererseits arbeiten. Das Fairphone ist für sie ein Versuch, alternative, fairere Produktionsprozesse zu realisieren wodurch sich mit Blick auf die Kaufentscheidung der Fairphone-Nutzer*innen die soziale Dimension von Nachhaltigkeit (s. Einleitung) als zentral erweist: Die Käufer*innen wollen ein Smartphone erwerben, das unter menschenwürdigen Bedingungen hergestellt wurde.

Ressourcenschonung ist aber nicht nur ein Ziel der Fairphone-Nutzer*innen, sondern gleichzeitig auch ein Kritikpunkt am Fairphone. So bemängelt der 33-jährige Mitarbeiter einer Umweltorganisation, dass er den Akku seines Fairphones häufiger 
aufladen müsse als dies bei anderen Geräten nötig sei, was er in Studien bestätigt fand. Über technische Unzulänglichkeiten, gerade im Vergleich mit anderen Smartphones, klagten mehrere der interviewten Personen.

Ressourcenschonung ist auch ein zentrales Thema auf der Onlineplattform Utopia.de. Neben Produkten, die Ressourcen schonen (sollen), wie z. B. Bienenwachstücher zur Vermeidung von Frischhalte- oder Aluminiumfolie bei der Aufbewahrung von Lebensmitteln (Ayoub 2019), werden auch konkrete Praktiken zur Ressourcenschonung im Alltag beschrieben, v. a. Praktiken des Selbermachens wie z. B. die Herstellung von Zahnpasta oder Putzmitteln, Hafermilch oder Hustensaft (z. B. Utopia 2018). Auch verweist Utopia.de auf andere Onlineplattformen, über die Nutzer*innen Konsumgüter tauschen oder teilen können, mit dem Argument: „Gebraucht-Kaufen [schont, S. K.] die natürlichen Ressourcen und somit auch das Klima.“ (Utopia, o. J.)

Auch digitale Medientechnologien werden in den Artikeln des Onlinemagazins in Hinblick auf Ressourcen thematisiert. So wird z. B. die Ökobilanz von E-Book-Readern analysiert (Matting 2015). Dabei werden nicht nur die in den E-Book-Reader verarbeiteten Ressourcen und deren Abbauprozesse in den Blick genommen, sondern auch der Stromverbrauch bei der Nutzung dieser Endgeräte (ebd.). Empfohlen werden neben einer bestimmten Art und Weise des Lesens von Büchern aus Papier (z. B. „öffentliche Leihbibliotheken nutzen, bei Tageslicht lesen, auf Ökostrom umstellen, Bücher in der Stadt gebraucht kaufen, gelesene Bücher tauschen oder verschenken“, ebd.) auch bestimmte Produkte, also E-Book-Reader, für die eine Kaufempfehlung ausgesprochen wird (ebd.). ${ }^{10}$

In der Diskussion der Möglichkeiten nachhaltigen Kaufens digitaler Medientechnologien (Winterer 2015a) wird neben der Nutzungsdauerverlängerung der Geräte (,,Jedes Gerät verbessert seine Ökobilanz dadurch, dass man es möglichst lange verwendet“, ebd.) auch der Verzicht (,Das nachhaltigste Gerät ist das, das nicht gekauft wird“, ebd.) und der Kauf gebrauchter Geräte (,Wer ein Gerät benötigt, sollte auch dem Gebrauchtmarkt eine Chance geben“, ebd.) empfohlen.

Der Verzicht auf digitale Medientechnologien wird in Onlineartikeln auf Utopia.de wiederholt als beste Möglichkeit, zu einer nachhaltigen Gesellschaft beizutragen, benannt, so auch in der Besprechung modularer Smartphones:

„Nach wie vor bleiben zwei Dinge die bessere Wahl [als modulare Smartphones zu kaufen, S. K.]: 1. Das gebrauchte Smartphone, denn jedes nicht produzierte Gerät ist

\footnotetext{
${ }^{10}$ Hier zeigt sich, dass die Medienpraktiken der Nicht-Nutzung (z. B. Roitsch 2020; Woodstock 2014; Kaun und Schwarzenegger 2014; Portwood-Stacer 2013; s. Abschn. 3.3.1) und des Sharings (z. B. Lobinger/Schreiber 2017 zum Sharing von Medieninhalten) auch mit Bezug zu Nachhaltigkeit diskutiert werden müssen.
} 
das bessere. Und 2. gar kein Handy mehr (aber klar: das will derzeit kaum jemand für sich umsetzen).“(Winterer 2019a)

Wie das Zitat zeigt, ist die tatsächliche Nichtnutzung digitaler Medientechnologien im Allgemeinen und von Smartphones im Besonderen für den Utopia-Autor keine Option. Empfohlen wird also nicht ein Ausstieg aus der digitalen Gesellschaft, sondern vielmehr das Gestalten dieser auf eine Art und Weise, die die Utopia GmbH als nachhaltig einschätzt (s. hierzu detaillierter Abschn. 4.5).

Auch das Bemühen um eine bessere Ressourcennutzung in der Produktion digitaler Medientechnologien wird thematisiert, dabei steht auf der Onlineplattform Utopia.de v. a. das Fairphone im Fokus. In Onlineartikeln mit Überschriften wie z. B. „Fairphone macht Lieferketten von Zinn, Gold, Tantal und Wolfram transparent“ (Winterer 2016) oder „Fairphone 2: Modul-Handy will faires Gold nutzen“ (Haderer 2015) wird nicht nur auf die sozial-ökologischen Folgen des Abbaus von für Smartphones benötigten Ressourcen hingewiesen, sondern mit dem FairphoneUnternehmen auch eine Initiative vorgestellt, die diese Abbauprozesse nachhaltiger gestalten will. Dabei wird das Fairphone sehr positiv besprochen (ebd.), aber mit dem Hinweis auf die nur wenigen fair gehandelten Ressourcen im Fairphone der zweiten Generation durchaus auch etwas kritischer in den Blick genommen:

„Utopia meint: Zinn, Gold, Tantal und Wolfram sind nicht alles. Doch Fairphone zeigt weiten Teilen der Elektronikbranche einmal mehr, dass die Herkunft konfliktfreier Mineralien zuverlässig dokumentierbar ist - wenn man es nur will. Käufer eines zugegeben recht teuren Fairphone 2 sollten wissen: Sie kaufen nicht nur ein Smartphone, sie unterstützen die ersten Schritte für einen nachhaltigen Wandel in der Elektronikbranche.“ (Winterer 2016, Hervorhebung im Original)

Das Zitat zeigt worauf auch Nutzer*innen des Fairphones verweisen: Beim Erwerb des Fairphones geht es letztendlich nicht darum, ein tatsächlich nachhaltiges produziertes Smartphone zu kaufen, sondern eine Initiative zu unterstützen, die das Potenzial hat, ein nachhaltiges Smartphone zu produzieren.

Schließlich ist für die Onlineplattform Utopia.de festzuhalten, dass Ressourcenschonung im Allgemeinen und der Zusammenhang von Ressourcen und digitalen Medientechnologien im Besonderen zwar ein zentrales Thema auf der Plattform ist, dass die Onlineartikel, Gewinnspiele, Produkttests etc. aber als Kaufempfehlungen für von der Utopia $\mathrm{GmbH}$ als nachhaltig bewertete Produkte schließlich wieder zu Konsum und damit Ressourcenverbrauch anregen.

Zusammenfassend lässt sich festhalten, dass in den drei Fallstudien Medienpraktiken untersucht wurden, die das Ziel der Ressourcenschonung verfolgen, dass darin jedoch Grenzen und Paradoxien auszumachen sind, da die Ressourcenschonung durch das Reparieren von Medientechnologien, die Produktion und Nutzung 
eines fairen Smartphones oder die Information über (vermeintlich) ressourcenschonende Produkte und Praktiken, punktuelle Versuche der Ressourcenschonung sind; dem stehen ein Verbrauch von Ressourcen u. a. durch die Komplexität des eigenen Medienrepertoires, die geringe Anzahl verwendeter fairer Ressourcen im Fairphone oder die Anregung zum erneuten Konsum und damit Ressourcennutzung gegenüber.

\section{Müllvermeidung}

Ein zweites dominantes Ziel der Akteur*innen, das über die Fallstudien hinweg herausgearbeitet wurde, ist das der Müllvermeidung. Dies wird von allen Akteursgruppen in den Repair Cafés (Organisator*innen, Helfer*innen, Hilfesuchende) mit dem Reparieren von Konsumgütern im Allgemeinen und dem der digitalen Medientechnologien im Besonderen verfolgt. So erklärt eine Teilnehmerin des Oldenburger Repair Cafés, die ihr altes Mobilfunkgerät reparieren möchte: „Ich möchte nicht, dass wir unsere Welt vermüllen mit lauter Sachen, die zwar in Ordnung sind, aber wo eine Schraube locker ist.“ Eine Universitätsangestellte, die das Oldenburger Repair Café mitorganisiert, bezieht sich in diesem Zusammenhang hingegen konkreter auf die problematischen Entsorgungsprozesse elektronischen Mülls:

„Es gibt ein Ausfuhrverbot für nicht mehr funktionsfähige, technische Geräte. Und der Zoll kommt gar nicht hinterher und manchmal habe ich auch das Gefühl, dass die gar kein Interesse daran haben. Da werden vorne ein paar funktionierende Geräte vorgestellt und dahinter befindet sich nur Elektromüll. Und wenn du dir diese „Agbogbloshie“-Geschichte ${ }^{11}$ mal anguckst, da wird dir ja so übel. Und das Verrückte daran ist, dass die Fischbestände, die vor dieser Küste, und die mit den Schwermetallen gefüttert werden und man muss ja wirklich inzwischen von Fütterung sprechen, die landen auch auf unseren Tellern, sofern wir den Fisch dann essen. [...] Es ist grauenvoll, was da passiert, grauenvoll.“

Nicht zuletzt aus dieser Kritik heraus organisiert sie das Repair Café, um Menschen eine Möglichkeit zu geben, ihre defekten Konsumgegenstände und insbesondere elektronische Geräte wie Medientechnologien zu reparieren, um damit die Produktion elektronischen Mülls und eine von ihr beschriebene Verschiffung nach Ghana zu vermeiden.

Auch die Organisatorin des Repair Cafés in Garbsen, die 65-jährige Rentnerin, weist auf die Umwelteinflüsse des Mülls hin, die sie mit der Nutzungsdauerverlängerung von Konsumgütern durch das Reparieren verhindern möchte: „Wenn wir die Müllberge so weiter höher werden lassen, und die ganzen Gifte in [...] unser Grundwasser gehen, dann werden unsere Kinder [...] die Zeche zahlen müssen. "Hier wird

${ }^{11}$ In Agbogbloshie, Ghana befindet sich eine der weltweit größten Deponien für elektronischen Müll, der dort unsachgemäß entsorgt wird, s. Abschn. 2.2.2. 
die intergenerative Bedeutung von Nachhaltigkeit deutlich, in der der Schutz der Bedürfnisse zukünftiger Generationen durch das Handeln heutiger Generationen postuliert wird (siehe Kap. 1).

Das Repair Café in Berlin organisiert eine Künstlerin in Kooperation mit dem Verein Kunst-Stoffe e. V. (s. Abschn. 3.3.2). Eine Mitarbeiterin des Vereins, welche die Künstlerin bei der Planung und Durchführung der Reparaturveranstaltungen unterstützt, hat ihr eigenes Verhalten in der Müllproduktion durch ihre Mitarbeit beim Repair Café reflektiert:

\begin{abstract}
„Vorher hab ich [...] die Sachen einfach weggeschmissen und jetzt, seitdem ich bei Kunststoffe arbeite und [...] beim Repair Café mitmache, kommt halt erst das Bewusstsein: ,Okay, überleg dir zweimal, ob du es wegschmeisst.' Und dann versuch ich erst, es zu reparieren."
\end{abstract}

Durch die Repair Cafés werden also Menschen, selbst die Organisator*innen, dazu angeregt, ihre eigene Müllproduktion zu reflektieren und gleichzeitig die Verursachung von (elektronischem) Müll durch das Reparieren zu vermeiden. Die bildende Künstlerin, die das Repair Café in Berlin organisiert, beschreibt dieses als einen „Rettungsort, wo Geräte und Dinge, die sonst im Müll landen würden,“ repariert werden können.

Müllvermeidung ist auch ein zentrales Ziel des Fairphone-Unternehmens und der Fairphone-Nutzer*innen. Wie bereits im vorherigen Kapitel in der Auseinandersetzung mit Medienpraktiken und Materialität erklärt wurde, ist das Fairphone mit der Intention konzipiert, auseinander gebaut und repariert werden zu können:

„The Fairphone 2 is designed to last longer than the rest by combining a modular architecture with the good old-fashioned power of repair. Affordable spare parts and helpful tutorials make it easy for anyone to fix the most commonly broken parts. And because we know how important software is to longevity, we're opening up our source code to owners and developers." (Fairphone 2016b)

Um die Reparatur der Smartphones zu ermöglichen, produziert und verkauft das Fairphone-Unternehmen Ersatzteile. Allerdings wird diese zunächst durch das Unternehmen hervorgehobene und beworbene Reparierbarkeit eingeschränkt, da seit Juli 2017 keine Ersatzteile mehr für das sich seit 2013 auf dem Markt befindliche Fairphone der ersten Generation produziert werden. Der Gründer des FairphoneUnternehmens Bas van Abel begründet dies damit, dass die Nachfrage für Ersatzteile zu gering sei und ihre Produktion somit zu teuer wäre (in Tricarico 2017). Auch äußert sich van Abel, dass der Haltbarkeitsaspekt des Fairphones ursprünglich nicht im Vordergrund gestanden habe (in ebd.). Die für die hier präsentierte Analyse der Onlineplattform des Unternehmens zeigt jedoch, dass die Reparierbarkeit des 
Fairphones und das daran geknüpfte Haltbarkeitsversprechen sehr wohl als ein Argument für (vermeintliche) Nachhaltigkeit des Smartphones durch das Unternehmen hervorgehoben wurde.

Neben der modularen Bauweise und (eingeschränkten) Reparaturmöglichkeiten will das Fairphone-Unternehmen Müll vermeiden, indem es Menschen auffordert, ihre alten Mobilfunkgeräte und Smartphones einzuschicken, damit diese durch eine Partnerorganisation recycelt werden können (Fairphone 2019e; s. o.). In der Nutzungsdauerverlängerung der Endgeräte durch die Reparaturmöglichkeit des Fairphones sowie mit Recyclingprojekten, für die das Unternehmen Menschen aufruft, ihre alten Mobilfunkgeräte und Smartphones einzuschicken, damit diese durch eine Partnerorganisation recycled werden können, sieht das Unternehmen also eine Möglichkeit der Müllvermeidung. Diese nimmt das Unternehmen aufgrund der sozial-ökologischen Folgen der Entsorgung digitaler Medientechnologien als gesellschaftliche Notwendigkeit wahr:

„When you buy a new mobile phone, the old one is often quickly forgotten. Some of these phones are properly discarded, but others may end up in landfills or are recycled in locations with dangerous working conditions." (Fairphone 2019d)

Ein 36-jähriger Softwareentwickler und Fairphone-Nutzer sieht in der Reparierbarkeit des Fairphones die Möglichkeit, die Folgen der Wegwerfgesellschaft zu reduzieren:

„Ich fand es [den Kauf des Fairphones, S.K.] für mich sinnvoll, [...] weil es halt nicht nur den Anspruch hat: , Wir wollen fair produzierte Komponenten drin verbauen', sondern eben auch noch den Nachhaltigkeitsgedanken: ,Wir wollen nicht, dass es ein Wegwerfprodukt ist. ' Und damit finde ich handelt man konsequent auf jeden Fall richtig, wenn man ein Produkt kauft, was kein Wegwerfprodukt ist, dann hilft man damit, die Folgen der Wegwerf-Gesellschaft zu minimieren.“

Nachhaltigkeit knüpft er an die Reduktion von Müll und weniger an die Produktionsprozesse des Fairphones. Für einen 68-jährigen Rentner und Fairphone-Nutzer ist hingegen der Crowdfunding-Prozess, nach dem die verschiedenen Generationen des Fairphones produziert werden, eine zentrale Möglichkeit der Müllreduktion:

„Ich finde das auch in Ordnung, dass man nicht einfach so auf Halde produziert und danach die Sachen wegschmeißt, sondern das man das produziert, was gebraucht wird, und da braucht man eben eine Vorfinanzierung."

Müllreduktion ist neben Ressourcenschonung also eines der dominanten Ziele des Fairphone-Unternehmens sowie auch der Nutzer*innen, wobei diese neben der 
Möglichkeit der Reparierbarkeit auch durch den Crowdfunding-Prozess gewährleistet werden soll. Dass hier Grenzen bzw. Paradoxien auszumachen sind, zeigt die Einstellung der Ersatzteilproduktion für die erste Fairphone-Generation (s. o.).

Müllreduktion ist neben Ressourcenschonung auch eines der zentralen Themen in den Artikeln des Onlinemagazins auf der Plattform Utopia.de. Wie bei der Rohstoffschonung sind es auch bei der Müllvermeidung zum einen Produkte, zum anderen Praktiken, die beworben werden. Einerseits werden Produkte wie die in Hinblick auf Ressourcenschonung bereits angeführten Bienenwachstücher aufgrund ihrer Wiederverwendbarkeit zur Vermeidung von Müll angepriesen (Ayoub 2019), andererseits werden Onlineshops beworben, über die man plastikfrei einkaufen kann (Utopia 2019d). Auch in Hinblick auf digitale Medientechnologien werden neben der Ressourcenschonung (s. o.) Möglichkeiten der Müllvermeidung aufgezeigt. So werden neben dem Fairphone (z. B. Winterer 2016; Haderer 2015; s. o.) auch die vom hessischen Start-up Shiftphone produzierten Smartphones als reparierbar und durch die damit verbundene Nutzungsdauerverlängerung als nachhaltig beworben (s. Winterer 2019a). Wenn die Entsorgung digitaler Medientechnologien nicht vermieden werden kann, so wird auf Utopia.de zumindest zu einer sachgemäBen Entsorgung der Endgeräte geraten: „Wenn ein Gerät das Ende seiner Lebenszeit erreicht hat, bemühe dich um eine fachgerechte Entsorgung" (Winterer 2015a).

Neben reparierbaren und damit langlebigen Medientechnologien werden auch Medienpraktiken in Artikeln des Onlinemagazins besprochen, die zu Müllvermeidung beitragen sollen, wobei Müllvermeidung. Das Leihen digitaler Medientechnologien wird im Vergleich zum Neukauf als eine nachhaltigere Praktik vorgestellt und gleichzeitig auf Anbieter, bei denen Elektrogeräte geliehen werden können, hingewiesen (Schulz 2018). Auch der Kauf gebrauchter Konsumgüter im Allgemeinen und digitaler Medientechnologien im Besonderen sowie die Möglichkeiten des Gebrauchtkaufens über Onlineportale wird auf Utopia.de als eine Option der Müllreduktion besprochen: „Der Gebrauchtkauf vermeidet Müll“ (Utopia o. J. a). Dabei werden Initiativen und Unternehmen, die gebrauchte digitale Medientechnologien wiederaufbereiten und zum Kauf anbieten, vorgestellt (Schulz 2019).

Aber nicht nur das Vermeiden des Neukaufs digitaler Medientechnologien durch die Praktiken des Leihens oder Gebrauchtkaufens, sondern auch Möglichkeiten der Vermeidung der Entsorgung digitaler Medientechnologien wird auf der Onlineplattform thematisiert, z. B. durch den Verweis auf die Option des Verschenkens: So wird die französische Initiative Back Market vorgestellt, die gebrauchte Mobilfunkgeräte annimmt und diese zum Ressourcenschutz recyceln will, und die Leser*innen werden dazu aufgefordert, ,elektronischen Altgeräten ein zweites Leben“ zu schenken (Winterer 2018). 
Zusammenfassend lässt sich festhalten, dass Müllvermeidung ein zentrales Ziel der Akteur*innen der untersuchten Fallstudien ist, wobei Ressourcenschonung und Müllvermeidung in allen Fallstudien oftmals zusammengedacht werden. Ob mit dem Reparieren, Leihen, Gebrauchtkaufen und Verschenken tatsächlich Ressourcen geschont und Müll vermieden wird, kann hier in letzter Konsequenz nicht nachvollzogen werden, da die Akteur*innen in den Fallstudien nicht längerfristig begleitet wurden. Dass sich bei der Verfolgung dieser Ziele durch die verschiedenen Akteur*innen jedoch Grenzen und Paradoxien zeigen, wurde in Hinblick auf die eingeschränkten Reparaturmöglichkeiten in den Repair Cafés und des Fairphones thematisiert. Ob sich durch das auch auf Utopia.de beworbene Reparieren, Leihen, Gebrauchtkaufen Rebound-Effekte ${ }^{12}$, also hier ein gesteigerter Konsum durch Effizienzsteigerung und Einsparungen, einstellen, weil eingespartes Geld z. B. für den Neukauf anderer Konsumgüter investiert wird, muss an dieser Stelle offen bleiben und kann aufgrund des erhobenen Datenmaterials nicht abschließend beantwortet werden.

\section{Wertschätzung}

Wertschätzung der Konsumgüter im Allgemeinen und von (digitalen) Medientechnologien im Besonderen ist ein weiteres Motiv der Akteur*innen in den Fallstudien. Dabei steht die Wertschätzung in engem Zusammenhang mit den bis hierher diskutierten Zielen der Ressourcenschonung und Müllvermeidung. So schätzen viele der Beteiligten in den Repair Cafés den Wert der Dinge, die sie besitzen und deswegen reparieren. Ein 57-Jähriger Teilnehmer, der sein defektes Radiogerät im Berliner Repair Café reparieren möchte, erklärt:

„Es steckt ja auch eine Menge Arbeit hier drin [deutet auf sein defektes Radiogerät, S.K.], in so einem Gerät [...]. Da haben Leute dran gearbeitet, haben sich das ausgedacht, haben die Pläne gezeichnet, haben das Design entworfen und dann haben Leute in der Fabrik dran gesessen und haben das montiert. [...] Und ich finde einfach, es ist auch eine Wertschätzung von menschlicher Arbeit, wenn man versucht, ein Produkt nachher wieder zu reparieren, wenn es nicht mehr funktioniert.“

Letztendlich honoriert er in dieser Aussage die Materialität seines Radiogeräts, in der sich die Arbeit und Mühe einer Vielzahl von Arbeiter*innen manifestiert, die das Gerät hergestellt haben. Der Aneignungsprozess digitaler Medientechnologien kann auch dazu führen, dass sich eine Beziehung zwischen den Nutzer*innen und den Endgeräten entwickelt, wie ein 30-jähriger IT-Systemelektroniker, der Hilfe bei der Reparatur von Smartphones anbietet, erklärt: „Eigentlich hat man sich ja mit

\footnotetext{
${ }^{12}$ Siehe detaillierter zu verschiedenen Formen von Rebound-Effekten Santarius 2012.
} 
dem Smartphone so angefreundet, dass man das ja auch nicht jedes Mal wechseln will." Ein 41-jähriger Hochfrequenztechniker wiederum rekurriert im Interview auf den Diskurs um geplante Obsoleszenz und ermutigt die Hilfesuchenden im Repair Café, sich teurere elektronische Geräte zu kaufen, in der Annahme, diese seien von besserer Qualität und damit langlebiger, wenn er sagt: „Wenn ich mir was kaufe, möchte ich auch, dass ich einen Wert angeschafft hab.“

Grundsätzlich fällt auf, dass viele Hilfesuchende in den Repair Cafés Medientechnologien mitbringen, die schon länger in ihrem Besitz sind und zu denen sie eine persönliche Beziehung aufgebaut haben, wie ein 70-jähriger Rentner im Oldenburger Repair Café, der sein altes Radiogerät reparieren möchte, erklärt: „Ja, erst mal hänge ich an dem. [...] Ich bin damit groß geworden." Einige Teilnehmer*innen bringen geerbte Medientechnologien mit, z. B. mehrere Dekaden alte Radios, an denen Erinnerungen hängen und deren Nutzungsdauer sie daher verlängern wollen. Ein Rentner, der Hilfe bei der Reparatur elektronischer Geräte im Garbsener Repair Café anbietet, schätzt besonders die Materialität alter Radiogeräte wert:

„Alte Radios, ich habe schon mal zwei [...] hier gehabt, von 1955 oder so was. So was habe ich zuhause auch noch stehen, das schmeißt man einfach nicht mehr weg. Nicht weil das 150 Euro wert sein könnte, nee, einfach weil es antik ist, weil es schön ist, weil man es sieht, wenn da was glüht drin, es hat einfach irgendwie so ein Flair.“

Eine Wertschätzung der Medientechnologien ergibt sich also zum einen, wenn diese älter oder geerbt sind, zum anderen, wenn die in der Materialität der Gegenstände eingeschriebene Arbeit honoriert sowie wenn die Rohstoffe bewahrt werden sollen. Eine 50-jährige Teilnehmerin im Garbsener Repair Café, die ihren Laptop reparieren möchte, findet das Reparieren digitaler Medientechnologien einfach „vernünftig“ und erklärt: „Wenn ihnen ein Knopf abgeht, schmeißen Sie ja auch nicht gleich die ganze Bluse weg." Die Wertschätzung der existierenden Medientechnologien ergibt sich für manche aber auch aus einer finanziellen Notwendigkeit: Einige wenige Teilnehmer*innen äußerten in den Interviews, dass sie sich keine neuen Exemplare ihrer defekten Gegenstände leisten können, wobei dies vor allem von Studierenden, Erwerbslosen oder Rentner*innen geäußert wurde.

Wertschätzung ist auch eines der Motive des Fairphone-Unternehmens und seiner Nutzer*innen. Das Fairphone-Unternehmen schätzt nicht nur die von ihm produzierten Smartphones wert, indem sie die Nutzungsdauer der Geräte durch die modulare Bauweise und der damit einhergehenden Reparierbarkeit der Smartphones verlängern möchten (s. o.), sondern auch die Mobilfunkgeräte und Smartphones, über die Interessierte bereits vor Kauf des Fairphones verfügen. So postuliert das Unternehmen auf seiner Onlineplattform: ,the most sustainable phone available is the one you already own. So the longer you keep it, the more sustainable it becomes. Extending 
the lifespan of existing phones is the best strategy for reducing their impact on the planet." (Fairphone 2019h) Das Unternehmen will Nutzer*innen dazu ermutigen, existente Smartphones wertzuschätzen und so lange wie möglich zu nutzen. Dafür gibt das Unternehmen auch Hinweise, wie durch eine entsprechende Aneignung die Nutzungsdauer der Endgeräte verlängert werden kann, u. a. durch die regelmäBige Reinigung der Geräte, regelmäßige Software-Updates und das Reparieren, für das das Unternehmen auch Anleitungen auf seiner Onlineplattform zur Verfügung stellt (Fairphone 2019i). Und dennoch lädt das Fairphone-Unternehmen mit dem Versprechen, ein faires Smartphone zu verkaufen und durch verschiedene Werbestrategien, zum Konsum an, geht es dem Unternehmen nicht nur um den Kauf eines Endgerätes, sondern auch um den Verkauf einer Idee (s. u.).

Aus dem Datenmaterial ergibt sich, dass die Fairphones-Nutzer*innen dieses u. a. auch gekauft haben, da ihnen die Möglichkeit des Reparierens und einer entsprechend längeren Nutzungsdauer versprochen wurde, welche ihnen auch aufgrund der Wertschätzung der von ihnen genutzten Smartphones wichtig ist. Sie haben das Fairphone erworben, um die Nutzungsdauer ihres Smartphones durch das Reparieren desselben zu verlängern. Dieses Ziel haben viele Fairphone-Konsument*innen aufgrund ihrer Kritik an der Konsum- und Wegwerfgesellschaft entwickelt. So kritisiert der 36-jährige Softwareentwickler und Fairphone-Nutzer die Wegwerfgesellschaft in Hinblick auf die konventionelle Smartphone-Nutzung:

„Weil ein ganz großer Teil dieser Wegwerfgesellschaft bei Smartphones und generell im medientechnischen Bereich basiert darauf, dass man die Einzelteile nicht bewerten kann, dass sie keinen Wert haben. Das ist immer das komplette Produkt, was zählt. Du kannst nicht sagen: Moment, mein Tablet ist langsam geworden, ich baue irgendwie eine neue Platine auf oder stocke dem RAM auf, das funktioniert halt nicht.“

Die Möglichkeit des Reparierens seines Fairphones aufgrund der modularen Bauweise sowie das Angebot der Ersatzteile für das Fairphone durch das FairphoneUnternehmen, sind ihm daher besonders wichtig, weil er die von ihnen genutzten Medientechnologien wertschätzt. Dass in Hinblick auf die Reparierbarkeit des Fairphones jedoch Grenzen auszumachen sind, wurde bereits in Abschn. 4.1 erläutert. Auch lassen sich Paradoxien in den Alltagspraktiken der Fairphone-Nutzer*innen finden: So wollen die Nutzer*innen durch den Erwerb des Smartphones nachhaltig handeln, besitzen manche aber dennoch, ähnlich der Reparierenden in Repair Cafés, komplexe Medienrepertoires (hier verstanden als die Gesamtheit der Medientechnologien, die Individuen nutzen, s. Abschn. 3.3.2) oder ersetzen Medientechnologien regelmäßig aufgrund technischer Innovationen. Auch im Vergleich mit 
weiteren Alltagspraktiken wurden Paradoxien identifiziert, z. B. sind FairphoneNutzer*innen durchaus Viel- oder Langstreckenflieger*innen und handeln damit weniger nachhaltig.

Auch in den Artikeln des Onlinemagazins auf der Plattform Utopia.de ist die Wertschätzung von Konsumgütern im Allgemeinen und Medientechnologien im Besonderen ein zentrales Thema. So werden z. B. Hinweise gegeben, wie Lebensmittelverschwendung vermieden werden (Utopia o. J. b), aber auch, wie die Nutzungsdauerverlängerung digitaler Medientechnologien ein Beitrag zu Nachhaltigkeit sein kann: „Jedes Gerät verbessert seine Ökobilanz dadurch, dass man es möglichst lange verwendet. Sinnvoll ist also, Smartphones und Tablets so lange wie möglich zu benutzen und schonend zu behandeln." (Utpia 2015b) Dabei steht die Wertzuschreibung auch im Beispiel der Onlineplattform Utopia.de in einem engen Zusammenhang mit den Zielen der Ressourcenschonung und Müllvermeidung, da in den Onlineartikeln, in denen Ressourcenschonung und Müllvermeidung im Allgemeinen und solche in Hinblick auf Medientechnologien im Besonderen, diese auch im Zusammenhang mit der Wertschätzung von Konsumobjekten bzw. digitalen Medientechnologien diskutiert werden.

Zusammenfassend lässt sich für alle drei Fallstudien festhalten, dass die Akteur*innen Konsumobjekte im Allgemeinen und digitale Medientechnologien im Besonderen wertschätzen, auch, um Ressourcen zu schonen und Müll zu vermeiden, aber auch, weil sie persönliche Beziehungen zu den Endgeräten aufgebaut haben.

\section{Wissensverbreitung und Lernen}

Neben den Zielen der Ressourcenschonung und Müllvermeidung sowie dem Motiv der Wertschätzung, wurde das Ziel der Wissensverbreitung und des Lernens über die Fallstudien hinweg herausgearbeitet. Viele der in den drei Fallstudien handelnden Akteur*innen wollen über die sozial-ökologischen Folgen der Konsumgesellschaft im Allgemeinen und die der Produktion und Entsorgung digitaler Medientechnologien im Besonderen eine breitere Bevölkerung aufklären sowie Alternativen aufzeigen und anbieten bzw. Wissen über alternative und nachhaltigere Medienpraktiken verbreiten.

So organisieren ganz unterschiedliche Personen die Repair Cafés, um ihr Wissen über die sozial-ökologischen Auswirkungen der Produktion und Entsorgung digitaler Medientechnologien weiterzugeben. Mit der Ausrichtung des Repair Cafés möchte der Betreiber der Oldenburger Kneipe, in der zunächst das Repair Café ausgerichtet wurde, ein Bewusstsein über die sozial-ökologischen Folgen der Produktion von Konsumgütern im Allgemeinen und Medientechnologien im Besonderen schaffen: 
„Dieses Bewusstsein [über die Problematik der Produktionsbedingungen, S. K.] muss einfach da sein und das ist für mich tatsächlich [wichtig, S. K.], dass man dieses Bewusstsein verbreitet, dass man da unheimlich viel Werbung für macht, dass immer mehr Leute irgendwie aufmerksam darauf werden. Und auch diese Problematiken sehen, [..., und, S. K.] dass man damit einfach wesentlich bewusster umgeht.“

Er sieht in den Repair Cafés eine Möglichkeit, Menschen über die Relevanz der Ressourcenschonung und Müllvermeidung aufzuklären. Auch die bildende Künstlerin des Berliner Repair Cafés möchte dieses nutzen, um Wissen über die Auswirkungen der Produktion und Entsorgung digitaler Medientechnologien zu teilen:

„Es geht hier auch viel um Bildung, man [...] muss wissen: Okay, diese Metalle kommen aus diesen Länder, wo es Krieg gibt [und, S. K.] die Leute arm sind. Und auch die Entsorgung [digitaler Medientechnologien, S. K.] ist sehr schwierig und sehr problematisch, weil [...] viel illegal geliefert wird nach Afrika.“

Neben der Wissensverbreitung über die globalen Produktions- und Entsorgungsketten, die sie als eine „Katastrophe“ bezeichnet, möchte sie aber auch, dass Teilnehmer*innen Wissen um die sachgemäße Nutzung ihrer Geräte erlernen, wie beispielsweise die Entnahme der Batterien oder Akkus aus elektronischen Geräten bei längerer Nichtnutzung.

Somit wollen Organisator*innen und Helfer*innen in den Repair Cafés nicht nur ihr Wissen um die sozial-ökologischen Folgen der Produktion, Nutzung und Entsorgung von Konsumgütern im Allgemeinen und digitalen Medientechnologien im Besonderen verbreiten, sondern auch Wissen über die richtige Nutzung elektronischer Geräte weitergeben. Des Weiteren wollen Helfer*innen auch Kompetenzen in der Praktik des Reparierens teilen. Der 30-jährige Systemelektroniker, der seine Hilfe bei der Reparatur von Mobilfunkgeräten in Berlin anbietet, erklärt:

„Wir arbeiten sehr viel mit Anleitung, sodass derjenige, wenn's jetzt ein Displayschaden ist oder so, die Reparatur selber machen sollte mit unserer Anleitung und unserer Hilfe. [...] Ich hatte sehr viele Kunden, die einfach interessiert sind, die Handys selber zu reparieren."

In diesem Zitat wird die bereits oben erläuterte Paradoxie zwischen dem Anspruch, „Hilfe-zur-Selbsthilfe“ zu leisten, sowie der Praxis einer Dienstleistung (suggeriert durch die Verwendung des Begriffs „Kunden“) offenbar.

Dass unter den Hilfesuchenden aber Interesse am Erlernen des Reparierens besteht, zeigt das folgende Zitat einer Beteiligten im Berliner Repair Café beispielhaft: „Ich find's immer spannend, dabei zuzugucken [beim Reparieren, S. K.], was ist jetzt kaputt und warum. [...] Ich [finde] es immer cool, mir das anzugucken und 
auch sich so ein bisschen was abzugucken." Doch haben die Prozesse der Wissensvermittlung und des Lernens auch Grenzen. Viele der Teilnehmer*innen haben v. a. mit digitalen Medientechnologien Berührungsängste und trauen sich das Reparieren nicht selber zu, wobei dies gleichermaßen für Männer wie auch für Frauen gilt. So sagt ein 31-jähriger Musiker in Oldenburg, der den defekten Verstärker seiner Musikanlage mitgebracht hat:

„Ich würde es [das Reparieren, S. K.] wahnsinnig gerne selber können, aber ich habe leider so was völlig Unnötiges gelernt wie Musiker und ich bewundere das wahnsinnig, wie man sich hinsetzen kann, die Technik verstehen kann und sagen kann: Na ja, das und das müssen wir ersetzen und dann geht das Ding wieder. [...] Ich würde mich nie trauen, das selber jetzt aufzumachen."

Und auch eine 64-jährige Teilnehmerin des Repair Cafés in Garbsen, die ihren defekten Fernseher reparieren lassen möchte, antwortet auf die Frage, ob sie sich in den Reparaturprozess einbringen möchte: „Nein, nein, mit Technik habe ich es nicht so. Nein. Das kann ich nicht. Und brauche ich auch nicht." Genau wie Rosner und Ames (2013, S. 327), zeigt auch meine Analyse, dass oftmals für die Teilnehmenden repariert wird. Aber viele Hilfesuchende interessiert zumindest das Öffnen der Geräte und das Beheben des Defekts und beobachten die Reparaturprozesse.

Auch die Helfer*innen nehmen diese Grenzen der Wissensvermittlung wahr. So erklärt der 70-jährige pensionierte Hauptschullehrer, der in Oldenburg bei der Reparatur elektrischer Geräte und auch Medientechnologien hilft: „Hier einem totalen Laien zu erklären, was man an den technischen Geräten macht, das führt natürlich zu weit. Also, das geht sicher bei einigen Sachen, aber bei so Elektronik sicher nicht." Die Beobachtungen in den verschiedenen Reparaturveranstaltungen zeigen tatsächlich, dass z. B. mehr Hilfesuchende in den Reparaturprozess von Textilien oder Fahrrädern eingebunden werden als in den elektronischer Geräte. Die Art der defekten Dinge beeinflusst also, inwiefern das Reparieren ein gemeinsamer Akt ist und sein kann und inwiefern das Reparieren erklärt bzw. erlernt werden kann.

Für Personen, die im Alltag bereits reparieren und Technikwissen sowie kompetenz mitbringen, ist das Repair Café ein Ort, an dem Werkzeuge, Ressourcen und Unterstützung zur Verfügung gestellt werden, die zuhause fehlen. So erklärt ein Helfer im Oldenburger Repair Café:

„Also viele kommen hier auch her, die haben eine technische Vorbildung und kennen sich ein bisschen mit solchen Dingen aus, denen fehlt eben nur das Werkzeug und brauchen hier und da mal einen Tipp. [...] Wir sehen uns zu allererst als Unterstützer“. 
Die Unterstützung findet nicht nur im Reparaturprozess durch die Helfenden statt, sondern auch durch die Bereitstellung von Ressourcen und einer Infrastruktur während der Reparaturveranstaltungen. Findet die Wissensvermittlung in den Repair Cafés vis-à-vis statt, so tauschen sich auch einige, wenn auch wenige Reparierende über die Onlineforen der Plattform der Anstiftung \& Ertomis aus. Auch hier wird Reparaturwissen erfragt oder weitergeben. Dennoch bleiben die lokalen Reparaturveranstaltungen die zentralen Momente des Wissensaustauschs.

Während der Covid-19-Pandemie wurden Reparaturveranstaltungen auch online organisiert - durch einzelne Reparaturinitiativen bzw. in netzwerkweiten Veranstaltungen, die durch die Anstiftung \& Ertomis organisiert wurden. Diese Onlineveranstaltungen wurden $u$. a. auf der durch die Stiftung gestalteten Onlineplattform beworben (www.repararur-initiativen.de), sowie auch im Newsletter der Anstiftung.

Auch in der Fallstudie zum Fairphone ist das Ziel der Wissensvermittlung zentral. Das Fairphone-Unternehmen verkauft nicht nur ein Smartphone, sondern vermittelt Wissen über die sozial-ökologischen Folgen von konventionellen Smartphones im Allgemeinen sowie der Produktion des Fairphones im Besonderen. Dabei liegt ein Schwerpunkt auf der Problematik des Ressourcenabbaus und auf hier liegende Potenziale fairer Abbauprozesse sowie auf der Problematik der Entsorgung von Smartphones und hier liegenden Möglichkeiten der Müllvermeidung durch Nutzungsdauerverlängerung (s. o.). Im Onlineforum auf der Plattform des Unternehmens tauschen sich Fairphone-Nutzer*innen über die Reparaturmöglichkeiten des Smartphones aus, und auch in lokalen von einzelnen Fairphone-Nutzer*innen organisierten Veranstaltungen wird Wissen über das Smartphone, die Herstellungsprozesse und Repariermöglichkeiten ausgetauscht (s. hierzu detaillierter Abschn. 4.4).

Schließlich will das Fairphone-Unternehmen den Diskurs um (un-)faire Produktionsbedingungen elektronischer Geräte beeinflussen (Fairphone 2015b, S. 1), zum einen durch die Entwicklung des Fairphones selbst, zum anderen durch Kampagnen, in denen das Unternehmen über die globalen Auswirkungen der Produktion und Entsorgung von Smartphones aufklärt. Durch die Informationsverbreitung der eigenen Produktion schafft das Fairphone-Unternehmen Transparenz (siehe detaillierter zum Wert der Transparenz Abschn. 4.4). Hierfür nutzt es nicht nur die eigene Onlineplattform, sondern auch Onlinenetzwerke wie Facebook und Instagram und den Mikrobloggingdienst Twitter.

Auch in der Fallstudie zur Onlineplattform Utopia.de ist das Ziel der Wissensvermittlung zentral, denn die Utopia $\mathrm{GmbH}$ beschreibt als Anliegen, dass sie „Millionen Verbraucher informieren und inspirieren [will, S. K.], ihr Konsumverhalten und ihren Lebensstil nachhaltig zu verändern.“ (Utopia 2019c, s. o.) In Artikeln des 
Onlinemagazins wird nicht nur Wissen über als nachhaltig deklarierte Produkte und Praktiken, sondern auch über sozial-ökologische Folgen des als nicht nachhaltig eingeschätzten Konsums weitergegeben. Hier werden auch die Auswirkungen der Produktion und Entsorgung digitaler Medientechnologien thematisiert (s. o.). So wird z. B. auch die oben erläuterte Problematik im Abbau der für digitale Medientechnologien benötigten Ressourcen, wie dem Coltanabbau in der Demokratischen Republik Kongo, durch den Warlords ihren Krieg gegen die Zentralregierung finanzieren, und Menschen, oftmals Kinder, unter unwürdigen und lebensbedrohlichen Bedingungen arbeiten, unter Artikeltiteln wie „Handy - Krieg und Verwüstung in der Hosentasche" (Utopia 2013) thematisiert.

In den Onlineforen sowie v. a. über verschiedene Facebook-Gruppen tauschen sich Nutzer*innen über verschiedene Themen aus und teilen hier ihr Wissen über nachhaltigen Konsum (s. o.). Die Utopia GmbH nutzt des Weiteren einen eigenen YouTube-Kanal, in dem sie Kurzfilme über verschiedene Themen nachhaltigen Konsums präsentiert und hierüber Wissen an die Rezipierenden vermitteln will (s. o.).

Zusammenfassend lässt sich festhalten, dass der Wissensaustausch in den unterschiedlichen Fallstudien über vis-à-vis in lokalen Veranstaltungen oder medial vermittelt über die eigenen Onlineplattformen oder über Profile auf Onlinenetzwerken oder Mikrobloggingdiensten stattfindet. Diese (medial vermittelte) Kommunikation ist auch ein zentrales Moment der Vergemeinschaftungsprozesse, die in den Fallstudien auszumachen sind und die in Abschn. 4.4 näher betrachtet werden.

Dem Ziel der Wissensvermittlung und des Lernens inhärent ist das Ziel der Ermächtigung, das eine Folge der Wissensvermittlung und des Lernens sein kann und sein soll. Ermächtigung wird in Anlehnung an Rosner und Ames (2014, S. 326) hier als ein Prozess definiert, in dem sich Wissen um Gegenstände entwickelt, um besser informierte Entscheidungen über diese zu treffen. Die Auswertung des Datenmaterials zeigt deutlich, dass die Akteur*innen der verschiedenen Fallstudien Wissen über Medienpraktiken und digitale Medientechnologien teilen, um besser informierte Entscheidungen treffen zu können - z. B. über nachhaltigen Konsum im Allgemeinen, digitale Medientechnologien und die Medienpraktik des Reparierens im Besonderen. In der Fallstudie zum Reparieren von (digitalen) Medientechnologien in Repair Cafés und in der Produktion und Aneignung des Fairphones geht es letztendlich um eine Ermächtigung der Geräte selbst. In dem Datenmaterial zeigten sich jedoch auch Paradoxien und Grenzen in der Wissensvermittlung und damit auch der Ermächtigung. 


\section{Konsumkritische Medienpraktiken}

Die folgende Tab. 4.2 gibt eine Übersicht über die dominanten Ziele und Motive, welche die Akteur*innen der drei Fallstudien verfolgen.

Es sind die Ziele der Ressourcenschonung, Müllvermeidung, Wissensvermittlung und des Lernens sowie des Motivs der Wertzuschreibung, welche die Medienpraktiken der untersuchten Fallstudien als konsumkritisch charakterisieren. Konsumkritische Medienpraktiken definiere ich als solche, in denen a) Medien entweder genutzt werden, um (eine bestimmte Art von) Konsum zu kritisieren oder b) Alternativen zum Konsum (im Sinne des Verbrauchens und Kaufens) von Medientechnologien entwickelt bzw. praktiziert werden (s. auch Kannengießer 2018a, S. 217 und Kap. 1).

Sind konsumkritische Medienpraktiken solche, in denen explizit der Zusammenhang von Medien (als Technologien, Inhalte und Organisationen) und Konsum thematisiert wird, so werden kritische Medienpraktiken allgemeiner durch zwei Charakteristika definitorisch bestimmt:

„1) In kritischen Medienpraktiken reflektieren Akteure Routinen, die sich auf Medien (als Organisationen, Inhalte oder Technologien) beziehen, und/oder Metaprozesse wie Mediatisierung, Digitalisierung oder Datafizierung. 2) Auf der Grundlage dieser Reflektion entwickeln Akteure alternative Routinen in ihren Medienpraktiken und gestalten Prozesse der Mediatisierung, Digitalisierung oder Datafizierung." (Kannengießer und Möller 2021, S. 256).

Konsumkritische Medienpraktiken sind also eine spezifische Form kritischer Medienpraktiken.

Wie gezeigt wurde, können die hier untersuchten Medienpraktiken jeweils als konsumkritisch bezeichnet werden, da entweder Konsum an sich bzw. eine bestimmte Art von Konsum in den Medien kritisiert wird bzw. eine Art von Konsum proklamiert wird, der als nachhaltig angesehen wird (so im Beispiel von Utopia.de) oder durch die Medienpraktiken des Reparierens von Medientechnologien bzw. Produzierens und Aneignens fairer Medientechnologien Alternativen zum Konsum von Medientechnologien etabliert werden sollen, zum einen, um die Nutzungsdauer digitaler Medientechnologien zu verlängern und damit Ressourcen zu schonen sowie Müll zu vermeiden, zum anderen in der Produktion und Nutzung eines Smartphones, das (zu einem gewissen Anteil) nachhaltig produziert wird und reparierbar ist - wodurch auch Ressourcen geschont sowie Müll vermieden werden soll.

Die vier Ziele Ressourcenschonung, Müllvermeidung, Wissensvermittlung und Lernen sowie das Motiv der Wertzuschreibung stehen dabei in einem engen Zusammenhang, sollen durch die Vermittlung des Wissens über die sozial-ökologischen Folgen der Produktion und Entsorgung digitaler Medientechnologien Nutzer*innen 


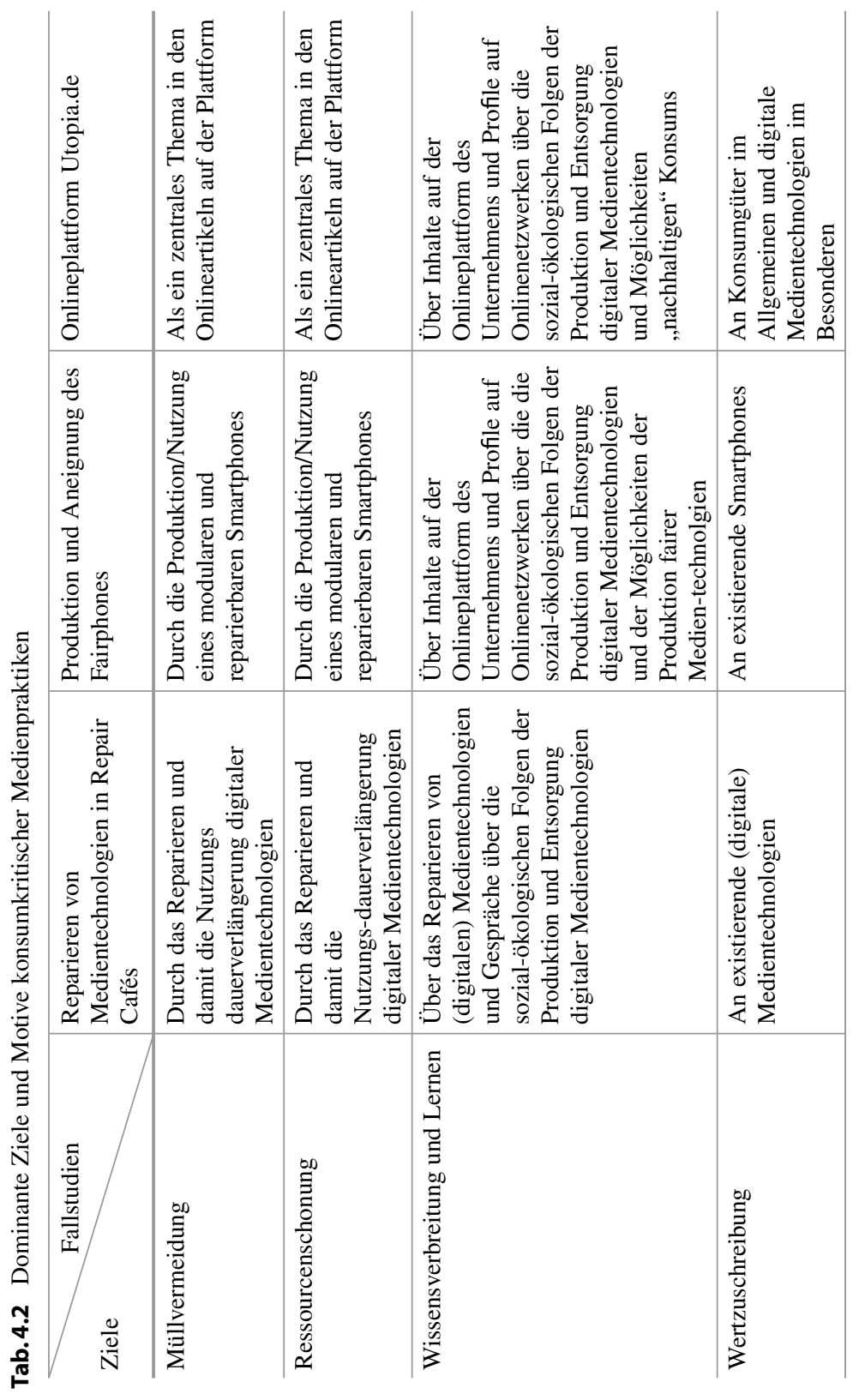


in den verschiedenen Fallstudien aufgeklärt werden, um ihre Medienpraktiken zu reflektieren. Des Weiteren sollen sie dazu motiviert werden, durch Medienpraktiken, wie dem Reparieren, Ressourcen zu schonen und Müll zu vermeiden. Die Wertschätzung der vorhandenen Apparate ist schließlich eine Bedingung und zugleich Folge der Ressourcenschonung und Müllvermeidung, schreiben die Nutzer*innen ihren Geräten doch einen Wert zu, weil sie um die integrierten Ressourcen und in den Apparaten materialisierte Arbeit wissen, und versuchen sie entsprechend die Entsorgung digitaler Medientechnologien aufgrund dieses Wissens zu vermeiden.

Kritik wird hier zum einen im Sinne Kants (1996 [1790], S. 18 ff.) als „Urteilskraft" verstanden, da Akteur*innen Produkte und Praktiken bewerten, zum anderen im Sinne Foucaults (1992 [1978]) als die Entwicklung von Alternativen - hier von Produkten und Praktiken, die nicht dem mehrheitlichen Konsum bzw. verbreiteten Konsumgütern entsprechen. Stellt Kritik ,gesellschaftliche Werte, Praktiken und Institutionen und die mit diesen verbundenen Welt- und Selbstdeutungen ausgehend von der Annahme infrage, dass diese nicht so sein müssen, wie sie sind" (Jaeggi und Wesche 2009, S. 7), so hinterfragen die hier untersuchten konsumkritischen Medienpraktiken die derzeit mehrheitlich verfolgten Medienpraktiken von Konsumierenden und Produzierenden, bewerten diese und entwickeln andere Produkte und Praktiken.

Mit den konsumkritischen Medienpraktiken wollen die Akteur*innen der drei Fallstudien zu einer nachhaltigeren Gesellschaft beitragen. Wie das Datenmaterial zeigt, bezieht sich Nachhaltigkeit dabei nicht nur auf die ökologische Dimension (s. Kap. 1), indem die Umwelt durch Ressourcenschonung und die Müllvermeidung geschützt wird, sondern auch auf die soziale Dimension, in dem Produktionsprozesse digitaler Medientechnologien fairer gestaltet und gesundheitsgefährdende Entsorgungsprozesse vermieden werden. Schließlich geht es auch um die ökonomische Dimension von Nachhaltigkeit, indem ein alternativer, nachhaltigerer Markt für Medientechnologien geschaffen bzw. beworben wird.

Neben den vier das Handeln der Akteur*innen dominierenden Zielen, welche ich als konsumkritisch bezeichne, wurden auch weitere Ziele und Motive in der Materialauswertung identifiziert, wie z. B. die Freude am Reparieren oder die finanzielle Notwendigkeit (s. o.), die weniger politisch motiviert sind, also weniger darauf zielen, Gesellschaft zu gestalten. Es sind jedoch die konsumkritischen Ziele, welche im Datenmaterial dominierten. Auch ist zu betonen, dass die verschiedenen Ziele nicht nur von unterschiedlichen Personen vertreten werden, sondern, dass einzelne Personen auch unterschiedliche Ziele verfolgen, und dass es schließlich nicht zwingend zu Widersprüchen zwischen den Zielen kommen muss. So kann eine Person digitale Medientechnologien aufgrund einer finanziellen Notwendigkeit oder Freude an der 
Auseinandersetzung mit dem Endgerät reparieren und dies gleichzeitig aufgrund der Ressourcenschonung und Müllvermeidung tun.

Weiterhin wurde gezeigt, dass in den konsumkritischen Medienpraktiken durchaus Paradoxien zu finden und diese mit ihren eigenen Grenzen konfrontiert sind. Im Falle des Reparierens von Medientechnologien hat z. B. die Vermittlung des Wissens über Reparaturprozesse ihre Grenzen, weil Helfer*innen oftmals für Hilfesuchende reparieren und letztere nicht zwingend selbst. Des Weiteren zeigte das Interviewmaterial, dass an den Repair Cafés Beteiligte, die mit dem Reparieren die Ziele der Ressourcenschonung und Müllvermeidung verfolgen, auch über komplexe Medienrepertoires verfügen und ihre Medientechnologien aufgrund technischer Innovationen regelmäßig ersetzen, was mit dem übergeordneten Ziel der Nachhaltigkeit konfligiert. Dies erklären überwiegend technisch affine Reparaturhelfer*innen. Einige andere Personen erzählten aber auch von Konsumverzicht in Hinblick auf Medientechnologien oder von der Nutzung sehr alter Medienapparate.

Auch aufseiten des Fairphone- und des Utopia-Unternehmens lassen sich jeweils Paradoxien finden. So regt die Onlineplattform Utopia.de aufgrund ihrer Kaufberatung durchaus und v. a. zum Kauf an, auch wenn dieser nach Einschätzungen der Utopia $\mathrm{GmbH}$ nachhaltig sein soll. Aber tatsächlich nachhaltig im Sinne einer konsequenten Müllvermeidung und Ressourcenschonung wäre eher der Konsumverzicht bzw. Konsumreduktion. Solche Praktiken werden zwar wiederholt in Onlineartikeln der Plattform thematisiert, dominant ist aber das Bewerben als nachhaltig deklarierter Produkte - nicht zuletzt sicherlich aufgrund der Finanzierung der Onlineplattform, welche durch (nachhaltige) Unternehmen gewährleistet wird (s. Abschn. 4.1).

Und auch wenn die Reparierbarkeit des Fairphones zwar den Konsum neuer Geräte verhindern könnte, so veranlassen die Existenz dieses Gerätes und das Unternehmen selbst über den Kauf des Smartphones doch wieder Konsum - nämlich den Erwerb des Fairphones. Auch sind für die erste Generation des Fairphones keine Ersatzteile mehr beziehbar, sodass dieses nicht zwingend reparierbar ist. Dies erstaunt v. a., da die Fairphones der ersten Generation erst wenige Jahre alt sind (die erste Auslieferung erfolgte 2013) und eine durch das Unternehmen versprochene Langlebigkeit des Smartphones somit nicht gewährleistet ist. Eine Paradoxie in Hinblick auf die Fairphone-Nutzer*innen lässt sich ähnlich wie bei den Reparierenden in Repair Cafés anhand der Medienrepertoires festmachen, denn einige Nutzer*innen verfügen über komplexe Medienrepertoires oder ersetzen bestehende Medientechnologien regelmäßig aufgrund technischer Innovationen.

Neben den Paradoxien innerhalb der konsumkritischen Medienpraktiken müssen diese auch im Kontext weiterer Alltagspraktiken beobachtet werden. So zeigt sich 
bei vielen der Reparateur*innen und Fairphone-Nutzer*innen, dass die konsumkritischen Motive für das Reparieren bzw. den Kauf des Fairphones einige Personen nicht davon abhalten, in ihrer Freizeit trotzdem z. B. Viel- oder Langstreckenflieger*innen zu sein und hier das Ziel der Nachhaltigkeit weniger zu verfolgen.

Menschen handeln also durchaus konsumkritisch mit Medien(-technologien), aber die konsumkritischen Medienpraktiken weisen dennoch Paradoxien auf und sind auch im Kontext weiterer Alltagspraktiken (und ihrer Relevanz für Konsumkritik) zu beobachten. Nichtsdestoweniger können konsumkritische Medienpraktiken als Versuche bezeichnet werden, mit Medien(-technologien) zu einer nachhaltigen Gesellschaft beizutragen.

\subsection{Konsumkritische Medienpraktiken aus medienethischer Perspektive}

Wurden im vorherigen Kapitel die Ziele und Motive der in den Fallstudien untersuchten Medienpraktiken untersucht, durch welche diese als konsumkritisch zu charakterisieren sind, so stehen in diesem Teilkapitel die Werte im Mittelpunkt, welche den konsumkritischen Medienpraktiken inhärent sind. Denn die im vorhergehenden Kapitel herausgearbeiteten Ziele und Motive der in den Fallstudien agierenden Personen zeigen, dass viele der Beteiligten bestimmte und ähnliche Wertvorstellungen konstruieren und verfolgen. Die Werte konsumkritischer Medienpraktiken werden durch das Einnehmen einer medienethischen Perspektive (s. Abschn. 3.2.3) auf das Datenmaterial sichtbar.

Nimmt eine medienethische Perspektive Wertevorstellungen auf der Makro, Meso- und Mikroebne in den Blick (Krainer et al. 2016, S. 10), so stehen in diesem Buch mit den Beispielen besonders die Meso- und die Mikrobene im Fokus, da zum einen Medienpraktiken von Individuen untersucht werden (wie den Fairphone-Nutzer*innen), aber auch solche, die organisiert (wie das Reparieren von Medientechnologien in Repair Cafés) oder durch Organisationen bzw. Unternehmen (z. B. das Fairphone-Unternehmen und die Utopia GmbH) praktiziert werden. Die Makroebene hingegen spielt als Rahmen für die untersuchten Medienpraktiken eine Rolle, der die Medienpraktiken reguliert bzw. durch diese kritisiert wird - so weisen Beteiligte an Repair Cafés und FairphoneKonsument*innen beispielsweise auf die Baseler Konvention hin, in der die Verschiffung elektronischen Mülls von Staaten der Europäischen Union in andere Länder verboten ist (s. Abschn. 2.2.2). Das Wissen um das Ignorieren dieser Konvention und die illegale Verschiffung elektronischen Mülls auf u. a. die 
größte Deponie der Welt in Ghana aufgrund der Rezeption dies thematisierender Medienberichte, veranlasst die Akteur*innen, sich um Müllvermeidung zu bemühen (s. vorheriges Kapitel). Bildet dieses Wissen die Motivation der Akteur*innen in den Fallstudien, so wird diese Makroebene, also z. B. die Gesetzgebung zu globalen Wertschöpfungsketten nicht detaillierter untersucht, sondern als Rahmen der konsumkritischen Medienpraktiken erläutert. Im Folgenden erläutere ich die Werte, welche den untersuchten Medienpraktiken inhärent sind.

Wie in Abschn. 3.2.3 erklärt, kann mit einer medienethischen Perspektive die Moral in Medienpraktiken von Akteur*innen oder Gemeinschaften untersucht werden, wobei unter Moral der ,in einer bestimmten Gruppierung, Gemeinschaft oder Gesellschaft geltenden Komplex an Wertvorstellungen, Normen und Regeln" (Rath 2002, S. 59) verstanden wird. Die hier untersuchten konsumkritischen Medienpraktiken sind moralische, weil mit ihnen bestimmte Werte verfolgt werden. Wenn Werte, Ziele und Normen konkrete Verhaltensregeln sind (Funiok 2016, S. 322), dann sind den in den untersuchten Medienpraktiken Werte inhärent, da die verschiedenen Akteur*innen freiwillig bestimmte Ziele verfolgen und den konsumkritischen Medienpraktiken keine konkreten Verhaltensregeln zugrunde liegen.

Durch eine Abstrahierung der im vorherigen Kapitel erläuterten Ziele sowie Motive und eine weitere Auswertung des Datenmaterials aus medienethischer Perspektive wurden sechs dominante Werte herausgearbeitet, die den in den Fallstudien untersuchten konsumkritischen Medienpraktiken inhärent sind und die bereits in Abschn. 3.2.3 theoretisch erläutert wurden: Verantwortung und Gerechtigkeit, Gemeinwohl und Selbstbestimmung, Transparenz und Würde.

Oben wurde bereits verdeutlicht, dass sich der Begriff Verantwortung auf die Frage bezieht, „ob die Folgen unseres Handelns als ethisch akzeptabel gelten können“. (Debatin 2016, S. 68) Genau diese Frage stellen sich die Akteur*innen in den Fallstudien in Hinblick auf ihre Medienpraktiken, indem sie die ethischen Auswirkungen ihrer und anderer Medienpraktiken reflektieren: Wie im vorherigen Kapitel herausgearbeitet, kritisieren sie die konventionellen Produktions- und Entsorgungsprozesse digitaler Medientechnologien in Hinblick auf die unwürdigen Bedingungen, in denen Menschen die für die Apparate benötigten Ressourcen gewinnen, die Endgeräte herstellen bzw. sie (unsachgemäß) entsorgen, sowie auch die schädlichen Auswirkungen der Produktion- und Entsorgung auf die Umwelt. Auch gängige Aneignungsprozesse, in denen digitale Medientechnologien aufgrund technologischer Innovationen regelmäßig ersetzt oder bei einem Defekt ohne Reparaturversuche entsorgt werden, kritisieren sie. Die Akteur*innen aller drei Fallstudien informieren nicht nur über die sozial-ökologischen Folgen der Produktion, Aneignung und Nutzung digitaler Medientechnologien, sondern 
werben darüber hinaus für von ihnen als nachhaltig bewertete Medientechnologien und -praktiken (Utopia.de) bzw. wollen mit dem Reparieren von (digitalen) Medientechnologien eine nachhaltige Medienpraktik durchführen und über Repair Cafés verbreiten sowie mit dem Fairphone ein reparierbares und fair produziertes und dadurch nachhaltiges Smartphone produzieren bzw. kaufen.

Aufgrund des Wissens um die sozial-ökologischen Folgen der komplexen Produktions-, Aneignungs- und Entsorgungsprozesse digitaler Medientechnologien übernehmen die Akteur*innen Verantwortung für ihre Medienpraktiken, indem sie versuchen die negativen Auswirkungen ihrer Medienpraktiken zu minimieren. Um dies zu erreichen, nutzen sie Onlinemedien als Informationsquelle über nachhaltigen Konsum, verlängern die Nutzungsdauer ihrer Endgeräte durch das Reparieren bzw. die Produktion/den Kauf eines reparierbaren Smartphones, um Konsum und damit auch die Produktion und Entsorgung von Medientechnologien zu vermeiden. Das Fairphone-Unternehmen will die Produktion des Smartphones nachhaltiger gestalten, indem die Herstellungsprozesse menschenwürdiger vollzogen werden sollen. Das Unternehmen bewertet das eigene Produkt explizit als ethisch: „The world's first ethical, modular smartphone“ (Fairphone 2019a; Hervorhebung, S. K.) und betont die eigene Verantwortung, der sie mit ihrem Ansatz nachkommen wollen: „We're addressing the full lifespan of mobile phones, including use, reuse and safe recycling. We believe that our responsibility doesn't end with sales.“ (Fairphone 2016d; Hervorhebung, S. K.)

Der (medien-)ethische Terminus der Verantwortung wurde als ein relationaler Begriff eingeführt und aus medienethischer Perspektive die Frage aufgeworfen (s. Abschn. 3.2.3): Was machen Menschen (Verantwortungssubjekte) mit Medien (Verantwortungsgegenstand), sodass die Folgen des Handelns akzeptabel gegenüber anderen (Verantwortungsinstanz) sind? Diese Frage kann auf die untersuchten Fallstudien wie folgt beantwortet werden: Individuen (Verantwortungssubjekte) reparieren ihre digitalen Medientechnologien bzw. erwerben reparierbare Medientechnologien, damit ihre Aneignung von Medien (Verantwortungsgegenstand) akzeptabler gegenüber der in den Produktions- und Entsorgungsprozessen involvierten Umwelt (verstanden als Natur und Lebewesen) ist. Eine ethisch akzeptable Medienproduktion verfolgt auch das Fairphone-Unternehmen (Verantwortungssubjekt) mit der Produktion des Fairphones (Verantwortungsgegenstand) gegenüber der Umwelt (Verantwortungsinstanz), die in die Herstellungsprozesse des Smartphones involviert sind. Schließlich ist es die Utopia GmbH (Verantwortungssubjekt), welche eine Onlineplattform nutzt (Verantwortungsgegenstand), um für nachhaltigen Konsum zu werben, und sich bemüht, darüber die Folgen des Konsums für die Umwelt (Verantwortungsinstanz) akzeptabel zu gestalten. Unterscheiden sich die Verantwortungssubjekte in den Fallstudien (Individuen, 
Nichtregierungsorganisationen, Unternehmen), so sind die Verantwortungsgegenstände ähnlich, nämlich Medien(-technologien) (verschiedenster Art in den Repair Cafés, ein Smartphone beim Beispiel des Fairphones und Internetmedien bei Utopia.de). Die Veranstaltungssubjekte sind gleich, nämlich die Umwelt (Natur und Lebewesen), welche durch Konsum im Allgemeinen und den digitaler Medientechnologien negativ betroffen ist. Es sind also v. a. Menschen, Tiere und Natur in ökonomisch weniger entwickelten Ländern und Schwellenländern, in denen die für digitale Medientechnologien benötigten Ressourcen abgebaut, die Geräte produziert und entsorgt werden, vor denen sich die in den Fallstudien untersuchten Akteur*innen in Industrienationen (das Fairphone-Unternehmen in den Niederlande, Fairphone-Nutzende in Deutschland sowie auch Beteiligte an Repair Cafés und die Utopia GmbH in Deutschland) verantworten, indem sie die Folgen ihres Konsums im Allgemeinen und der digitaler Medientechnologien im Besonderen transparent machen und versuchen, die negativen Folgen zu ändern.

Die hauptsächlichen Verursacher*innen der negativen sozial-ökologischen Auswirkungen der Produktion, Aneignung und Entsorgung digitaler Medientechnologien sind überwiegend Akteur*innen in den Industriestaaten, während die Menschen in ökonomisch weniger entwickelten Ländern meist diejenigen sind, die unter den Folgen leiden, zum einen, weil sie in die Produktions- und Entsorgungsprozesse direkt involviert sind, zum anderen, weil die Folgen des Klimawandels, der auch durch den Konsum und die Aneignung von Medientechnologien verursacht wird (z. B. durch den Verbrauch fossiler Energien für das Betreiben digitaler Medientechnologien bzw. für Onlinekommunikation benötigte Server) und überwiegend in ökonomisch weniger entwickelten Ländern spürbar ist.

Aus den Motiven und Zielen der Akteur*innen konnte herausgearbeitet werden, dass sich die Akteur*innen bewusst sind, dass Menschen in anderen Ländern unter den sozial-ökologischen Folgen derzeitiger Produktion und Entsorgung digitaler Medientechnologien leiden und diese die Lebensgrundlage der Menschen in ökonomisch weniger entwickelten und Schwellenländern zerstören oder bedrohen.

Mit ihren Medienpraktiken versuchen die Akteur*innen, ihre Verantwortung für die Umwelt in diesen Ländern wahrzunehmen, also ihr Medienhandeln ethisch akzeptabel gegenüber der Umwelt in diesen Ländern zu gestalten. So versuchen die Reparierenden in Repair Cafés, den Konsum im Sinne eines Verzichts und Verbrauchs bestehender Medientechnologien zu verhindern und wollen die Akteur*innen der Fairphone- und der Utopia-Studie nicht auf Konsum (digitaler Medientechnologien) verzichten, aber diesen anders gestalten und damit 
auch die sozial-ökologischen Folgen des Konsums. Die untersuchten konsumkritischen Medienpraktiken sind also verantwortungsvolle Medienpraktiken, da Akteur*innen mit diesen verantwortungsvoll, also ethisch akzeptabel handeln wollen.

Dass diesen Medienpraktiken Grenzen und Paradoxien inhärent sind, wurde im vorherigen Kapitel dargelegt. So ist die Verantwortung, der die Akteur*innen in den drei Fallstudien nachkommen wollen, schließlich auch durch Grenzen und Paradoxien durchzogen, da die untersuchten Medienpraktiken nicht ohne negative sozial-ökologische Folgen vollzogen werden können: So regt einerseits die Werbung für nachhaltigen Konsum auf der Onlineplattform Utopia.de sowie die Produktion des Fairphones zum Konsum an, für den immer weitere Ressourcen benötigt werden, die mitnichten alle fair abgebaut werden, wie das Beispiel des Fairphones exemplarisch zeigt. Auch kommen die Akteur*innen der Fallstudien der Verantwortung eher partiell nach - so reparieren sie z. B. ihre Medientechnologien, um nachhaltig zu handeln, fliegen aber regelmäßig. Ändern sich also die Verantwortungsgegenstände, ändern sich dementsprechend durchaus auch die Praktiken der Verantwortungssubjekte. Aber auch in Hinblick auf das Verantwortungssubjekt der Medientechnologien wandeln sich die Praktiken, wenn Menschen z. B. ihre Medientechnologien mit dem Ziel der Nachhaltigkeit reparieren, aber komplexe Medienrepertoires besitzen und diese regelmäßig ersetzen (s. vorheriges Kapitel).

Für den bis hierher herausgearbeiteten relationalen Begriff der Verantwortung ist der in Abschn. 3.2.3 erläuterte (medien-)ethische Terminus der Gerechtigkeit zentral. Denn es ist ein Ungerechtigkeitsempfinden, dass die in den Fallstudien agierenden Akteur*innen zu den verantwortungsvollen Medienpraktiken veranlasst. Es geht ihnen also in ihrem Handeln auch darum, mit den konsumkritischen Medienpraktiken die Umwelt, welche von den negativen sozial-ökologischen Folgen der Produktion, Anregung und Entsorgung digitaler Medientechnologien betroffen sind, zu ihrem Recht auf ein ,gutes Leben“ kommen zu lassen, indem sie diese negativen Folgen aktiv begrenzen.

Dabei zeigen die in den Fallstudien untersuchten Medienpraktiken, dass der Begriff der Gerechtigkeit aus einer medienethischen Perspektive noch breiter gedacht werden muss, als es Krainer (2018, S. 320 ff.) bereits vornimmt, die a) die Freiheit in der Informationsbeschaffung und der Meinungsäußerung, b) den Zugang zu Medien sowie einen gerechten Besitz medialer Produktionsmittel und c) gleichberechtigtes Vorkommen unterschiedlicher Personen oder Meinungen innerhalb der vorhandenen Medien als verschiedene medienethische Betrachtungsmöglichkeiten des Gerechtigkeitsbegriffs aufzählt. Wie die Fallstudien zeigen, ist Gerechtigkeit in einer medienethischen Perspektive nicht nur in 
Hinblick auf die Medieninhalte, deren Produktion und Rezeptionsmöglichkeiten zu denken, sondern auch im Zusammenhang mit den sozial-ökologischen Auswirkungen der Produktion, Aneignung und Entsorgung digitaler Medientechnologien. Die Akteur*innen der hier untersuchten Fallstudien weisen mit den konsumkritischen Medienpraktiken auf Ungerechtigkeit in diesen Prozessen hin, darauf, dass Mensch und Natur Unrecht in diesen Prozessen erfahren, da die Menschen unter unwürdigen, gesundheitsschädlichen und gar lebensbedrohlichen Bedingungen arbeiten und die Natur ausgebeutet und zerstört wird. In ihrem Unrechtsempfinden versuchen die Akteur*innen der Fallstudien, Medien zu nutzen, um über dieses Unrecht zu informieren und diesem entgegenzuwirken, entweder, in der Vermeidung der Unterstützung dieser Ungerechtigkeit durch das Reparieren ihrer Medientechnologien (Repair Cafés), in der Information über diese Ungerechtigkeit und im Aufzeigen von Alternativen (Utopia.de) oder der Gestaltung gerechter Produktionsprozesse digitaler Medientechnologien (Fairphone).

Eng im Zusammenhang mit Fragen der Gerechtigkeit in Produktions- und Entsorgungsprozessen digitaler Medientechnologien stehen auch Fragen nach der Würde der in diesen Prozessen involvierten Menschen. Wie oben angeführt wurde, wird Würde im medienethischen Diskurs v. a. in Hinblick auf die Menschenwürde in Medieninhalten diskutiert. Die hier diskutierten Fallstudien zeigen aber, dass sowohl die Würde des Menschen als auch anderer Lebewesen in Produktions- und Entsorgungsprozessen digitaler Medientechnologien relevant ist und in solchen verletzt wird. Die Akteur*innen der drei Fallstudien kritisieren die Verletzung der Menschenwürde in diesen Prozessen und versuchen, mit den konsumkritischen Medienpraktiken die Würde des Menschen zu schützen, indem sie durch das Reparieren digitaler Medientechnologien unwürdige Produktions- und Entsorgungsprozesse vermeiden oder diese durch eine andere Gestaltung derselben fairer und damit auch menschenwürdiger produzieren wollen. Auch die Information und das Werben für nachhaltige Konsumgüter auf der Onlineplattform Utopia.de dient letztendlich dazu, Menschenwürde zu schützen. Wie in Abschn. 3.2.3 argumentiert wurde, bezieht sich in der neuzeitlichen Philosophie und in aktuellen politischen Normen wie den Menschenrechten Würde vor allem auf die Autonomie und Selbstbestimmung des Einzelnen (s. Borhmann 2018, S. 55). Selbstbestimmung ist in den hier untersuchten Fallbeispielen auf zweierlei Weise ein relevanter (medien-)ethischer Begriff: Verknüpft mit dem Schutz der Menschenwürde in Produktions- und Entsorgungsprozessen, geht es den Akteur*innen der Fallstudien zum einen darum, den in diesen Prozessen involvierten Menschen, Möglichkeiten der Selbstbestimmung zu garantieren. Dafür kooperiert das Fairphone-Unternehmen z. B. mit Partnerorganisationen in 
ökonomisch weniger entwickelten und Schwellenländern, nicht nur, um Nichtregierungsorganisationen und Unternehmen vor Ort selbstbestimmtes Handeln in Produktionsprozessen digitaler Medientechnologien zu ermöglichen, sondern auch, die einzelnen Arbeitnehmer*innen in ihrer Selbstorganisation zu unterstützen: „[We] strengthen employee representation structures to increase workers' voice in decision-making processes and ownership of lasting improvements in factory conditions" (Fairphone 2016f).

Des Weiteren geht es bei den Fallbeispielen um die Selbstbestimmung der Konsument*innen im Allgemeinen und Nutzer*innen digitaler Medientechnologien im Besonderen. So beschreibt eine Mitarbeiterin der Stiftung Anstiftung \& Ertomis, die die Organisation von Reparaturveranstaltungen in Deutschland unterstützt, den Reparaturprozess als einen der Aneignung der Alltagsgegenstände:

„Zum einen natürlich ist es [das Reparieren, S. K.] eine Aneignung, also man schaut sich [...] das Gerät [an, S. K.], das man da benutzt, man wird selber tätig. Also [die, S. K.] Idee der Reparaturinitiative ist ja, es nicht reparieren zu lassen, sondern sich das Gerät selber zu nehmen, es mit einem Helfer zusammen aufzumachen, den Fehler zu [..., finden S. K.] und es wieder zum Laufen zu bringen.“

Wird in der Kommunikations- und Medienwissenschaft der Begriff der Medienaneignung als die Integration von Medien in den Alltag durch Nutzer*innen sowie die Sinnzuschreibung an diese (s. Abschn. 3.2.1) definiert, so ist das Reparieren ein Aneignungsprozess. Dabei geht es jedoch nicht um die Aneignung von Medieninhalten oder Sinnzuschreibung an sie, wie dies traditionell in der Kommunikations- und Medienwissenschaft verstanden wird, sondern um einen Prozess der Aneignung der (digitalen) Medientechnologien selbst. Den an Repair Cafés Beteiligten ist es wichtig, dass sich Nutzer*innen digitaler Medientechnologien diese aneignen, sie verstehen, Defekte erkennen und diese reparieren können. In dieser Aneignung liegt ein Moment der Selbstbestimmung, da die Nutzer*innen selbst erkennen und entscheiden können, ob sie das defekte Gerät reparieren können und wollen und den Reparaturprozess im besten Fall auch selbstbestimmt durchführen können. Dass diesem Moment der Selbstbestimmung ein Problem inhärent ist, wurde bereits in den Abschn. 4.1 und 4.2 erläutert, denn zwar ist das selbstständige und dadurch selbstbestimmte Reparieren eines der Ziele der Organisator*innen und Helfer*innen der Repair Cafés, doch wird aufgrund der Komplexität gerade digitaler Medientechnologien oftmals für die Hilfesuchenden repariert.

Der Wert der Selbstbestimmung findet sich auch in der Fallstudie zum Fairphone wieder. So hat das Fairphone-Unternehmen ein modulares Smartphone entwickelt, das die Möglichkeit der Reparierbarkeit offeriert, damit die 
Nutzer*innen sich selbstbestimmt mit dem von ihnen genutzten Apparat auseinandersetzen können. Diese Selbstbestimmtheit ist den Fairphone-Nutzer*innen wichtig. So äußert sich der 33-jährige Mitarbeiter einer Umweltorganisation begeistert: „Fairphone ist insofern super, weil du kannst das jederzeit aufmachen." Dass die Möglichkeit der Reparierbarkeit jedoch eingeschränkt ist, wurde in den Abschn. 4.1 und 4.2 erläutert.

Schließlich ist es auch ein Anliegen der Utopia GmbH, Verbraucher*innen über Möglichkeiten des vom Unternehmen als nachhaltig eingestufte Konsumgüter auf der Onlineplattform zu informieren, damit die Nutzer*innen aufgeklärte und bewusste (Kauf-)Entscheidungen treffen können. Ist dies eine informationelle Selbstbestimmung im Sinne eines Zugangs zu Informationen, wie sie v. a. in der Kommunikations- und Medienwissenschaft gedacht wird (s. z. B. Heesen 2017), so ist die Selbstbestimmung in den Fallbeispielen der Repair Cafés und des Fairphones eine, die sich auf die Medientechnologien bezieht und nicht die Medieninhalte.

Die Voraussetzung für solche informierten Konsumentscheidungen und eine selbstbestimmte Aneignung digitaler Medientechnologien ist Transparenz. Die Schaffung von Transparenz ist ein implizites oder explizites Ziel in den Fallstudien und gleichzeitig ein weiterer (medienethischer) Wert in diesen. So informiert das Fairphone-Unternehmen auf seiner Onlineplattform über die verwendeten Ressourcen und deren Abbauprozesse sowie die Herstellungsprozesse der Smartphones. Transparenz ist dabei ein Kernziel des Unternehmens, so argumentiert der Gründer des Unternehmens Bas van Abel (2015): „At Fairphone, transparency is one of our core principles for creating fairer electronics." Die Transparenz bezieht sich dabei v. a. auf die globale Wertschöpfungskette, die das Unternehmen transparent machen möchte: „We want you to understand where your products come from, so we are tracing our materials to their source and making improvements in the supply chain among their way" (Fairphone 2016b). Insofern informiert das Unternehmen auf der Onlineplattform nicht nur über den Herstellungsprozess der Smartphones, sondern auch über die Art und Weise der Ressourcengewinnung, wobei v. a. über die Prozesse berichtet wird, die bereits unter faireren Bedingungen stattfinden. Aber auch die Produktionskosten und die Gewinne aus dem Verkauf der Produkte macht das Unternehmen auf seiner Onlineplattform transparent (van Abel 2015) und unterstreicht damit den Anspruch des Unternehmens, ein „social entrepreneur“ zu sein. Die Kommentare unter dem entsprechenden Artikel auf der Onlineplattform zeigen, dass die Nutzer*innen diese Transparenz schätzen und loben.

Transparenz ist auch in der Fallstudie zu Utopia.de ein relevanter Wert: Die Utopia $\mathrm{GmbH}$ informiert über von ihnen als nachhaltig bewertete Konsumgüter 
und deren Produktionsprozesse, um Transparenz über die Materialität der Güter und ihrer Produktionsprozesse zu schaffen (s. detaillierter Abschn. 4.2).

Zusammenfassend lässt sich für den Wert der Transparenz in den Fallstudien hervorheben, dass hier Beispiele der „Fremd-Transparenz“ und „SelbstTransparenz" (Meier 2017, S. 225) vorliegen: Das Fairphone ist ein Beispiel für Selbst-Transparenz, da es Informationen über das eigene Produkt und dessen Herstellungsprozesse veröffentlicht sowie über das Unternehmen selbst; die Onlineplattform Utopia GmbH ist ein Beispiel für „Fremd-Transparenz“, da hier überwiegend Informationen über andere Unternehmen und deren Produkte publiziert werden. Dabei ist jedoch zu bedenken, dass viele der auf der Onlineplattform veröffentlichten Inhalte durch Kooperationen mit Unternehmen produziert werden, da diese die Produktionsprozesse der Medieninhalte auf unterschiedlichste Art und Weise finanzieren. Die Fremd-Transparenz wird damit z. T. zur Selbst-Transparenz. Im Falle der Selbst-Transparenz sind die Eigeninteressen der Unternehmen in der Herstellung von Transparenz zu hinterfragen.

Schließlich ist es der (medien-)ethische Begriff des Gemeinwohls, der in den konsumkritischen Medienpraktiken, die in den drei Fallstudie untersucht wurden, relevant ist. Betont der Begriff des Gemeinwohls, „dass neben individuellen (privaten) Interessen auch überindividuelle (gemeinsame, öffentliche) Interessen Maßstäbe des Handelns sein können und sollen“ (Filipović 2017, S. 10), so zeigt die Analyse der Fallstudien, dass neben individuellen Interessen eben auch über das Individuum hinausgehende Interessen Maßstäbe der konsumkritischen Medienpraktiken sind. Denn die Akteur*innen in den verschiedenen Fallstudien haben neben den Eigeninteressen wie der Wissensaneignung und Selbstbestimmung auch Interessen anderer im Blick, die sie durch ihre Medienpraktiken verfolgen, wie z. B. den Schutz der Würde der Menschen, die in den Produktionsund Entsorgungsprozessen digitaler Medientechnologien und weiterer Konsumgüter involviert sind. Schließlich zielen konsumkritische Medienpraktiken auf eine nachhaltige Gesellschaft und damit die Interessen zukünftiger Generationen, ist doch das zentrale Ziel konsumkritischer Medienpraktiken, die Umwelt, also die Lebewesen und Lebensgrundlagen heutiger Generationen zu schützen, sodass die Bedürfnisse zukünftiger Generationen und damit deren Gemeinwohl, nicht eingeschränkt werden (s. Definition des Nachhaltigkeitsbegriffs in Kap. 2). Dabei wird erneut deutlich, dass auch in der medienethischen Diskussion um den Begriff des Gemeinwohls nicht nur die Medieninhalte im Fokus stehen (s. Abschn. 3.2.3), sondern auch die Medientechnologien und die Produktions- und Entsorgungsprozesse, die sich in diesen materialisieren. Denn wie digitale Medientechnologien produziert und entsorgt werden und wie Menschen mit ihren Endgeräten umgehen und damit die Nutzungsdauer dieser bestimmen, ist eine medienethische Frage im 
Spannungsfeld der eigenen Interessen und solcher anderer. Die Forderung von Filipović, dass „Akteure die moralische Pflicht (Verantwortung) [haben, S. K.], in ihrem Medienhandeln nicht nur ihre eigenen Interessen zu berücksichtigen, sondern auch immer die der Allgemeinheit" (Filipović 2017, S. 17), kann (so zeigen die Fallbeispiele) und muss eben nicht nur auf Medieninhalte bezogen gedacht werden, sondern auch auf Medientechnologien.

In digitalen Medientechnologien, dies zeigen die Fallstudien, materialisieren sich auch die Werte einer Gesellschaft. Sind es überwiegend saubere, glatte, glänzende digitale Medientechnologien, die in der Konsumgesellschaft genutzt und aufgrund technologischer Innovationen regelmäßig ersetzt werden, so zeigt die Fallstudie des Reparierens digitaler Medientechnologien in Repair Cafés, dass auch ältere, länger genutzte Apparate mit Gebrauchsspuren für die Nutzer*innen einen Wert haben.

Einer der Organisator*innen des Oldenburger Repair Cafés betont die Relevanz einer solchen Materialität des Gebrauchten für die Reparierenden:

\begin{abstract}
„Also die Repair-Bewegung [...] hat teilweise solche Formen von Identitätsbildung auf Basis einer ganz bestimmten Produktästhetik schon hervorgebracht. [...] Das sind die ganz Harten [...], so junge Leute, die so einen uralten Nokia haben. Also wo wirklich mit Isolierband und so weiter das Gehäuse fixiert ist, weil es sonst auseinanderfällt und wo der [sic] kleine Display so verschrammt ist, dass die schon gucken müssen. Aber da stehen die drauf, das finden die gut und sie wollen damit eine politische Aussage treffen, das ist absolut unverkennbar."
\end{abstract}

Auf den im Zitat erwähnten Bewegungsaspekt werde ich in Abschn. 4.6 detaillierter eingehen. Hier sei die im Zitat erwähnte Produktästhetik hervorgehoben, in der sich die Werte der Reparierenden materialisieren, die sich vom Neuen, Schönen und Innovativen abwenden und sich, wie Jackson (2014) in seinem „broken world thinking" (s. auch Abschn. 3.1.1) betont, der Abnutzung und dem Verfall zuwenden und diese betonen.

Auch das Fairphone zeigt, dass Medientechnologien ,cultural properties“ sind, wie Jansson (2014, S. 284) für Medieninhalte konstatiert, und als solche entweder abgelehnt oder angenommen werden. In den gesellschaftlich angenommenen oder abgelehnten Medieninhalten und -technologien spiegeln sich die Werte einer Gesellschaft wieder. Dabei zeigen die Fallstudien, dass durchaus unterschiedliche Medientechnologien ähnliche Werte verkörpern können: So sind es die alten, gebrauchten Medientechnologien, deren Reparatur einen Beitrag zu einer nachhaltigen Gesellschaft leisten soll, und es ist das neu produzierte Fairphone, das aufgrund nachhaltiger Produktionsprozesse und seiner modularen Bauweise einen 
solchen Beitrag leisten kann. Weiterhin zeigt sich an der Onlineplattform Utopia.de und ihrer Popularität, dass Nachhaltigkeit und die mit dieser verbundenen Werte, ein zentrales Thema auch in aktuellen Medieninhalten sind.

Dass die alte Praktik des Reparierens zunehmend an Popularität gewinnt, zeigt die steigende Anzahl der Repair Cafés - auch in Deutschland. In dieser deutet sich ein Wertewandel in der Gesellschaft an, der sich - zumindest in einer Nische - von der Konsum- und Wegwerfgesellschaft hin zu einer nachhaltigeren Gesellschaft entwickelt. Ein solcher zeigt sich auch in der Etablierung und der Popularität der Onlineplattform Utopia.de, die für nachhaltigen Konsum wirbt. Schließlich materialisiert sich ein solcher Wertewandel auch im modularen Fairphone. Mit der Perspektive der Science and Technology Studies kann das Fairphone als eine sozial-technologische Imagination (Jasanoff 2015, S. 28) beschrieben werden, die Verkörperung einer wünschenswerten Zukunft, in der langlebige Konsumgüter nachhaltig produziert werden. Als eine sozialtechnologische Imagination zeigt sich im Fairphone das Zusammenspiel von Wissenschaft, Technologie und Gesellschaft.

Es ist aber nicht nur das Fairphone als digitale Medientechnologie, in der sich im Sinne der Science and Technology Studies (z. B. Jasanoff 2015) eine gesellschaftliche Utopie materialisiert. Die weiteren Fallstudien zeigen, dass auch auf der Medieninhalts- und Medienaneignungsebene gesellschaftliche Utopien verhandelt werden. So setzen sich die Medieninhalte auf der Onlineplattform Utopia.de letztendlich in der Beschäftigung mit nachhaltigen Produkten und Praktiken mit den Möglichkeiten der Realisierung einer nachhaltigen Gesellschaft auseinander, und so versuchen auch die an den Repair Cafés Beteiligten, die Utopie einer nachhaltigen Gesellschaft zu leben. Dabei sind diese Utopien durch Grenzerfahrungen der Akteur*innen und Paradoxien in den Praktiken und Zielen gekennzeichnet, wie im vorherigen Kapitel herausgearbeitet wurde. Durch diese Grenzen und Paradoxien sind die Akteure schließlich mit der Unmöglichkeit der Realisierung ihrer Utopie konfrontiert.

Und dennoch stellen sich die Akteur*innen der Fallstudien die zentrale ethische Frage nach dem ,guten Leben“ in Hinblick auf ihr Handeln in Bezug zu Medien. Entsprechend des handlungstheoretischen Paradigmas in der Kommunikations- und Medienwissenschaft fragt Couldry (2012, S. 189): „How should we act in relation to media, so that we contribute to lives that, both individually and together, we would value on all scales, up to and including the global?" Es ist eine solche normative Frage, die sich auch die Akteur*innen in den Fallstudien stellen und die sie mit ihren Medienpraktiken beantworten wollen.

In den konsumkritischen Medienpraktiken: in der Medienaneignung des Reparierens, der Produktion und Aneignung fair produzierter Medientechnologien und 
auch in den Medieninhalten, die für nachhaltigen Konsum werben, wird die Frage nach dem ,guten Leben“ gestellt, gesellschaftliche Missstände kritisiert und Alternativen aufgezeigt und praktiziert. Dabei erfahren die Akteur*innen durch die konsumkritischen Medienpraktiken Resonanz, da die Akteur*innen mit den konsumkritischen Medienpraktiken eine Beziehung zur sie umgebenden Welt aufbauen und sich in den konsumkritischen Medienpraktiken ,das Subjekt und Welt berühren und zugleich transformieren“ (Rosa 2016, S. 285 und 298) und die Akteur*innen in den Repair Cafés, mit dem Fairphone und auf der Onlineplattform Utopia.de ein Angebot entsprechend ihrer Werte finden. Mehr noch, die Akteur*innen handeln nicht alleine, sondern in Gemeinschaften, denen sie sich zugehörig. Dieses Ergebnis der vergleichenden Studie wird im folgenden Teilkapitel erläutert.

\subsection{Medienvermittelte und kommunikative Vergemeinschaftungen für eine nachhaltige Gesellschaft und das „gutes Leben“}

Wie zuletzt angedeutet, handeln die Akteur*innen in den Fallstudien nicht alleine, um mit den konsumkritischen Medienpraktiken zu einer nachhaltigen Gesellschaft und einem ,guten Leben“ beizutragen, sondern zusammen mit anderen in Vergemeinschaftungen. In diesem Teilkapitel wird dieses Ergebnis der durchgeführten vergleichenden Studie genauer erläutert. In Rückbezug zu den bis hierher vorgestellten Ergebnissen und den in Abschn. 3.2.4 beschriebenen Erkenntnissen der Vergemeinschaftungsforschung wird herausgearbeitet, wer (und wer nicht) die Akteur*innen sind, die die Vergemeinschaftungen in den hier diskutierten Fallstudien bilden, wie sich diese Vergemeinschaftungen konstituieren und welchen Sinn sowie welche gesellschaftliche Relevanz sie diesen Vergemeinschaftungen zuschreiben. ${ }^{13}$

Zunächst sei hier die Weber'sche Definition von Vergemeinschaftung in Erinnerung gerufen, in der soziale Beziehungen als Vergemeinschaftungen definiert werden, wenn diese, auf subjektiv gefühlter (affektueller oder traditionaler) Zusammengehörigkeit der Beteiligten beruht" (Weber 1972, S. 21, s. Abschn. 3.2.4). In der theoriegeleiteten vergleichenden Analyse der drei Fallstudien konnten die von Hitzler, Honer und Pfadenhauer benannten fünf

${ }^{13}$ Zur Vergemeinschaftung in Repair Cafés siehe auch Kannengießer (2018c, S. 221 ff., e, S. $112 \mathrm{f}$.), zur Vergemeinschaftung in der Faiphone- und Utopia.de-Studie in aller Kürze auch Kannengießer (2020a, S. 181 und 184). 
Merkmale von Vergemeinschaftungen herausgearbeitet werden: 1) die Abgrenzung gegenüber einem „Nicht-Wir“, 2) ein Zusammengehörigkeitsgefühl, 3) ein gemeinsames Anliegen, 4) eine Wertschätzung gegenüber den anderen Mitgliedern und 4) den Mitgliedern zugängliche Interaktions(-zeit-)räume (Hitzler et al. 2008, S. 10). Nicht alle Merkmale treffen auf die sich in den drei verschiedenen Fallstudien konstituierenden Vergemeinschaftungen in gleicher Intensität zu, vielmehr zeigen sich mit den drei Fallbeispielen unterschiedliche Arten von Vergemeinschaftungen, deren Gemeinsamkeit daran liegt, dass ihre Mitglieder mit konsumkritischen Medienpraktiken zu einer nachhaltigen Gesellschaft und einem „guten Leben“ beitragen wollen.

In der Fallstudie zum Reparieren digitaler Medientechnologien in Repair Cafés konstituieren sich Vergemeinschaftungen auf verschiedenen Ebenen. So bilden sich zunächst kommunikative Vergemeinschaftungen während der jeweiligen Reparaturveranstaltungen, denn nicht nur verhandeln ihre Mitglieder Themen kommunikativ (Knoblauch 2008, S. 74), sondern ist auch die im Zentrum der Reparaturveranstaltung stehende Praktik des Reparierens eine kommunikative, über die die an den Repair Cafés Beteiligten in den Austausch kommen (s. Abschn. 4.1).

Wie bereits in Abschn. 4.1 herausgearbeitet wurde, impliziert der Name der Veranstaltungen die Relevanz der Kommunikation für diese: Es ist ein Repair Café und damit Kommunikation für die Veranstaltungen zentral. Ein Helfer im Oldenburger Repair Café bezeichnet dieses als einen Ort der Begegnung, und auch ein 27-jähriger Fahrradkurier, der seinen Laptop im Oldenburger Repair Café repariert, meint, das Repair Café bringe Menschen zusammen.

Das Oldenburger Repair Café hat während der Kooperationsphase mit dem Oldenburgischen Staatstheater (s. hierzu Abschn. 4.1) einen Programmpunkt in die Reparaturveranstaltungen eingebaut, der explizit Kommunikation zwischen Teilnehmenden forcieren will: die Vermittlungsshow, bei der zwei Personen einen Theaterbesuch gewinnen können. Das Konzept erläutert eine der Organisator*innen:

„Es geht halt nicht darum, dass sozusagen Singles miteinander vermittelt werden, sondern es geht um die Idee, dass man halt auch Kultur gemeinsam erleben kann und sozusagen nicht einsam zuhause vor dem Fernseher sitzen sollte, sondern dass [...] die Sozialkontakte [...] repariert [werden].“

Der Reparaturbegriff wird hier breit ausgelegt, da nicht nur die Reparatur von Gegenständen, sondern metaphorisch auch die zwischenmenschlichen Beziehungen repariert werden. Hier wird das Anliegen der an der Organisation der Repair Cafés Beteiligten offenbar, mit den Veranstaltungen gesellschaftlichen 
Individualisierungsprozessen entgegen zu wirken und kommunikativen Austausch zwischen Menschen zu ermöglichen, der eben auch zu Vergemeinschaftungen führen kann.

Im Interviewmaterial wurde wiederholt deutlich, dass Repair Cafés eine soziale Bedeutung für die Beteiligten haben. Für die sich in Rente befindenden Helfer*innen sind die Reparaturveranstaltungen eine Möglichkeit, das Haus zu verlassen und eine Aufgabe zu finden: „Was soll ich zu Hause, zu Hause kann ich sitzen, wenn es gesundheitlich nicht mehr geht,“ erklärt ein helfender Rentner. Ein 82-jähriger Helfer meint, er langweile sich zu Hause als Rentner. Ähnliches formulieren auch Helfer*innen, die erwerbslos sind. Ein Mitarbeiter der Anstiftung \& Ertomis beschreibt die Rolle der Reparaturveranstaltungen für Rentner*innen und Erwerbslose wie folgt:

„Es geht vor allen Dingen [in den Repair Cafés] um soziale Kohäsion, weil einfach Menschen, die in unserer Gesellschaft wenig Platz haben, beispielsweise Rentner, Menschen die aus dem Berufsleben ausgeschieden sind, finden dort mit ihren Fähigkeiten, ihren Kompetenzen einen ganz neuen Wirkungskreis, können ihr Wissen anbieten und erhalten dafür auch Anerkennung, da entstehen Freundschaften und Kontakte.“

Neben dem Zusammenkommen während der Reparaturveranstaltungen, stehen bei manchen Reparaturinitiativen die Organisator*innen und Helfer*innen auch zwischen den Veranstaltungen in Kontakt (s. Abschn. 4.1). Während die Kommunikation die Organisation der Veranstaltungen betreffend oftmals medial vermittelt stattfindet, werden auch weitere Vis-à-vis-Treffen, die zwischen den Reparaturveranstaltungen stattfinden, für den Zweck der Gemeinschaftsbildung organisiert. So erklärt die Organisatorin des Garbsener Repair Cafés, dass die Gruppe der Reparaturhelfer*innen eine Gemeinschaft gebildet habe, die über die Reparaturveranstaltungen hinauswirke: „Das ist eine ganz nette Gemeinschaft so geworden untereinander. Und Weihnachten machen wir was zusammen, nächsten Freitag grillen wir zusammen, alle." Diese Treffen werden, genauso wie die Reparaturveranstaltung, überwiegend von der 65-jährigen pensionierten Lehrerin organisiert.

Den durch die Repair Cafés entstehenden Gesellungsgebilden fühlen sich viele der Beteiligten zugehörig und sie unterstreichen dies als subjektives Erleben in den Interviews. So betont ein 72-jähriger Helfer das Zusammengehörigkeitsgefühl, das durch diese Veranstaltungen entstehe: „Wir kegeln um Weihnachten noch mal so als ganze Gruppe. Und das ist ja dieses Zusammengehörigkeitsgefühl, was auch immer so ganz wichtig ist.“ Er erklärt, dass sich sein 
Bekanntenkreis durch die Veranstaltungen „kräftig“ erweitert habe. Ein 68jähriger Helfer, der Unterstützung bei der Reparatur von Laptops und Computern anbietet, beschreibt sein Zugehörigkeitsgefühl zur Reparaturgemeinschaft:

„Leute, die bei sowas [dem Repair Café] mitmachen, haben eine andere gesellschaftliche und politische Einstellung. [...] Für mich ist es netter, etwas Kooperatives zu unternehmen als in der Wirtschaft, [...] weil das eine Zugehörigkeit ergibt. Ich gehöre nicht zu Saturn, ich kaufe dort, aber eigentlich ist mir Saturn scheiß egal.“

Während der Repair Cafés entstehen im Weber'schen Sinne (1922, S. 21) also Vergemeinschaftungen: Die Menschen teilen konsumkritische Ziele (s. Abschn. 3.2.4) und fühlen sich der Gemeinschaft zugehörig. Viele der an den Reparaturveranstaltungen Beteiligten beschreiben eine Gemeinschaft, die sich in den Repair Cafés bilde. So konstituieren sich während der Veranstaltungen lokale Gemeinschaften (Hepp und Hitzler 2014, S. 47). Es sind „Eventgemeinschaften“ (ebd., S. 46), die für die Dauer der Veranstaltungen in den jeweiligen Räumen hergestellt werden. Konstituieren sich diese Vergemeinschaftungen während der Reparaturveranstaltungen vis-à-vis, so bilden sich auch medienvermittelte translokale Vergemeinschaftungen (ebd., S. 47), zwischen den Mitgliedern einzelner lokaler Reparaturveranstaltungen durch die Vernetzung z. B. über E-MailingListen, aber auch koordiniert durch die Stiftung Anstiftung \& Ertomis über die Onlineplattform www.reparatur-initiativen.de, über das hier integrierte Onlineforum, in dem sich Reparaturinteressierte austauschen sowie über den regelmäßig durch die Mitarbeiter der Anstiftung \& Ertomis verschickten E-Mail-Newsletter. Die Onlineplattform beschreibt eine Mitarbeiterin der Anstiftung \& Ertomis als einen „Community-Ort“. Im auf der Onlineplattform integrierten Onlineforum geben v. a. die Mitarbeiter*innen der Anstiftung \& Ertomis Hinweise zur Organisation von Reparaturveranstaltungen, zu Haftungsfragen und zur Öffentlichkeitsarbeit. Die meisten Forenbeiträge, an denen sich viele Helfer*innen beteiligen, beschäftigen sich mit Fragen zu Reparaturmöglichkeiten verschiedener Konsumgüter (https://www.reparatur-initiativen.de/forum/).

Über die Onlineplattform abrufbar ist auch das von der Anstiftung \& Ertomis publiziertes Fanzine SPLiTTER, das seit 2019 erscheint und von Mitgliedern der Reparaturgemeinschaft mitgestaltet werden kann. Auf der Plattform wird das Magazin von der Anstiftung \& Ertomis beschrieben:

„Ihr seid viele, euch ähnlich und doch verschieden. Ihr seid alle wichtig und nicht allein mit eurem Engagement für Umweltschutz und Gemeinwohl. Das soll SPLiTTER dokumentieren. Es ist angelegt wie ein „Fanzine“, ein handgemachtes Magazin von Fans für Fans. Wir, eure Fans, haben uns überlegt, was euch Reparatur-Fans an 
Themen und Infos interessieren und inspirieren könnte.“ (Anstiftung und Ertomis 2019)

In diesem Zitat werden nicht nur Aspekte der Vergemeinschaftung deutlich, sondern auch der Charakter dieser: So wird zum einen ein gemeinsames Ziel des Umweltschutzes und Gemeinwohls betont sowie eine Ähnlichkeit und Gemeinschaft: ,ihr seid [...] euch ähnlich [...] und nicht allein“, aber auch die Heterogenität der Reparierenden: ,,ihr seid [...] doch verschieden“. Mit dem digitalen Magazin hat die Reparatur-Vergemeinschaftung eine Möglichkeit, sich (in ihrer Heterogenität) darzustellen, auszutauschen und letztendlich auch, sich über dieses online als Gemeinschaft zu konstruieren.

Neben der medienvermittelten Vernetzung organisieren die Mitarbeitenden der Anstiftung \& Ertomis jährlich stattfindende regionale Treffen für Organisierende und Helfende von Reparaturveranstaltungen in einem bestimmten geographischen Ort, aber auch ein jährliches bundesweites Vernetzungstreffen, zu dem alle Organisator*innen und Helfer*innen, die den E-Mailing-Newsletter abonniert haben, eingeladen werden. Eine Mitarbeiterin der Anstiftung \& Ertomis, die die (über-)regionalen Vernetzungstreffen der Repair Cafés organisiert, unterstreicht die Relevanz der Vis-à-vis-Begegnung:

„Das ist total wichtig, dass sich die Menschen treffen und das ist auch das, was an uns
zurückgespiegelt wird jedes Mal. Also, das ist doch für alle total schön sich zu treffen
und ich habe auch den Eindruck, wenn ich da in die Mittagsrunde und so weiter gucke,
da sitzen nicht die zwei, die zusammen angereist sind, sondern [...] sofort mischt sich
das, sofort ist ein Austausch über das Thema da.“

Meine Beobachtungen in solchen regionalen und bundesweiten Netzwerktreffen zeigen, dass in diesen durch organisierte Programmpunkte wie zum einen die Vermittlung von für die Organisation und Durchführung von Reparaturveranstaltungen relevantem Wissen stattfinde, dass zum anderen aber der informelle kommunikative Austausch bei den Veranstaltungen für die Beteiligten zentral ist. Es ist dieser Austausch, der ein Zugehörigkeitsgefühl zu einer translokalen Reparaturgemeinschaft schafft. An diesen Vergemeinschaftungen sind Organisator*innen und Helfer*innen der Repair Cafés beteiligt, meist jedoch nicht Hilfesuchende, die punktuell Teil der lokalen Reparaturgemeinschaften werden.

Die translokalen Netzwerktreffen, aber auch die lokal stattfindenden Repair Cafés sind die Interaktions(-zeit-)räume, welche eines der von Hitzler, Honer und Pfadenhauer (2008, S. 10) benannten Vergemeinschaftungsmerkmale bilden. Auch die weiteren für Vergemeinschaftungen genannten Merkmale eines gemeinsamen Anliegens (nämlich die in Abschn. 4.2 herausgearbeiteten Ziele der an Repair Cafés Beteiligten) sowie ein Zusammengehörigkeitsgefühl und schließlich 
auch eine Abgrenzung gegenüber einem „Nicht-Wir“ lassen sich hier finden. Das „Nicht-Wir“ ist die Konsum- und Wegwerfgesellschaft, gegen die sich die Reparierenden abgrenzen (s. Abschn. 4.5). Die Vergemeinschaftungen konstituieren sich dabei organisiert - entweder in lokalen Veranstaltungen oder aber translokal durch die Anstiftung \& Ertomis koordiniert.

Auch in der Fairphone-Studie lässt sich eine Vergemeinschaftung identifizieren, die sich medienvermittelt translokal vernetzt, wobei das FairphoneUnternehmen die Vernetzung maßgeblich steuert und fördert. So wird eine Fairphone-Gemeinschaft schon alleine dadurch hergestellt, dass das Unternehmen sie in seiner Onlinepräsenz konstruiert. So ist der Begriff der „Community“ auf der Onlineplattform des Unternehmens prominent platziert als ein eigener Reiter neben den Reitern Phone, unter dem man Informationen über das Smartphone bekommt und dieses bestellen kann, Story, unter dem die Geschichte und die Ideen des Unternehmens präsentiert werden sowie auch Hintergrundinformationen zum Herstellungsprozess, und Support, unter dem u. a. Reparaturanleitungen zu finden sind (Fairphone 2019j). „Welcome to the Fairphone Community“ (Fairphone 2019k) titelt das Fairphone Unternehmen auf der Website unter dem entsprechenden Reiter.

Mitglieder der Fairphone-Community werden hier als „Fairphoners“ (ebd.) bezeichnet. Die „Fairphoner“ bilden vis-à-vis und medienvermittelte Vergemeinschaftungen. Auf der Onlineplattform des Unternehmens werden lokale Treffen der „Fairphoner“ oder Interessierter bekannt gegeben (Fairphone 20191). In Düsseldorf und Aachen werden diese Veranstaltungen als "Stammtische“ bezeichnet (ebd.) und damit der informelle Vergemeinschaftungscharakter dieser Treffen hervorgehoben. Detaillierte Ankündigungen und Austausch von „Fairphonern“ oder Interessierten zu den jeweiligen lokalen Treffen finden im „Community Forum" der Onlineplattform des Fairphone-Unternehmens statt (Fairphone Community Forum 2019a). Unter den Kategorien „Discuss“, „Participate“, „Help“, „Market" tauschen sich Fairphone-Nutzer*innen und Interessent*innen über das faire Smartphone und dessen Reparaturmöglichkeiten aus oder suchen bzw. bieten gebrauchte Fairphones und Ersatzteile zum Kauf an (ebd.). In einem vom Fairphone-Unternehmen publizierten Leitfaden im Onlineforum wird erläutert, wie man Teil der „Fairphone-Community“ werden kann (Fairphone Community Forum 2019b). Neben dem Hinweis auf die Möglichkeiten der Onlinekommunikation über Online-Chat-Anbieter wie Riot oder Freenode, über die sich Fairphone-Nutzer*innen austauschen (s. https://riot.im/app/\#/room/\#wearef airphone:matrix.org), werden Möglichkeiten der lokalen Fairphoner-Vernetzung aufgezeigt. So werden auf einer „Fairphone Community Landkarte“ (Fairphone Community Forum 2019d) zum einen lokale Veranstaltungen angezeigt, in denen 
sich „Fairphoners“ und Interessent*innen vis-à-vis in lokalen Gemeinschaften treffen. Hinter den als Kontakt angegebenen E-Mail-Adressen verbergen sich sogenannte „Fairphone Angels“ (Fairphone 2019k), die als lokale Ansprechpartner*innen fungieren, Fairphone-Nutzer*innen technisch unterstützen, Interessent*innen beraten und/oder lokale Treffen organisieren (Brand 2019):

„Fairphone Angels are truly heaven-sent. These extremely active community members took the initiative to create a special network of super-helpers who offer assistance to Fairphoners in their local area. Their hard work is helping us to build local networks and to spread the word about the power of longevity, all while assisting the Fairphone Support team with updates, repairs or simply showing people how to make the most of their phones." (Brand 2019)

Die „Engel“ werden als essentielle Erweiterung des Unternehmens durch dieses wahrgenommen (ebd.) und tragen letztendlich ehrenamtlich zur Öffentlichkeitsarbeit des Fairphone-Unternehmens und zum technischen Support der Geräte bei. Dabei ist es sicherlich kein Zufall, dass die Engagierten analog zu den ehrenamtlichen Helfer*innen beim jährlich stattfindenden Kongress des ChaosComputerClubs als „Engel“ bezeichnet werden (zu den Engeln des ChaosComputerClubs s. MDR 2018).

Wie die Onlinelandkarte zeigt, befinden sich die „Fairphone-Engel“ bzw. die lokalen Gemeinschaften alle in Westeuropa, wobei die meisten Einträge (nämlich 14) in Deutschland verortet sind (s. Fairphone Community Forum 2019d). Hier wird deutlich, dass das Fairphone eine primäre Verbreitung in Westeuropa hat. So zeigt der auf der Onlineplattform des Fairphone-Unternehmens integrierte Kalender, dass im Zeitraum von Januar bis September 2019 zehn lokale Treffen von und für Fairphone-Nutzer*innen und Interessent*innen stattfanden: neben Paris, Brüssel, Innsbruck, überwiegend in Deutschland in Städten wie München, Hamburg, Düsseldorf und Aachen. In diesen Veranstaltungen geht es nicht nur um Austausch über das Fairphone und Unterstützung bei der Reparatur, vielmehr haben diese lokalen Zusammenkünfte auch einen großen sozialen Aspekt, der besonders deutlich in einem Treffen der Fairphone-Vergemeinschaftung in Innsbruck wird, das als Gesellschaftsspielabend für Fairphone-Nutzer*innen organisiert wird (Fairphone Community Forum 2019c).

Kommen Fairphone-Vergemeinschaftungen im Lokalen unabhängig vom Unternehmen zusammen - wenn auch aufgrund der Nutzung eines bestimmten medientechnologischen Produktes - so spielt das Unternehmen eine zentrale Rolle bei der translokalen Vergemeinschaftung der Fairphone-Nutzer*innen. Seit 2016 findet ein jährliches Treffen zwischen Fairphone-Nutzer*innen und Mitarbeiter*innen des Unternehmens in Amsterdam statt (Fairphone Community 
Forum 2019b). Neben dem Besuch des Unternehmens und dem Austausch mit Unternehmensmitarbeiter*innen, erkunden die Nutzer*innen gemeinsam die Stadt Amsterdam, fahren Rad und gehen Bouldern (ebd.). Über die Gemeinsamkeit der Nutzung einer bestimmten Medientechnologie und daran geknüpfter Ziele und Werte, findet sich im Rahmen dieses fünftägigen Ausflugs eine Gruppe, die neben einem inhaltlichen Austausch, zusammen Freizeit verbringt. So traf sich jährlich bis zur Covid-19-Pandemie vis-à-vis in Amsterdam eine translokale Vergemeinschaftung von Fairphone-Nutzer*innen. Ist dies ein kleiner Teil der Fairphone-Vergemeinschaftung (auf dem Fairphone Community Forum findet sich ein Foto, das 16 Personen als Besuchende des Fairphone-Unternehmens während des Ausflugs 2018 zeigt), so entsteht eine größere Vergemeinschaftung der Fairphone-Nutzer*innen über das auf der Onlineplattform des Unternehmens integrierte Onlineforum sowie die vom Fairphone-Unternehmen bespielten Profile auf u. a. Facebook, Twitter und Instagram. Diese translokale medienvermittelte Vergemeinschaftung wird maßgeblich durch das Unternehmen koordiniert und moderiert. Denn seine Profilseiten auf Facebook, Twitter und Instagram nutzt das Unternehmen zum einen für die Öffentlichkeitsarbeit und Vermarktung des Smartphones, zum anderen zur Herstellung einer Vergemeinschaftung der Fairphone-Nutzenden, welche auch dem Zweck der Vermarktung des Smartphones dient.

Das Facebook-Profil des Fairphone-Unternehmens haben 152.569 Personen abonniert (Stand 20. Juni 2021). In den Posts des Unternehmens bewirbt dieses das Smartphone, berichtet über die Ambitionen der fairen Ressourcengewinnung und über die negativen sozial-ökologischen Folgen der Produktion und Entsorgung herkömmlicher Smartphones. Auch wird in Posts auf die Teilnahme des Unternehmens auf Veranstaltungen wie z. B. Messen hingewiesen. Für diese Informationen verwendet das Fairphone-Unternehmen nicht nur Schrift in englischer Sprache, sondern auch Fotos und sehr kurze Filme, in denen sich u. a. Mitarbeiter*innen äußern. Damit wird dem Fairphone-Unternehmen „ein Gesicht" verliehen, die Personen dahinter werden sichtbar, als jung, gutgelaunt in überwiegend legerer Kleidung inszeniert. Die Posts des Fairphone-Unternehmens werden durch Facebook-Nutzer*innen in überwiegend englischer Sprache kommentiert. In den Kommentaren werden zum einen technische Fragen zur Hardund Software des Fairphones gestellt, aber auch die Medientechnologie sowie dir Firma bewertet. Die Kommentare sind dabei sowohl positiv als auch negativ: Sie reichen von einer negativen Bewertung des Smartphones und des Unternehmens bis hin zu sehr großem Lob sowohl für das Produkt als auch die Firma. Anlässlich der Einführung des Fairphones der dritten Generation am 27. August 2019 
z. B. äußern sich Nutzende in 168 Kommentaren positiv und negativ: So bewertet eine Facebook-Nutzerin das Fairphone pauschal: „I'm done with Fairphone [...] my God the phone is awful!" und erhält hierauf weitere Kommentare, die sich ebenfalls negativ äußern, wie z. B.: „Super same here! Always broken, every update lots of bugs and not reliable at all.“ oder "So no one is sueing them yet?? This phone is the WORST!“, aber auch widersprechende Kommentare: „I don't have any problem with my Fairphone 2 which I use over more than 2 years." oder „I never had any problems with my phone [...] It worked perfectly fine“" (abgerufen am 16. September 2019 unter https://de-de.facebook.com/Fairphone).

Andere Facebook-Nutzer*innen gratulieren dem Fairphone-Unternehmen zur Einführung der dritten Generation und loben das Unternehmen (z. B. „You guys are great! You even made the Fairphone 3 cheaper than the Fairphone 2! Keep up the good work as soon as I can gather the money I will get one!"). Am 28. August 2019 laden Fairphone-Mitarbeiter*innen, u. a. die derzeitige Geschäftsführerin Eva Gouwens, Facebook-Nutzer*innen ein, über die FacebookKommentarfunktion Fragen zu stellen, die dann über die Kommentarfunktion beantwortet werden. Die Vorstellung der Mitarbeiter*innen alleinig mit ihren Vornamen auf Facebook (und so auch auf der Onlineplattform des Unternehmens, s. Fairphone 2019m) suggeriert einen informellen Austausch und eine Begegnung auf Augenhöhe.

Ähnlich dieser Nutzung des Facebook-Profils ist auch die Nutzung des TwitterAccounts des Fairphone-Unternehmens, wobei es neben den eigenen Tweets auch solche anderer Organisationen und Unternehmen retweeted, die entweder das Fairphone-Unternehmen oder das Smartphone kommentieren oder aber für das Fairphone relevante Themen beinhalten, wie die Produktion fairer Medientechnologien, das Reparieren etc. Durch die Hinweise auf andere Unternehmen und Organisationen, die entweder die Anliegen des Fairphone-Unternehmens teilen oder aber das Smartphone selbst zum Thema haben, unterstreicht die Firma nicht nur die Relevanz des eigenen Handelns, sondern bildet ein Netzwerk mit anderen Akteur*innen aus dem Bereich der fairen Produktion, das durch das Teilen gemeinsamer Ziele im Weber'schen Sinn (s. Abschn. 3.2.4) ein Vergesellschaftungsmoment enthält. Der Twitter-Account des Fairphone-Unternehmens hat 43.688 Follower sowie 42.000 auf Instagram (Stand 20. Juni 2021). Die von mir für die Fairphone-Studie interviewten Nutzer*innen gehören jedoch ausnahmslos nicht zu diesen und äußern sogar, dass sie dem Unternehmen weder über Facebook (mit einer Ausnahme) noch über Twitter oder Instagram ,folgen“, entweder, weil sie diese Internetmedien per se nicht nutzen oder weil sie kein Interesse haben, weitere Informationen vom Fairphone-Unternehmen zu erhalten, oder sich nicht mit anderen Fairphone-Nutzer*innen medienvermittelt austauschen wollen. 
Einige Interviewpartner*innen betonen jedoch, dass sie in ihrem Freundes- und Bekanntenkreis mit anderen Nutzer*innen über das Smartphone reden.

Zusammenfassend lässt sich festhalten, dass die von Hitzler, Honer und Pfadenhauer (2008, S. 10) herausgearbeiteten Charakteristika posttraditionaler Vergemeinschaftungen in der Fairphone-Studie zu identifizieren sind. So teilen das Fairphone-Unternehmen sowie die Nutzer*innen des Fairphones das Ziel, dass Medientechnologien unter faireren Bedingungen hergestellt werden und durch die Reparierbarkeit der Apparate aufgrund einer modularen Bauweise die Technologien lange nutzbar sind, damit Ressourcen geschont und die Produktion elektronischen Mülls vermieden werden. Das übergeordnete Ziel des Unternehmens und der Fairphone- Nutzer*innen ist damit eine nachhaltige Gesellschaft.

Außerdem kann als weiteres Charakteristikum von Hitzler, Honer und Pfadenhauer (2008, S. 10) eine Wertschätzung gegenüber den Mitgliedern der Vergemeinschaftung wahrgenommen werden, so unterstreicht das FairphoneUnternehmen die Relevanz der Fairphone-Nutzer*innen und der „Engel“ für eine nachhaltige Gesellschaft. Die Wertschätzung der Fairphone-Nutzer*innen vonseiten des Unternehmens dient sicherlich auch der Verbreitung und Vermarktung des Fairphones. Diesen Zwecken dient auch die Konstruktion einer „Community“, die als solche auf der Onlineplattform des Unternehmens hergestellt wird. Dabei wird diese nicht nur alleine durch die Verwendung des Begriffs geschaffen, sondern auch durch die Möglichkeit der medialen Vernetzung im Onlineforum der vom Fairphone-Unternehmen betriebenen Plattform und über die vom Unternehmen bespielten Profile auf Onlinenetzwerken sowie auch über lokale und über die Onlineplattform des Unternehmens beworbene Treffen von Fairphone-Nutzer*innen und Interessent*innen. Diese lokalen Zusammenkünfte, der jährliche Austausch zwischen Fairphone-Nutzer*innen und Mitarbeiter*innen des Unternehmens sowie die mediale Vernetzung über das Onlineforum sowie Onlinenetzwerke, stellen für die Mitglieder einer Fairphone-Vergemeinschaftung zugängliche Interaktions(-zeit-)räume (ebd.) dar - ein weiteres Charakteristikum posttraditionaler Vergemeinschaftungen.

Ein zusätzliches Kriterium posttraditionaler Vergemeinschaftungen, das Zugehörigkeitsgefühl, das auch Weber als zentrales Moment von Vergemeinschaftungen benennt, lässt sich aus den bis hierher herausgearbeiteten Charakteristika ableiten: Alleine das lokale Zusammenkommen der Fairphone-Nutzer*innen, das über technische Anliegen hinausgeht, sondern, wie das Datenmaterial deutlich macht, auch einen sozialen Aspekt hat, zeigt, dass sich die an diesen Treffen teilnehmenden Fairphone-Nutzer*innen dieser Gruppe, welche sich über die 
Fairphone-Nutzung konstituiert, zugehörig fühlen. Auch verdeutlichen die positiven Kommentare der Facebook- und zugleich Fairphone-Nutzer*innen auf dem Facebook-Profil des Fairphone-Unternehmens, dass sich viele Nutzer*innen mit dem Unternehmen und seinem Produkt identifizieren. Gleichzeitig lassen die vielen negativen Kommentare von Fairphone-Nutzer*innen, in denen diese das Fairphone-Unternehmen und/oder sein Produkt kritisieren, erkennen, dass es sehr wohl Brüche in der „Fairphone-Community“ gibt, Fairphone-Nutzer*innen aus der Vergemeinschaftung austreten oder sich entfremden, weil sie entweder aufgrund technischer Unzulänglichkeiten vom Fairphone selbst enttäuscht sind oder vom Unternehmen insgesamt, z. B. aufgrund der Einstellung der Ersatzteilproduktion für das Fairphone der ersten Generation.

Die geringe Anzahl der lokalen Treffen sowie die geringe Beteiligung im Onlineforum der vom Fairphone-Unternehmen betriebenen Plattform und die meist geringe Anzahl der Kommentare unter den Facebook-Posts zeigen, dass die medienvermittelte und vis-à-vis zusammenkommende Vergemeinschaftung der Fairphone-Nutzenden eher klein ist. Die in dieser Fallstudie identifizierte Vergemeinschaftung wird primär vom Fairphone-Unternehmen initiiert, das Möglichkeiten der Vergemeinschaftung für Fairphone-Nutzer*innen und Interessent*innen medial ermöglicht und lokal unterstützt sowie verstärkt und moderiert.

Ein ähnliches Ergebnis lässt sich für die Fallstudie zur Onlineplattform Utopia.de festhalten. In den Anfangszeiten der Onlineplattform nach ihrer Gründung 2007 war in diese neben dem Onlinemagazin auch ein Onlinenetzwerk integriert, in dem sich registrierte „Utopist*innen“ vernetzen konnten: Mit dem Slogan „In 30 Sekunden Utopist werden“ lud die Utopia GmbH (2015c) zur Onlinegemeinschaft der „Utopist*innen“ ein. Unter dem Reiter „Community“ fordert die Utopia GmbH heute zur Mitgliedschaft in der über die Onlineplattform hergestellten Vergemeinschaftung auf: „Du kannst hier Gleichgesinnte finden und mit ihnen diskutieren, von deinen Erfahrungen berichten, Hilfe suchen und dich mit anderen Utopisten zu vielen verschiedenen Nachhaltigkeits-Themen austauschen und verbinden." (Utopia 2019b; Hervorhebung im Original) Der Begriff der Gleichgesinnten betont die Übereinstimmung der Ziele und Werte der Mitglieder, Nachhaltigkeit wird dabei explizit als gemeinsamer Referenzrahmen durch die Utopia GmbH gesetzt.

Das Angebot der Vernetzung der „Utopist*innen“ wurde dann wiederholt modifiziert: Zunächst wurde das Onlinenetzwerk reduziert und die „Utopist*innen" konnten sich zum Zeitpunkt der Datenerhebung für die hier diskutierte Studie (s. Abschn. 3.3.2) in Onlineforen vernetzen. Die folgenden Ergebnisse beziehen sich auf diese Möglichkeit. Zum Zeitpunkt der Überarbeitung dieses Buchmanuskriptes im Juni 2021 wurden diese Onlineforen auf der 
Plattform utopia.de nicht mehr angeboten, vielmehr werden die „Utopist*innen“ nun für „Utopia-Community-Gruppen“ auf die Vernetzungsmöglichkeiten über Facebook verwiesen.

Als registrierte „Utopist*innen“ konnte sich diese in verschiedenen Gruppen in Onlineforen zu unterschiedlichen Themen austauschen. Diese Gruppen waren auch für nicht registrierte Nutzer*innen einsehbar, Beiträge schreiben konnten aber nur registrierte Personen. Auf der Onlineplattform registriert sind insgesamt 2127 Personen (Stand am 16. September 2019), die wiederum Mitglied in einer oder mehreren der 26 thematisch unterschiedlichen Gruppen werden können. Diesen gehörten zwischen 15 (in der Gruppe „,Vegetarisch leben“) und 76 Mitgliedern (in der Gruppe „Essen und Trinken“) an (Utopia 2019b). Es sind also nicht alle der auf der Onlineplattform registrierten Personen einer der Gruppen beigetreten, zumal einige „Utopist*innen“ mehreren angehörten.

Die Themen der Gruppen beschäftigten sich zum einen mit unterschiedlichen Produkten wie „Kleidung und Fashion“ oder „Erneuerbare Energien“ und zum anderen mit Praktiken wie „Vegetarisch leben“ oder "Selbst machen“ (s. Utopia 2019e). Der Austausch unter den Mitgliedern innerhalb der verschiedenen Gruppen war wiederum in thematisch unterschiedliche Foren-Threats strukturiert. Meine Beobachtungen im Rahmen der virtuellen Ethnographie zeigten, dass viele der Diskussionen in den Onlineforen seit Wochen oder Monaten nicht weitergeführt wurden, der Austausch unter den Utopist*innen war unregelmäßig oder wenig rege (einer der möglichen Gründe für die Einstellung dieses Angebots).

Medien wurden in der Gruppe „Literatur, Filme, Musik, Schauspiel und Kunst“ explizit als Inhalt thematisiert. Bereits die Beschreibung der Gruppe betonte den Vergemeinschaftungsaspekt: „Diese Gruppe ist ein Treffpunkt für Menschen, die gute Filme, Bücher, Musik und Schauspiele lieben. Hier findet man Empfehlungen und kann sich mit Gleichgesinnten austauschen." (ebd.) Auch hier wurde die Gemeinsamkeit der Mitglieder betont, wobei der gemeinsame Referenzrahmen sich hier nicht auf Nachhaltigkeit bezog, sondern auf „gute“ Medienformate.

Das Anliegen, eine Vergemeinschaftung unter den „Utopist*innen“ herzustellen, wurde vor allem in der Gruppe „Rund um Utopia“ deutlich, in der „Utopist*innen“ (einige wenige) Informationen über Nutzungsmöglichkeiten der Onlineplattform erhielten und aufgefordert wurden, Kritik und Wünsche an die Onlineplattform zu äußern (Utopia 2019f). Besonders interessant in Hinblick auf die Konstruktion einer Vergemeinschaftung ist der in dieser Gruppe abgebildete Liedtext des „Utopia Songs“, der von einer „Utopistin“ geschrieben wurde und der ,nach der Melodie des Titanic Songs - My Heart Will 
Go On“ (Utopia 2019g) gesungen werden kann. Unter dem Liedtitel „Herzlich willkommen! Unser Weg nach Utopia (Utopia-Song)“ (ebd.) finden sich im Text verschiedene Aspekte posttraditonaler Vergemeinschaftung: So werden zum einen die Mitglieder wertgeschätzt: „,[J]eder von euch ist für uns ein Gewinn“ und es erfolgt eine Abgrenzung gegenüber dem „Nicht-Wir“, einer diffusen Gruppe Mensch (,Was hat der Mensch mit der Zeit angefangen, für unsere Umwelt war nicht viel getan."), die spezifiziert werden kann, interpretiert man die im Lied genannten Ziele: So gehören Vielfliegende und Autofahrende sowie Plastikkonsumierende entsprechend des Liedtextes wohl weniger zu der im Text konstruierten Vergemeinschaftung als vielmehr Fußgänger*innen und Radfahrer*innen, Biokonsument*innen und Naturliebhaber*innen. Neben dieser inhaltlichen Abgrenzung wird im Liedtext Bezug auf die wahrgenommene Größe der Vergemeinschaftung genommen, so formuliert der Text „Wir sind nicht viel an der Zahl“" (ebd.). Hier erfolgt nicht nur erneut eine Abgrenzung zu einer gröBeren Gruppe (eben der der Vielflieger, Autofahrer etc.), sondern es wird implizit ein Zusammenhalten der „Utopist*innen“ angedeutet, das explizit in der Metapher des Händereichens gefordert wird: „Reicht euch die Hand auf dem Weg nach Utopia“ (ebd.). Über diese Metapher wird ein Zugehörigkeitsgefühl zu der Gruppe der „Utopist*innen“ provoziert. Ein solches wird auch in der Adressierung der Utopist*innen in ihrer (möglichen) Elternrolle angesprochen: „Denn unsre Kinder, sie sollen erleben saubere Luft und ein sauberes Meer." (ebd.) Hier wird der Generationenaspekt des Nachhaltigkeitskonzepts (s. Einleitung) betont und über die Elternrolle, die zukünftige Generationen schützen wollen, eine Vergemeinschaftung konstruiert. Dass nicht alle Utopist*innen zwangsläufig Eltern sind, wird dabei ignoriert.

Die Vergemeinschaftung der „Utopist*innen“ fand aber nicht nur über die Onlineplattform der Utopia GmbH selbst statt, sondern auch über weitere von der Utopia $\mathrm{GmbH}$ bespielte Onlinemedien, über die die Vergemeinschaftung der „Utopist*innen“ auch nach der Einstellung des Angebots der Onlineforen auf der Plattform stattfindet. Ähnlich dem Fairphone-Unternehmen nutzt auch die Utopia GmbH die Angebote von Onlinenetzwerken und Mikrobloggingdiensten und unterhält Profile auf Facebook, Twitter, Instagram, Pinterest sowie einen eigenen YouTube-Kanal. Die Reichweite der jeweiligen von der Utopia GmbH gestalteten Profile divergiert stark: Während das Profil der Utopia GmbH 287.685 Facebook-Nutzer*innen abonniert haben, folgen dem Unternehmen 28.800 Personen auf Twitter sowie 121.000 Personen auf Instagram (Stand am 20. Juni 2021). Meine Beobachtungen im Rahmen der virtuellen Ethnographie zeigen, dass sich die Inhalte in diesen verschiedenen Internetmedien gleichen: Was die 
Utopia GmbH auf Facebook postet, wird auf Twitter getweeted und auf Instagram geteilt. Inhaltlich beschäftigen sich die Beiträge mit als durch die Utopia $\mathrm{GmbH}$ nachhaltig bewertetem Konsum, indem, ähnlich wie im Onlinemagazin, auf der von der Utopia GmbH betriebenen Plattform als nachhaltig eingestufte Produkte und Praktiken beworben bzw. als nicht nachhaltig bewertete Produkte und Praktiken skandalisiert werden (s. Abschn. 4.1).

Das Betreiben dieser Profile auf den verschiedenen Onlinenetzwerken dient einerseits der Öffentlichkeitsarbeit der Utopia $\mathrm{GmbH}$, andererseits der Vergemeinschaftung. So zeigt sich auf dem von der Utopia $\mathrm{GmbH}$ bespielten Facebook-Profil, dass viele der Posts eine rege Beteiligung von FacebookNutzer*innen auslösen. Selten werden Posts mit weniger als zehn Kommentaren versehen, oftmals finden sich zwischen 100 und 200 Kommentare. Diese, so zeigt meine Beobachtung, sind Zustimmung zu den von der Utopia GmbH veröffentlichten Posts, zum anderen aber auch inhaltlich ablehnend oder sich lustig machende Beiträge. Von letzteren grenzen sich Mitglieder der „UtopiaVergemeinschaftung" wiederum ab und bestätigen die Zugehörigkeit zur Utopia $\mathrm{GmbH}$. Dies zeigen auch die Beobachtungen der Kommentare auf dem von der Utopia GmbH auf Instagram betriebenen Profil. Eine Bestätigung der Ziele und Werte findet daneben auch in den von den Nutzer*innen vergebenen „likes“ (Facebook) oder ,gefällt“ (Instagram und Twitter) statt. Ähnliche Erkenntnisse lassen sich auch für den Youtube-Kanal der Utopia GmbH festhalten: Auf diesem finden sich Filme (die in einem Zeitraum zwischen 2008 und 2018 eingestellt wurden, Stand 18. September 2019) zu verschiedensten Themen des nachhaltigen Konsums, welche in Kommentaren ablehnend (dies eher selten) oder zustimmend bewertet werden. Ihre Meinung artikulieren die Nutzer*innen auch in den „Mag ich“ bzw. „Mag ich nicht“-Angaben. 3280 Personen haben den Kanal der Utopia $\mathrm{GmbH}$ abonniert.

Der wohl intensivste Austausch der „Utopist*innen“ neben den auf der von der Utopia $\mathrm{GmbH}$ bespielten Onlineplattform findet in den acht Facebook-Gruppen statt, in denen die „Utopist*innen“ zu thematisch in Oberthemen sortierten Gruppen über nachhaltigen Konsum kommunizieren. Den Gruppen gehören zwischen 1521 (in der Gruppe „Utopia.de Medientipps - nachhaltige Dokus, TV-Tipps, Videos, Bücher ...") und 42.824 (in der Gruppe „Utopia.de - nachhaltig leben: eure Ideen, Tipps und Fragen“) Personen an (Stand 20. Juni 2021).

Die Ergebnisse zeigen, dass, ähnlich der durchgeführten Fairphone-Studie, ein Teil der „Utopia-Gemeinschaft“ über verschiedene Internetmedien in Verbindung tritt, sich in ihren Zielen und Werten bestätigt sowie auch eine Zugehörigkeit herstellt, indem z. B. Facebook-Nutzer*innen in Kommentaren das Personalpronomen „wir“ nutzen (so schreibt z. B. ein Nutzer in einem Kommentar am 18. 
September 2019: „Bitte handeln wir bewusst selbst und seien wir ein Teil der Veränderung auf Erden“, Hervorhebung S. K.).

Zusammenfassend kann in Hinblick auf die von Hitzler, Honer und Pfadenhauer (2008, S. 10) benannten Kriterien für posttraditionale Vergemeinschaftungen festgehalten werden, dass eine Utopia-Vergemeinschaftung zu identifizieren ist, die ihre Interaktions(-zeit-)räume medienvermittelt auf der von der Utopia $\mathrm{GmbH}$ betriebenen Onlineplattform findet sowie auch über weitere durch die Utopia $\mathrm{GmbH}$ genutzte Onlinenetzwerke. Diese Vergemeinschaftung ist translokal: Ihre Mitglieder sind „Utopist*innen“ an verschiedenen Orten. Aufgrund der Nutzung der deutschen Sprache in den von der Utopia GmbH in den verschiedenen Internetmedien generierten Inhalten, ist die Zugehörigkeit zur Utopia-Vergemeinschaftung jedoch an diese Sprachkenntnis gebunden. In den Inhalten der hier hergestellten Interaktions(-zeit-)räume findet sich das gemeinsame Anliegen des nachhaltigen Konsums, eine Abgrenzung gegenüber einem „Nicht-Wir“" und ein Zusammengehörigkeitsgefühl.

Die drei Fallstudien vergleichend lässt sich festhalten, dass in allen drei Fallstudien Vergemeinschaftungen zu identifizieren sind, die sich vis-à-vis und medienvermittelt (trans-)lokal zusammenfinden und deren Mitglieder ähnliche Ziele und Werte teilen und sich den jeweiligen Vergemeinschaftungen zugehörig fühlen. Dabei divergieren die Vergemeinschaftungen in ihrer räumlichen Erstreckung, den Formen der Kommunikation sowie durch diese beiden Charakteristika sicherlich auch in ihrer Qualität. Auch zeigt sich, dass die Vergemeinschaftungen koordiniert sind, wobei diese Koordinationsfunktion durch Unternehmen (Fairphone und Utopia $\mathrm{GmbH}$ ) oder Nichtregierungsorganisationen (Anstiftung \& Ertomis) und Individuen (im Falle der ehrenamtlichen Organisator*innen der Repair Cafés) wahrgenommen wird. Bei den hier identifizierten Vergemeinschaftungen handelt es sich um posttraditionale Vergemeinschaftungen (Hitzler et al. 2008), deren Mitglieder freiwillig für einen bestimmten Zeitraum beitreten. Die in den Fallstudien identifizierten Vergemeinschaftungen sind ,(international) communities of consumers" (Canclini 2003, S. 43 f.), deren Mitglieder einem bestimmten Lebensstil (zum Lebensstil und Konsum s. u. a. Lüdtke 2004, S. 103) praktizieren (wollen), der zu einer nachhaltigen Gesellschaft und einem ,guten Leben“ beiträgt. Durch ihren Lebensstil, einem „Feld symbolischer Kommunikation“ (ebd., S. 118), drücken die Mitglieder der jeweiligen Vergemeinschaftung auch ihre Zugehörigkeit zu einer Gruppe aus. Als z. T. deterritoriale Vergemeinschaftungen (Hepp 2011, S. 106) sind diese vorgestellte Gemeinschaften (Anderson 2006 [1983]).

Die Mitglieder dieser Vergemeinschaftungen nehmen sich selbst als Pionier*innen wahr und bezeichnen sich explizit als solche (Kannengießer 2014b). 
So antizipiert einer der Organisator*innen des Oldenburger Repair Cafés einen Zusammenbruch der derzeitigen Konsumgesellschaft aufgrund der Klimakrise und sieht im Reparieren eine zukünftig notwendige Praktik, über deren Kompetenz die Teilnehmer*innen der Repair Cafés verfügen: „Das sind die innovativen Nutzer, die Pioniernutzer, die schon eine Bewegung vorwegnehmen, die mit einer gewissen Wahrscheinlichkeit [...] eintreten [kann, S. K.]“. Der Pioniercharakter der Reparierenden liegt dabei nicht darin, dass sie eine neue (Medien-)Praktik oder (Medien-)Technologien entwickeln. Vielmehr praktizieren sie die sehr alte Praktik des Reparierens und Verbreiten diese über die öffentlich zugänglichen Repair Cafés, über die das Wissen um die Praktik des Reparierens konserviert und einer breiteren Bevölkerung zugänglich gemacht werden soll. So betont der Organisator des Oldenburger Repair Cafés, dass ,,hier [in den Repair Cafés, S. K.] ein Bruch vollzogen wird und inszeniert wird. Ein Bruch mit mehrheitlich verankerten Routinen in Bezug auf Produktnutzung." Konsumiert die Bevölkerung in der derzeitigen Konsumgesellschaft mehrheitliche regelmäßig neue Medientechnologien (aufgrund von Obsoleszenz und technologischen Innovationen, s. Abschn. 2.2.3), so wollen die „Pioniere“, also die Reparierenden, diesen Konsum vermeiden und die Nutzungsdauer der von ihnen genutzten Produkte im Allgemeinen und Medientechnologien im Besonderen verlängern.

In den Repair Cafés kommt eine Vergemeinschaftung der Pionier*innen zusammen, was auch Ziel der Organisator*innen dieser Veranstaltungen ist. So erklärt einer der Organisatoren des Oldenburger Repair Cafés: Die Reparierenden bilden

„Pioniergruppen [...], die schon jetzt vorwegnehmen, was eine Antwort sein könnte, auf die [...] Zeit danach [nach dem Kollaps des derzeitigen gesellschaftlichen Systems, S.K.]. Also das heißt, diese Praktiken sind das worauf man dann zugreifen kann, wenn sozusagen sonst nichts mehr geht." (Hervorhebung S. K.)

Dass sich das Reparieren zukünftig wieder als Praktik durchsetzen wird, meint auch der Betreiber des Veranstaltungsortes, in dem das Oldenburger Repair Café anfänglich stattfand:

„Da bin ich ganz stolz, dass es [das Repair Café, S. K.] hier bei mir ist. Weil ich denke, dass das schon eine Kultur ist, die sich jetzt deutschlandweit etablieren wird. Kann man immer sagen, [...] in den Anfängen waren wir schon dabei und das erfüllt mich schon mit ein bisschen Stolz."

Auf diesen im Zitat angeführten Kulturwandel gehe ich in Abschn. 4.5 näher ein. Hier sei zunächst noch auf den Pioniercharakter der Akteur*innen in den weiteren Fallstudien eingegangen. 
Auch in der Fairphone-Studie werden die Fairphone-Nutzer*innen als „Pioniere" durch das Fairphone-Unternehmen wahrgenommen: ,We want to shine a light on the local Fairphone pioneers, change-makers and innovators that are shaping the future of the industry with us." (Fairphone 2019k, Hervorhebung S. K.). Das Unternehmen beschreibt hier die „Fairphone-Engel“ (s. o.), die im Lokalen Veranstaltungen organisieren, um Fairphone-Nutzer*innen bei technischen Problemen zu unterstützen und die Idee des Fairphones zu verbreiten. Auch die Mitarbeitenden des Unternehmens werden als Pionier wahrgenommen; so werden sie z. B. in Artikeln auf der Onlineplattform Utopia.de als „Amsterdamer Pioniere“ (Winterer 2015b) bezeichnet. Der Pioniercharakter liegt hier in der Entwicklung einer neuen Art und Weise der Produktion eines Smartphones, nämlich mit dem Ziel, diese fairer und nachhaltiger zu gestalten. Dieses Pionierhandeln materialisiert sich in der digitalen Medientechnologie, dem Fairphone selbst. Durch dieses neue Handeln auf dem Markt technologischer Ideen will das Fairphone-Unternehmen einen Akzent setzen und das Angebot der Medientechnologien verändern (s. Abschn. 4.2). Auch dieser Anstoß der Veränderung wird als ein Pionierhandeln wahrgenommen: „Als Pionier will das Unternehmen den Grundstein legen und andere Unternehmen davon überzeugen, dass auch in Demokratischen Republik Kongo Bergbau aus konfliktfreien Minen betrieben werden kann," schreibt der Autor Winterer (2015b; Hervorhebung S. K.) in einem Artikel auf der Onlineplattform Utopia.de. Im Umkehrschluss kann jede*r einzelne Fairphone-Nutzer*in als Pionier*in bezeichnet werden, der*die diese auf eine (zumindest in Teilen) innovative Art und Weise produzierte Medientechnologie erwirbt. Auch in dieser Fallstudie finden sich die Pioniere, wie hier herausgearbeitet werden konnte, in lokalen und medienvermittelten Vergemeinschaftungen zusammen.

Auch in der dritten Fallstudie kann der Pioniercharakter der Akteur*innen identifiziert werden. So bezeichnet sich die Utopia $\mathrm{GmbH}$ indirekt als Pionier, indem es sich als „Trendbarometer für den grünen Markt“ (Utopia 2016a) beschreibt. Auch die Nutzer*innen der Onlineplattform Utopia.de werden implizit als Pioniere charakterisiert, die Utopia GmbH spricht von ihnen als Avantgarde: „Die Nutzer von Utopia zählen zur Nachhaltigkeits-Avantgarde: Sie stellen sich als gut informierte, qualitätsorientierte Konsumentengruppe dar, der ethischer Konsum in allen Lebensbereichen wichtig ist.“ (Utopia 2019a, S. 5) Eine von der Utopia $\mathrm{GmbH}$ durchgeführte Studie über die Nutzer*innen zeigt jedoch, dass die ,große Mehrheit der Utopia-Nutzer [...] sich selbst weder als Avantgarde noch als Nachzügler in Sachen Nachhaltigkeit [versteht, S.K.]." (Utopia 2015b, S. 3) So lassen sich im Material selbst Widersprüche in Hinblick auf die Selbst- und Fremdwahrnehmung des Pioniercharakters der Utopia-Nutzer*innen 
finden. Festzuhalten ist jedoch für die Utopia-Nutzer*innen und auch die Nutzer*innen des Fairphones, dass sie sich, wie für die Reparierenden explizit aus dem Datenmaterial herausgearbeitet, gegen die Mehrheitsgesellschaft abgrenzen, welche in ihren Medienpraktiken nicht oder wenig nachhaltig konsumiert und handelt. Als Pioniere handeln die Akteur*innen nicht alleine, sondern in Vergemeinschaftungen (Kannengießer 2018c, S. 221 f.), die entsprechend des Pioniercharakters ihres Handelns (Kannengießer 2014b) Pioniergemeinschaften (Hepp 2016) bilden. Individuell und organisiert reflektieren und gestalten die Akteur*innen aktuelle Digitalisierungs- und Globalisierungsprozesse (KannengieBer 2018b, S. 84). In den Vergemeinschaftungen erfahren Individuen Resonanz als in der Welt seiend (Rosa 2016, S. 285). Die Vergemeinschaftungen stellen für die Individuen Resonanzachsen dar, also dauerhafte Resonanzbeziehungen, durch die die Individuen Stabilität und das ,gute Leben“ erfahren (ebd., S. 73). Insofern versuchen die Akteur*innen der Fallstudien durch ihre Medienpraktiken nicht nur, zu einem ,guten Leben“ für andere, an Produktions- und Entsorgungsprozessen digitaler Medientechnologien beteiligten Personen beizutragen, sondern durch ihre Praktiken und die hier entstehenden Vergemeinschaftungsprozesse auch zu ihrem eigenen „guten Leben“. Inwiefern diese Vergemeinschaftungen (Teile) soziale(r) Bewegungen sind, wird in Abschn. 4.6 herausgearbeitet. Dafür wird zunächst im folgenden Kapitel argumentiert, dass die konsumkritischen Medienpraktiken Formen unkonventioneller politischer Partizipation sind.

\subsection{Konsumkritische Medienpraktiken als unkonventionelle Formen politischer Partizipation}

In den vorherigen Kapiteln wurde herausgearbeitet, dass Akteur*innen mit verschiedenen Formen konsumkritischer Medienpraktiken alleine und in Vergemeinschaftungen zu einer nachhaltigen Gesellschaft und einem „guten Leben“ beitragen wollen. Mit den konsumkritischen Medienpraktiken versuchen sie also, Gesellschaft zu einer nachhaltigeren zu transformieren Aufgrund dieses gesellschaftlichen Gestaltungsanliegens sind die im Rahmen der hier diskutierten konsumkritischen Medienpraktiken als Formen politischer Partizipation zu begreifen. Denn versteht man Politik ,die aktive Teilnahme an der Gestaltung und Regelung menschlicher Gemeinwesen“" (Schubert und Klein 2018, o. S.) so sind die konsumkritischen Medienpraktiken politische Praktiken, da sie Gesellschaft gestalten wollen. Im Folgenden wird dieses Argument näher erläutert und unter Rückgriff auf die theoretischen Erläuterungen zu politischer Partizipation (s. Abschn. 2.2.5) und die bereits präsentierten empirischen Ergebnisse 
sowie unter der Heranziehung weiteren Datenmaterials werden die hier untersuchten konsumkritischen Medienpraktiken als Formen politischer Partizipation diskutiert. ${ }^{14}$

Wird Partizipation als freiwillige Handlungen von Bürger*innen, mit denen gesellschaftliche Prozesse beeinflusst und gestaltet werden sollen, definiert (de Nève und Olteanu 2013, S. 14), so sind das Reparieren von Medientechnologien, die Produktion und Aneignung des Fairphones sowie die Verbreitung von Informationen über nachhaltigen Konsum über die Onlineplattform Utopia.de als politische Partizipation zu bezeichnen, da die konsumkritischen Medienpraktiken freiwillig von den verschiedenen Akteur*innen verfolgt werden, um darüber Gesellschaft zu verändern. Diese Praktiken reichen über Engagement hinaus, da mit ihnen die Akteur*innen aktiv an Repair Cafés, dem Fairphone-Unternehmen und der Utopia GmbH, lokalen Vis-à-vis-Fairphone-Vergemeinschaftungen oder den medienvermittelten Vergemeinschaftungen (s. vorheriges Kapitel) und über diese schließlich auch aktiv an Gesellschaft teilnehmen.

Die hier untersuchten konsumkritischen Medienpraktiken sind als unkonventionelle Formen politischer Partizipation zu betrachten, da diese Formen der Beteiligung nicht institutionell verfasst sind (de Nève und Olteanu 2013, S. 14). Die konsumkritischen Medienpraktiken sind subpolitisch, da sie jenseits institutionalisierter Politikfelder stattfinden (Beck 1993, S. 103). Auch an dieser Stelle sei nochmals auf die SPD-Nähe der Utopia GmbH hingewiesen, jedoch sind die Praktiken der Utopia GmbH dennoch keine einer politischen Partei.

Altheides und Carpentiers oben erläuterte Unterscheidung (s. Abschn. 2.2.5) zwischen Partizipation in und durch Medien kann auf die hier diskutierten Fallstudien angewendet und gleichzeitig erweitert werden: So ist die Onlineplattform Utopia.de ein Beispiel für die Partizipation durch Medien, da hier Medieninhalte genutzt werden, um Verbraucher*innen zu informieren und über das Bewerben nachhaltiger Produkte und Praktiken Menschen zu veranlassen, nachhaltiger zu konsumieren und darüber Gesellschaft zu verändern. Das Fairphone-Unternehmen hingegen ist ein Beispiel für verschiedene Partizipationsformen: Zum einen findet über das Fairphone-Unternehmen eine Partizipation in Medien statt, da Mitarbeiter*innen über die Teilnahme an einer Medienorganisation Gesellschaft verändern (wollen). Dabei ist die Medienorganisation aber nicht, wie bei Altheide (1997) und Carpentier (2011, S. 67 ff.) gedacht, eine, die primär Medieninhalte produziert (obwohl das Fairphone-Unternehmen eine Onlineplattform und

\footnotetext{
${ }^{14}$ Das Reparieren in Repair Cafés wurde in Kannengießer (2017a) als Form unkonventioneller politischer Partizipation diskutiert; zu konsumkritischen Medienpraktken als Form politischer Partizipation siehe Kannengießer (2016).
} 
Profile auf Plattformen von Fremdanbietern bespielt, s. vorheriges Kapitel), sondern eine, die mit dem Fairphone eine Medientechnologie produziert und über diese Herstellungsprozesse Gesellschaft verändern will. Zum anderen ist das Fairphone-Unternehmen ein Beispiel für eine Partizipation mit und über Medientechnologien, da es Medientechnologien in den Mittelpunkt des Handelns stellt und damit in einem Prozess des ,acting on media“ (Kannengießer und Kubitschko 2017; s. Abschn. 3.2.1) über die Veränderung von Medientechnologien Gesellschaft beeinflussen möchte. Partizipation mit und über Medientechnologien kann also in der Fairphone-Studie identifiziert werden, da das Fairphone-Unternehmen über die Produktion einer fairen Medientechnologie Gesellschaft nachhaltiger gestalten will. Gleichzeitig ist der Konsum in Form des Erwerbs und der Aneignung ebenfalls eine Partizipation mit und über Medientechnologien, da auch die Nutzer*innen Gesellschaft durch diesen Kauf verändern wollen. Schließlich ist auch das Reparieren von Medientechnologien in Repair Cafés eine Partizipation mit und über Medientechnologien, da auch hier Gesellschaft über den Umgang mit Medientechnologien, die Nutzungsdauerverlängerung der Apparate durch das Reparieren, verändert werden soll.

So zeigt sich anhand der Fallbeispiele, dass die von Altheide und Carpentier getroffene Unterscheidung zwischen Partizipation in und durch Medien erweitert werden muss, will man verstehen, wie Menschen mit Medien an Gesellschaft teilhaben und diese verändern wollen, durch Partizipationsformen, die im Sinne eines ,acting on media“"Medientechnologien in den Fokus ihres Handelns stellen, sodass Partizipation mit und über Medientechnologien stattfindet.

Die Materialität der Medientechnologien ist für alle Formen der Partizipation in, durch, mit und über Medien relevant, dies wurde ausführlich in Abschn. 2.2.5 erläutert, in dem gezeigt wurde, welche Relevanz der Materialität digitaler Medientechnologien den konsumkritischen Medienpraktiken zukommt. Dennoch handelt es sich bei den hier untersuchten Partizipationsformen nicht um die von Marres (2012) entwickelte ,material participation“. Denn dieser Ansatz stellt als „device-centered perspective“ (ebd., S. 27 und 133) die Medientechnologien in den Fokus. Der in diesem Buch verfolgte Ansatz ist jedoch einer der „non-media-centric“ (Morley 2009) Kommunikations- und Medienwissenschaft. Entsprechend wurde in den vorherigen Teilkapiteln deutlich, dass es die verschiedenen Akteur*innen sind, welche die Materialität digitaler Medientechnologien reflektieren und durch konsumkritische Medienpraktiken, in denen Medien(-technologien) im Zentrum ihres Handelns stehen, Gesellschaft verändern wollen. Die Materialität digitaler Medientechnologien ist dabei zentral für das Handeln und die Partizipation der Akteur*innen, jedoch nicht der Ausgangspunkt. 
Das Ziel der politischen Partizipation durch konsumkritische Medienpraktiken, so zeigen die Fallstudien, ist die Herbeiführung eines kulturellen Wandels: So ist eines der Ziele der an Repair Cafés Beteiligten, die Konsum- und Wegwerfgesellschaft zu verändern. Sie verfolgen durch das Reparieren und die Verbreitung der Praktik des Reparierens in Repair Cafés einen Wandel kultureller Werte und Praktiken des Konsumierens: Sie wollen, dass sich das Reparieren gegenüber dem Wegwerfen gesellschaftlich etabliert, und hoffen, so eine nachhaltige Gesellschaft zu erreichen. Das Reparieren ist eine „Politik mit dem Einkaufswagen“ (Baringhorst 2010b), wobei der Einkaufswagen in diesem Fall leer bleiben, der Konsum neuer Medientechnologien durch das Reparieren vermieden werden soll. Das Reparieren ist insofern eine Boykott-Aktion (Baringhorst 2010a, S. 12), wobei hier nicht der Erwerb eines bestimmten Produktes vermieden wird, sondern der Konsum an sich.

Den Beteiligten an den Repair Cafés ist bewusst, dass das Reparieren durch die Konsumvermeidung einen Bruch mit etablierten Routinen darstellt. So konstatiert ein 57-Jähriger Teilnehmer in Berlin, der sein Radio repariert: „Wir [müssen] von dieser Konsummentalität wegkommen." Und einer der Organisator*innen des Oldenburger Repair Cafés betont die Relevanz des Reparierens für den kulturellen Wandel hin zu einer nachhaltigen Gesellschaft: „Ohne eine Reparaturkultur, ohne eine brutale Nutzungsdauerverlängerung brauche ich nicht über Nachhaltigkeit [...] [zu] reden." Doch ist er skeptisch, was die Verbreitung der Reparaturpraxis und die Etablierung einer Reparaturkultur durch die Repair Cafés angeht:

„Das wird sich dann durchsetzen, wenn wir griechische Verhältnisse haben, dann genau gibt es mehr als nur eine intrinsische Motivation, sich damit zu beschäftigen. Also, wenn nicht exogene Schocks da sind, die dazu zwingen oder die auch einen ökonomischen Aspekt damit verbinden, wird das ganz, ganz schwierig.“

Mit den „griechischen Verhältnissen“ rekurriert er auf die Situation in Griechenland nach der Finanzkrise 2008, in der die griechische Wirtschaft kollabierte und das Land in den folgenden Jahren einen kulturellen Wandel erfuhr, indem die Praxis des Reparierens aufgrund der wirtschaftlichen Notlage an Relevanz gewann. Ist das Reparieren im Alltag oftmals unsichtbar, ein ,normaler“ Prozess und Routine (Jackson 2014, S. 225), so findet es in den Repair Cafés öffentlich und als gemeinsamer Akt statt - auch, um für die Praktik des Reparierens zu werben und über dessen Verbreitung einen kulturellen Wandel herzustellen.

Auch die Anstiftung \& Ertomis hat es sich zum Ziel gemacht, mit der Unterstützung der Organisation von Repair Cafés und der Netzwerkbildung unter diesen in Deutschland die Konsumgesellschaft hin zu einer Reparaturgesellschaft zu transformieren. Mit dem Slogan „Hier geht's zur Reparaturgesellschaft“ 
bewirbt die Anstiftung \& Ertomis das von Stiftungsmitarbeiter*innen herausgegebene Buch „Die Welt reparieren“ (Baier et al. 2016) und lädt damit zu einem kulturellen Wandel ein. Ob sich der politische Anspruch der Anstiftung \& Ertomis und auch vieler an den Repair Cafés Beteiligter, die Konsumgesellschaft hin zu einer Reparaturkultur zu wandeln, realisieren lässt, ist jedoch kritisch zu hinterfragen. So wurden in der empirischen Analyse auch Grenzen und Paradoxien in den Zielen und Praktiken der Reparierenden herausgearbeitet (siehe Abschn. 4.1). Diese schränken auch die Erfolgschancen des kulturellen Wandels durch das Reparieren ein. Auch bleiben die Reparaturinitiativen trotz ihrer gestiegenen Anzahl auf mittlerweile 868 Initiativen registriert (Stand 14. Mai 2021, s. Einleitung) eine Nische in der gegenwärtigen Konsumgesellschaft.

Ähnliche Erkenntnisse lassen sich für die Fairphone-Studie festhalten. Auch die Akteur*innen dieser Fallstudie wollen mit der Produktion bzw. Nutzung des Fairphones Gesellschaft gestalten - hin zu einer faireren und nachhaltigeren. Die politische Partizipation ist auch in dieser Fallstudie eine „Politik mit dem Einkaufswagen“ (Baringhorst 2010b). Das Fairphone-Unternehmen sowie die Nutzer*innen dieses Smartphones vermeiden zum einen den Konsum, also das Füllen des Einkaufswagens, indem sie das Fairphone als reparierbare Medientechnologie produzieren/kaufen und hierdurch Konsum im Sinne eines Erwerbens neuer Smartphones vermeiden. Zum anderen wird der Einkaufswagen in dieser Studie durch die Nutzer*innen bewusst mit einer fair produzierten Medientechnologie gefüllt, der Konsum damit zu einer politischen Partizipation mit dem Einkaufswagen. Auch in dieser Fallstudie verursachen die Akteur*innen durch die Produktion bzw. den Erwerb einer fairen Medientechnologie einen Bruch mit etablierten Routinen - dem regelmäßigen Neukauf von herkömmlich produzierten Smartphones und dem regelmäßigen Entsorgen in der „Wegwerfgesellschaft“. Genau diese wird vom Fairphone-Unternehmen und den Nutzer*innen des Fairphones kritisiert. So will das Fairphone-Unternehmen durch die Produktion eines fairen Smartphones den Markt für Medientechnologien beeinflussen (s. Abschn. 4.2). Dies wollen die Nutzer*innen des Fairphones unterstützen. So erklärt der 36-jährige Softwareentwickler und Fairphone-Nutzer:

„Ich fand es für mich sinnvoll [den Kauf des Fairphones, S. K.], [...] weil es halt nicht nur den Anspruch hat: ,Wir wollen fair produzierte Komponenten drin verbauen', sondern eben auch noch den Nachhaltigkeitsgedanken: ,Wir wollen nicht, dass es ein Wegwerfprodukt ist. ' Und damit, finde ich, handelt man konsequent, auf jeden Fall richtig, wenn man ein Produkt kauft, was kein Wegwerfprodukt ist, dann hilft man damit, die Folgen der Wegwerfgesellschaft zu minimieren.“ 
Der Kauf des Fairphones ist somit eine Buykott-Aktion, also der bewusste Kauf eines Produktes (Baringhorst 2010a, S. 12), durch den Gesellschaft gestaltet werden soll.

Dass auch in die politische Partizipation über das Fairphone Grenzen und Paradoxien eingeschrieben sind, zeigt die Diskussion der Ziele und Praktiken der Fairphone-Produzierenden und -Konsument*innen (s. Abschn. 4.1 und 4.2). So ist zum einen die Produktion des Fairphones weit davon entfernt, umfassend fair zu sein, noch handeln die Nutzer*innen des Fairphones konsequent nachhaltig in ihren Konsumpraktiken. Und dennoch versuchen das Fairphone-Unternehmen sowie die Nutzer*innen des Smartphones durch die Produktion und Aneignung dieser Medientechnologie, diese sowie den Markt für Smartphones zu ändern, um Gesellschaft zu verändern.

Schließlich wollen auch die Betreiber*innen der Onlineplattform Utopia.de eine „Politik mit dem Einkaufswagen“ (Baringhorst 2010b) betreiben, indem sie für von ihnen als nachhaltig eingeschätzte Produkte und Praktiken werben. Durch diese politische Partizipation über Medieninhalte, soll das konventionelle Konsumverhalten der Verbraucher*innen verändert und damit ein gesellschaftlicher Wandel provoziert werden - ebenso der Wandel zu einer nachhaltigeren Gesellschaft. So wird auf der Onlineplattform die Veränderung der Welt durch die Veränderung des Konsumverhaltens postuliert: „Unsere Kaufentscheidung bestimmt, welches Unternehmen erfolgreicher ist. Und diese Entscheidungen haben wir täglich selbst in der Hand. Und so kann am Ende unser bewusster Konsum eben doch die Welt verändern." (Winterer 2019b) Auf dem FacebookProfil hat die Utopia GmbH als Titelbild eine Grafik mit dem Slogan „Dein Kassenbon ist ein Stimmzettel. Jedes Mal" platziert (Stand 7. Oktober 2019) und betont damit die politische Bedeutung des Konsums.

Die Grenzen und Paradoxien der Ziele und Praktiken der Utopia GmbH wurden in Abschn. 4.2 herausgearbeitet. Sie sind auf die politische Partizipation in dieser Fallstudie zu übertragen. Denn auch wenn das Unternehmen explizit einen gesellschaftlichen Wandel durch die Beeinflussung der Konsumkultur unterstützen möchte, so regt es mit den auf der Onlineplattform publizierten Kaufempfehlungen, den Konsum letztendlich wieder an - was im Widerspruch zum Ziel der Nachhaltigkeit steht. So ist also auch die über die Onlineplattform Utopia.de stattfindende politische Partizipation letztendlich von Widersprüchen gekennzeichnet.

Zusammenfassend lässt sich festhalten, dass in allen drei Fallstudien Formen der Partizipation auszumachen sind, die in, durch, mit und über Medien stattfinden. Die partizipativen Praktiken zielen darauf ab, mit Konsumpraktiken Gesellschaft zu verändern, wobei hier Medien entweder für das Werben für 
eine bestimmte Art von Konsum, nämlich nachhaltigen Konsum, genutzt werden, oder aber Gegenstand des Konsums sind, indem entweder der Konsum von Medientechnologien vermieden werden soll oder bestimmte (nachhaltige) Medientechnologien konsumiert werden. Konsumkritischen Medienpraktiken (s. Abschn. 4.2) sind also Formen unkonventioneller politischer Partizipation, durch die die Akteur*innen im Sinne einer „Vita activa“ (Arendt 2002 [1958]) Gesellschaft abseits institutionalisierter Politik nachhaltiger gestaltet (wollen).

Verbraucher*innen werden im Moment des Konsumierens zu Bürger*innen, die „Politik mit dem Einkaufswagen“ (Baringhorst 2010b) betreiben, wie für die einzelnen Fallstudien herausgearbeitet wurde. Der nachhaltige Konsum ist die kulturelle Praxis der in den Fallstudien untersuchten Citizens, die als solche ein Gefühl der Zugehörigkeit erleben (Canclini 2003, S. 20; s. Abschn. 4.4). Bezieht man die theoretische Diskussion um die verschiedenen Formen des Citizenship ein (s. Abschn. 3.2.5), so lässt sich für die Akteur*innen der Fallstudien eine Vermischung verschiedener Formen proklamieren: So finden sich in den konsumkritischen Medienpraktiken zum einen die Form des civil Citizenship, in dem die Partizipation an Wirtschaft als Produzent*innen und Konsument*innen erfasst wird (Marshall 1992), da Unternehmen wie die Utopia GmbH oder das Fairphone-Unternehmen Gesellschaft über ihr unternehmerisches Handeln und Verbraucher*innen über ihren Konsum den Markt und Gesellschaft verändern wollen. Zum anderen finden sich in den Fallstudien die Formen des cultural Citizenship, welches die kreative und erfolgreiche Teilhabe an einer Kultur beschreibt (Turner 2001, S. 12; Hermes und Dahlgren 2006), da die Akteur*innen die Kultur der Konsum- und Wegwerfgesellschaft verändern wollen. Schließlich findet sich in allen drei Fallstudien die Form des do-it-yourself Citizenship (Ratto und Boler 2014b), wobei do-it-yourself hier literal verstanden werden kann als politische Partizipation im Moment des Reparierens von Medientechnologien und Selbermachens. Die Bürger*innen werden hier zu Prosument*innen (Toffler 1980), jedoch nicht nur in Hinblick auf Medieninhalte, wie es mit dem Konzept der ProdUser*innen traditionell in der Kommunikations- und Medienwissenschaft gedacht wird (Bruns 2008, 2009), sondern auch in Hinblick auf Medientechnologien, die von Nutzer*innen im Prozess des Reparierens in Repair Cafés oder als Nutzer*innen des reparierbaren Fairphones gestaltet werden.

Im Sinne Canclinis (2003, S. 45) ist der Konsum in den hier diskutierten Fallstudien eine „Übung“ von Citizenship, sind die konsumkritischen Medienpraktiken eine politische Handlung, die die Konsument*innen zu Bürger*innen ermächtigt.

Dabei findet der Konsum zwar im Privaten statt, wird aber öffentlich über verschiedene Internetmedien oder auch die öffentlich stattfindenden Repair Cafés 
inszeniert. Der feministische Slogan „das Private ist politisch“ (Hanisch 1970), gilt somit auch für die hier untersuchte Form des subpolitischen Handelns: den Konsum. Denn, wie die Fallstudien zeigen, ist auch der im Privaten stattfindende Konsum, hier die Entscheidung für das Reparieren von Medientechnologien, den Erwerb fair produzierter Medientechnologien oder aber die Information über nachhaltige Produkte über Onlineplattformen, ein Akt des Politischen, mit dem die Konsumierenden Gesellschaft gestalten wollen und damit eine Form der ,life politics“" (Giddens 1991, S. 215 ff.) praktizieren.

Gegen die These, das politische Engagement der Bürger*innen sei in den vergangenen Dekaden rückläufig (Dahlgren 2009, S. 1), zeigen die empirischen Ergebnisse, dass sich andere Formen der politischen Partizipation herausbilden, die als unkonventionelle Formen der politischen Partizipation definiert werden können (s. o.). Diese Formen zeigen, wie Menschen versuchen, mit Medientechnologien umzugehen, um zu einer nachhaltigen Gesellschaft beizutragen.

Die konsumkritischen Medienpraktiken sind nicht unorganisiert. Vielmehr wurde bereits im vorherigen Kapitel herausgearbeitet, dass die Akteur*innen, welche konsumkritische Medienpraktiken verfolgen, nicht alleine handeln, sondern in Vergemeinschaftungen, die mehr oder weniger intensiv koordiniert werden: So werden die Repair Cafés oder lokale Treffen von Fairphone-Nutzer*innen durch Ehrenamtliche an unterschiedlichen lokalen Orten veranstaltet, Unternehmen wie das Fairphone-Unternehmen oder die Utopia GmbH koordinieren „ihre“ Vergemeinschaftungen auch medienvermittelt über die jeweiligen eigenen Onlineplattformen oder Onlineangebote von Fremdanbietern wie Facebook, Twitter, Instagram oder Youtube. Die von Bennett und Segerberg (2012, S. 756) entwickelte Typologie des „digitally networked action“ (s. Abschn. 3.2.5), kann also auch auf die hier diskutierten Fallbeispiele angewendet werden: Sowohl die lokalen vis-à-vis stattfindenden Aktionen in den Repair Cafés oder den Treffen der Fairphone-Nutzer*innen als auch die medienvermittelten translokal stattfindenden Aktionen sind kollektive Aktionen, die stärker koordiniert werden als die konnektiven. Die Utopia GmbH koordiniert in den von ihr bespielten Onlinenetzwerke wie Facebook, Twitter und Instagram die Kommunikation, sodass auch in dieser Fallstudie eine kollektive Aktion (Bennett und Segerberg 2012, S. 756) ausgemacht werden konnte.

Sind die konsumkritischen Medienpraktiken Formen unkonventioneller politischer Partizipation, welche als kollektive Aktionen stattfinden, wie in diesem Teilkapitel argumentiert wurde, so liegt die Vermutung nahe, dass sich durch die kollektiven Aktionen soziale Bewegungen bilden. Auch zeigt das Datenmaterial, dass Akteur*innen der Fallstudien bewusst versuchen, soziale Bewegungen herzustellen. Inwiefern dies der Fall bzw. erfolgreich ist und die in Abschn. 4.4 
beschriebenen Vergemeinschaftungen, die in den drei Fallstudien ausgemacht wurden, einzelne soziale Bewegungen sind oder gar Teile einer umfassenderen sozialen Bewegung, wird im folgenden Kapitel diskutiert.

\subsection{Soziale Bewegungen für eine nachhaltige Gesellschaft und das "gute Leben"}

Auf der Basis der in den vorhergehenden Teilkapiteln vorgestellten Ergebnisse zu Vergemeinschaftung und politischen Partizipation soll im Folgenden diskutiert werden, ob die einzelnen Vergemeinschaftungen als soziale Bewegungen beschrieben werden können. Dabei ist nicht nur relevant, herauszuarbeiten, inwiefern eine Reparaturbewegung, Fairphone-Bewegung oder Bewegung der nachhaltig Konsumierenden im Allgemeinen bzw. Utopist*innen im Besonderen auszumachen ist, sondern auch, ob von einer übergeordneten konsumkritischen Bewegung gesprochen werden kann, deren Teile u. a. die drei zuvor genannten Bewegungen bilden, oder ob gar eine "Nachhaltigkeitsbewegung" existiert, welche auch die seit 2018 aktive Fridays-for-Future-Bewegung integriert (s. Einleitung). Entsprechend dieser Fragen wird zunächst für jede der drei Fallstudien einzeln erläutert, ob hier soziale Bewegungen auszumachen sind. Daran anschlieBend wird diskutiert, inwiefern eine konsumkritische Bewegung oder gar eine „Nachhaltigkeitsbewegung“ identifiziert werden kann. Dafür ist auf die Erläuterungen zur theoretischen Dimension der sozialen Bewegung zurückzugreifen: Die Bewegungsforschung benennt mindestens vier Merkmale sozialer Bewegungen: 1) Ziele der gesellschaftlichen Veränderung, 2) Protest als Mittel für sozialen Wandel, 3) einen Netzwerkcharakter und 4) eine symbolische Interaktion und ein Zugehörigkeitsgefühl der Akteur*innen (Ullrich 2015, 10 ff.; s. Abschn. 3.2.6). Mithilfe dieser Kriterien wurde das Datenmaterial der Fallstudien theoriegeleitet in den Blick genommen, in dem jedoch bereits im offenen Kodierprozess Aspekte sozialer Bewegungen sichtbar wurden. ${ }^{15}$

In der aus dem aktivistischen Kontext entstandenen aktuellen Literatur zum Reparieren und Reparaturveranstaltungen (z. B. Heckl 2013, S. 11; Baier et al. 2016) wird eine soziale Bewegung proklamiert. Aber kann hier tatsächlich von einer sozialen Bewegung gesprochen werden? Die Anstiftung \& Ertomis will durch die Unterstützung der Organisation von Reparaturveranstaltungen und der Vernetzung deutscher Reparaturinitiativen dazu beitragen, dass sich eine Reparaturbewegung bildet. Das Ziel der Vernetzung sei, den einzelnen Akteur*innen

${ }^{15}$ Zur Reparaturbewegung siehe auch Kannengießer (2018c, S. 224, d, S. 296 ff.). 
aufzuzeigen, dass sie Teil einer größeren Bewegung seien, erklärt ein Mitarbeiter der Anstiftung \& Ertomis:

\begin{abstract}
„Das wollen wir für die Reparatur-Initiativen erreichen, dass die feststellen: ,Moment mal, es gibt viele,' und merken, dass das, was hier passiert, nicht ein punktuelles Ereignis ist, sondern das ist eine gesellschaftliche Welle, die da gerade durchs Land geht. An allen Ecken und Enden sind Menschen, die nicht mehr hinnehmen wollen, dass der Konsument auf eine bestimmte Art zu handeln und zu konsumieren, festgelegt ist. Das ist, das erreicht man dadurch, in dem man eben Andere sichtbar macht und sich untereinander bekannt macht dadurch."
\end{abstract}

Ist diese „gesellschaftliche Welle“ als Reparaturbewegung zu bezeichnen, als eine politische Bewegung für das Reparieren?

Die von der Bewegungsforschung benannten vier Merkmale sozialer Bewegungen, geteilte Ziele und ein Zugehörigkeitsgefühl der Akteur*innen, das Merkmal des Protests und ein Netzwerkcharakter, sind auch für eine Reparaturbewegung auszumachen: Wie in Abschn. 4.2 gezeigt, verfolgen die an Repair Cafés beteiligten Akteur*innen ähnliche Ziele. Auch wenn diese divers sind, so dominieren doch die konsumkritischen Ziele der Müllvermeidung und der Ressourcenschonung durch eine Verlängerung der Nutzungsdauer der Konsumgüter. Auch ein Gefühl der Zugehörigkeit ist bei vielen Beteiligten zu finden, wie in Abschn. 4.4 erläutert wurde. Beide Merkmale zeigten, dass sich in den Repair Cafés Vergemeinschaftungen bilden. Auch das für soziale Bewegungen signifikante Merkmal des Protests ist in dieser Fallstudie auszumachen: Die Reparaturveranstaltungen sind Protestveranstaltungen, durch die die Akteur*innen Kritik an der Konsumgesellschaft üben. Doch sie gehen auch über den bloBen Protest hinaus und bieten mit dem Reparieren eine Alternative für das von ihnen kritisierte Handeln an. So ist das Reparieren selbst eine Protesthandlung gegen die Konsumgesellschaft. Der Netzwerkcharakter als viertes Merkmal sozialer Bewegungen ist ebenfalls in dieser Fallstudie auszumachen. So versuchen die Organisator*innen von Reparaturveranstaltungen zum einen, ein Netzwerk zwischen Personen, die Reparieren können und bei Reparaturen unterstützen wollen, und solchen, die Hilfe suchen, zu bilden, zum anderen werden auch Netzwerke unter den Repair Cafés und professionellen Dienstleister*innen, die gegen Entgelt reparieren, hergestellt. Und auch Netzwerke zwischen verschiedenen konsumkritischen Initiativen finden mit Repair Cafés statt und in diesen Räumen: So fungiert das Repair Café in Oldenburg als ein Anlaufpunkt für verschiedene konsumkritische Projekte, wie eine der Organisatorinnen erklärt: „Also wir sehen das irgendwie auch ein bisschen so als quasi Nabelpunkt dieses kulturellen Wandels 
hier in Oldenburg. Das hat sich irgendwie so raus kristallisiert, dass wir so ein Ort sind, an dem man scheinbar zusammenkommt.“

Sind dies Netzwerke auf lokaler Ebene, so versucht die Anstiftung \& Ertomis durch überregionale Treffen und eine Onlinevernetzung ein bundesweites Netzwerk zwischen den Reparaturinitiativen herzustellen (s. o.). Damit trägt die Stiftung nicht unwesentlich zu einer Reparaturbewegung bei, wobei sie als zentrale Akteurin das Netzwerk koordiniert und damit als „Gatekeeper“ letztendlich auch Inhalte und Form der Bewegung maßgeblich beeinflusst. Die bereits im vorherigen Kapitel herangezogene Typologie der "digitally networked action“ (Bennett und Segerberg 2012, S. 756) soll hier nochmal herangezogen und in Hinblick auf die Diskussion um eine mögliche Reparaturbewegung konstatiert werden, dass es sich hier um eine Form der kollektiven Aktionen (ebd.) handelt, die durch die Organisator*innen der Repair Cafés im Lokalen bzw. die Anstiftung \& Ertomis im Translokalen koordiniert werden.

Die vier Merkmale sozialer Bewegungen lassen sich also in dieser Fallstudie ausmachen und damit eine Reparaturbewegung beschreiben. Diese ist mitnichten homogen. Im Gegenteil, die in diesem Rahmen diskutierte Studie zeigt, dass sowohl Orte als auch Akteur*innen und Ziele einer Reparaturbewegung sehr heterogen sind (s. Abschn. 4.2). Spricht man also von einer Reparaturbewegung, so muss ihre Heterogenität berücksichtigt werden.

Mögliche Wirkungen und Erfolge einer Reparaturbewegung sind schwierig zu erfassen. Der Initiator des Oldenburger Repair Cafés betont die Relevanz individuellen Handelns für die Reparaturbewegung und einen gesellschaftlichen Wandel:

„,[Die Reparaturbewegung] ist wirklich ganz, ganz klein, aber das muss nicht klein bleiben. Wir wissen es eben nicht und weil wir es nicht wissen, sagen wir, dann haben wir auch kein Recht den Kopf in den Sand zu stecken und von vornherein das Ganze nicht zu machen.“

Die Organisator*innen der Repair Cafés appellieren mit diesen Veranstaltungen primär an die Verantwortung der Individuen für eine nachhaltige Gesellschaft, die sie im Reparieren und damit einem nachhaltigen Handeln unterstützen wollen. Gleichzeitig wollen sie aber auch über die öffentlichen Reparaturveranstaltungen Druck auf die Politik ausüben, wie einer der Organisor*innen des Oldenburger Repair Cafés erklärt: „Was ich will, ist schlicht und ergreifend, damit ein Kommunikationsinstrument subversiver Art zu etablieren, weil ich glaube, dass damit auch wirklich der Druck auf die Wirtschaft und die Politik wachsen kann.“

Einen solchen Druck wollen auch die Mitarbeitenden der Anstiftung \& Ertomis auf die Politik und Wirtschaft ausüben und beteiligen sich u. a. an 
dem „Runden Tisch für Reparatur“ (s. https://runder-tisch-reparatur.de/), über den unterschiedliche zivilgesellschaftliche Organisationen versuchen, Einfluss auf Politik und Wirtschaft zu nehmen. Auch diese Versuche können als Charakteristika sozialer Bewegungen wahrgenommen werden, durch die politisches und wirtschaftliches Handeln und damit Gesellschaft verändert werden soll. Auch wenn der kausale Zusammenhang schwierig zu rekonstruieren ist, so zeigt doch die Diskussion um ein „Recht auf Reparatur“ im Europäischen Parlament (Europäisches Parlament 2020), dass die Relevanz des Reparierens auch auf politischer Ebene wahrgenommen wird, was sicherlich auch ein Erfolg der Reparaturbewegung ist.

Auch in der Fairphone-Studie können Momente einer sozialen Bewegung wahrgenommen werden. So spricht der Gründer Bas van Abel explizit von einer Bewegung für faire Elektronik (,,a movement for fair electronics“, Fairphone 2016c). Konsument*innen sind durch das Unternehmen eingeladen, durch den Erwerb eines Fairphones Teil dieser Bewegung werden: „buy a phone, join a movement" (Fairphone 2015c). Hier wird noch einmal deutlich, wie der Akt des Konsumierens politisiert wird - als politische Partizipation innerhalb einer sozialen Bewegung, die sich durch den Erwerb einer bestimmten Medientechnologie konstituieren soll. Formulieren und artikulieren sich soziale Bewegungen traditionell als Protestbewegungen vor allem über öffentliche Demonstrationen, wie im Bereich Nachhaltigkeit z. B. über Jahrzehnte die Anti-Atomkraft-Bewegung und aktuell die Fridays-for-Future-Bewegung, die sich bis zur Covid-19-Pandemie (und sicherlich auch wieder danach) jeden Freitag an unterschiedlichen Orten weltweit im öffentlichen Raum zu Protestdemonstrationen und Kundgebungen traf, so politisiert das Fairphone-Unternehmen den Kauf eines Fairphones und verspricht den Verbraucher*innen, durch diesen Teil einer sozialen Bewegung für fair produzierte Elektronik bzw. Medientechnologien zu werden. Das Unternehmen sieht sich selbst als Ermöglicher dieser Bewegung und beschreibt sich als „social enterprise that is building a movement for fairer electronics“ (Fairphone 2015a). Diese soziale Bewegung ist im Sinne Bennetts und Segerbergs (2012, S. 756) eine stärker koordinierte kollektive Aktion.

Bemüht man die vier von Ullrich (Ullrich 2015, S. 10 ff.) herausgearbeiteten Kriterien sozialer Bewegungen, so lassen sich diese wie folgt auf eine mögliche Fairphone-Bewegung bzw. eine Bewegung für faire Elektronik/Medientechnologien anwenden: Wie in Abschn. 4.2 herausgearbeitet, teilen die Fairphone-Nutzer*innen das Ziel, durch den Kauf eines Smartphones, das unter fairen Bedingungen mit nachhaltigen Ressourcen produziert werden soll, zu einer nachhaltigeren Gesellschaft beizutragen. Dass diese Ziele aufgrund der Anzahl der fairen Ressourcen eingeschränkt sind und der Kauf damit 
v. a. symbolisch bzw. die Unterstützung einer Idee ist, ist den Nutzer*innen bewusst. In Hinblick auf das Zugehörigkeitsgefühl, das Ullrich als eines der Merkmale sozialer Bewegungen benennt, wurden widersprüchliche Ergebnisse festgehalten: Während die Kommunikation über das auf der Onlineplattform des Fairphone-Unternehmens integrierte Onlineforum sowie die vom FairphoneUnternehmen bespielten Profile auf Facebook, Twitter und Instagram zeigen, dass sich Fairphone-Nutzer*innen einer „Fairphone-Gemeinschaft“ zugehörig fühlen, war ein solches Zugehörigkeitsgefühl im Sample meiner Interviewpartner*innen nicht vorhanden. Die Organisation lokaler Treffen der Fairphone-Gemeinschaft verfolgen oftmals das Ziel, Unterstützung bei technischen Problemen in der Fairphone-Nutzung zu geben. Die Treffen haben aber auch einen sozialen Charakter (s. Abschn. 4.4). In diesen Veranstaltungen und der medienvermittelten Kommunikation der Fairphone-Nutzer*innen zeigt sich damit auch der sozialen Bewegungen typische Netzwerkcharakter, auch wenn sich in den lokalen Veranstaltungen nur eine kleine Zahl der Fairphone-Nutzer*innen trifft.

Die medienvermittelte Kommunikation und die lokalen Veranstaltungen sind in dieser Fallstudie aber weniger solche des Protests oder der Inszenierung des Protests wie es die Repair Cafés sind, als vielmehr Unterstützungsangebote bei technischen Problemen oder Veranstaltungen mit Freizeitaspekt (s. o.). Aber dennoch ist der Moment des Protests, ein weiteres Merkmal sozialer Bewegungen, in der Produktion bzw. dem Kauf des Fairphones enthalten, da das Fairphone-Unternehmen mit der Produktion dieses Smartphones nicht nur die Verbraucher*innen aufklären will, sondern auch eine Alternative auf dem Smartphone-Markt schaffen und diesen dadurch beeinflussen will, und zwar dahingehend, dass die Käufer*innen durch den Erwerb dieses Smartphones eine Buykott-Aktion durchführen, also durch den bewussten Kauf (Baringhorst 2010a, S. 12) eines Produkts, ein Zeichen setzen, Gesellschaft verändern zu wollen (s. Abschn. 4.1 und 4.2).

Zusammenfassend lässt sich festhalten, dass Merkmale sozialer Bewegungen auch in der Fairphone-Studie zu identifizieren sind: Sind die Mitglieder dieser Bewegung die Fairphone-Nutzer*innen und das Fairphone-Unternehmen, das die Bewegung maßgeblich inszeniert, so lassen sich die Merkmale der geteilten Ziele und des Zugehörigkeitsgefühls, des Netzwerkcharakters sowie des Protests hier ausmachen. $\mathrm{Zu}$ betonen ist jedoch, dass sich nicht alle Fairphone-Nutzenden einer solchen „Fairphone-Bewegung“ zugehörig fühlen (so z. B. nicht meine Interviewpartner*innen). Und dennoch sind auch die Käufer*innen des Fairphones sowie das Unternehmen selbst Teil einer „Fair-trade-Bewegung“ (Moore 2004), deren 
Anfänge Moore in die 1960er Jahre datiert (ebd., S. 73). ${ }^{16}$ Die Mitglieder der „Fair-trade-Bewegung“ sind Produzierende bzw. Konsumierende fair produzierter bzw. gehandelter Produkte. Das Ziel dieses Produzierens und Konsumierens ist die Transformation der Gesellschaft - hin zu einer nachhaltigeren. Hat die Fairtrade-Produktion bzw. der Konsum und damit die „Fair-trade-Bewegung“ eine längere Tradition im Bereich der Lebensmittel- oder Bekleidungsindustrie, so ist eine „Fair-trade-Bewegung“, die den Bereich der Medientechnologien fokussiert, in den Anfängen. Das Fairphone ist eine Technologie einer solchen „Fair-tradeBewegung“, wenn auch nicht die einzige; andere Initiativen sind z. B. die Fairmouse, eine Computermaus, die von der Nichtregierungsorganisation Nager e. V. hergestellt wird (s. Einleitung und Kannengießer 2016). Das Fairphone ist jedoch sicherlich, nicht zuletzt wegen der Öffentlichkeitsarbeit des Unternehmens über verschiedene Onlinemedien und die Präsenz des Gründers Bas van Abel in der massenmedialen Berichterstattung, der bekannteste Versuch fairer Medientechnologieproduktion und damit Treiber einer sozialen Bewegung, die den Fokus auf faire Medientechnologien legt.

Auch in der Fallstudie von Utopia.de können unter Heranziehung der von Ullrich (2015, S. 10 ff.) ausgearbeiteten Merkmale sozialer Bewegungen Momente einer sozialen Bewegung ausgemacht werden. Denn wie die Analyse zeigte, vernetzt sich über die Onlineplattform Utopia.de eine Vergemeinschaftung der „Utopist*innen“, die Ziele teilen und sich der Gemeinschaft zugehörig fühlen (s. Abschn. 4.4). Die Utopia GmbH koordiniert über die Onlineplattform Utopia.de und die von ihr bespielten Onlinenetzwerke wie Facebook, Twitter und Instagram die Kommunikation dieser Bewegung, sodass auch in dieser Fallstudie eine kollektive Aktion (Bennett und Segerberg 2012, S. 756) ausgemacht werden konnte. Das Moment des Protests kann in den auf der Onlineplattform thematisierten Inhalten identifiziert werden, in denen eine bestimmte Art von Konsum kritisiert wird und in denen von der Utopia GmbH als nachhaltig eingestufte Produkte und Praktiken beworben werden (s. Abschn. 4.1), um Verbraucher*innen zum nachhaltigen Konsumieren anzuhalten. Somit werden Boykott- bzw. Buykott-Aktionen (Baringhorst 2010a, S. 12) auf der Onlineplattform Utopia.de und den von der Utopia GmbH bespielten Profilen auf Onlinenetzwerken vom Unternehmen sowie seinen Utopist*innen thematisiert und beworben, da zum Kauf als nachhaltig eingestufter Produkte bzw. zur Vermeidung des Kaufs als nicht nachhaltig eingestufter Produkte aufgerufen wird. Explizit spricht die Utopia GmbH jedoch nicht von einer sozialen Bewegung, wenngleich sie konstatiert, „dass nachhaltiger Konsum sich nur dann auf breiter gesellschaftlicher Basis durchsetzen wird,

${ }^{16}$ Zur historischen Entwicklung des fairen Handels s. Hauff und Claus (2012, S. 84 ff.). 
wenn die Angebote attraktiv - und damit massen(-markt-)tauglich - sind. Deshalb wollen wir es unseren Nutzern so leicht und so attraktiv wie möglich machen.“ (Utopia 2019c) Diese „Massentauglichkeit“ zeigt, dass die Utopia GmbH das Ziel einer gesellschaftlichen Transformation hin zu mehr Nachhaltigkeit verfolgt und dass Momente einer sozialen Bewegung ausgemacht werden können, wenngleich sicherlich nicht von einer Bewegung der „Utopist*innen“ zu sprechen ist. Vielmehr können die Utopia GmbH und die „Utopist*innen“ bzw. von ihnen bespielte weitere Internetmedien als Teil einer breiteren sozialen Bewegung wahrgenommen werden, die sich für nachhaltigen Konsum einsetzt, nachhaltige Güter produziert bzw. konsumiert und damit die gegenwärtige Konsumgesellschaft nachhaltiger gestalten möchte, wobei Konsum nicht gänzlich abgelehnt wird, sondern ein nachhaltiger Konsum beworben bzw. verfolgt wird.

In dieser Konsumkritik liegt eine zentrale Gemeinsamkeit der Fallstudien. Denn gemein ist den sozialen Bewegungen, die in den drei Fallstudien ausgemacht wurden, dass ihre Mitglieder (eine bestimmte Art von) Konsum kritisieren bzw. mit ihrem Konsum einen Beitrag zu einer nachhaltigen Gesellschaft leisten (wollen). Medien spielen für die hier untersuchten Bewegungen eine zentrale Rolle, da in Medieninhalten (eine bestimmte Art von) Konsum kritisiert wird bzw. für nachhaltigen Konsum geworben wird (wie in der Fallstudie Utopia.de) und Medientechnologien selbst im Fokus der Bewegungen stehen, die deren Produktion (wie in der Fallstudie zum Fairphone) oder deren Aneignung (wie in der Fallstudie zum Fairphone und den Repair Cafés) nachhaltiger gestalten (wollen). Die hier untersuchten Bewegungen lassen sich damit als Teil einer größeren und heterogenen „konsumkritischen Bewegung“ (Kannengießer und Weller 2018b, S. 16) beschreiben, in der eine Vielzahl unterschiedlicher Akteur*innen in verschiedenen „konsumkritischen Projekten und Praktiken“ (ebd., S. 7) agiert. Die Fallstudien sind in dieser Reihe von Projekten zu denken, mit denen Akteur*innen in ihrem Alltagshandeln im Kontext der Konsumgesellschaft versuchen, einen Beitrag für eine nachhaltige Gesellschaft zu leisten. So ist konsumkritisches Handeln auch in anderen Projekten, wie Transition Towns, Urban Gardening, Tauschringen bzw. -parties o. ä. zu finden (s. wissenschaftliche Analysen verschiedener Projekte in Kannengießer und Weller 2018a). Diese Projekte greifen traditionelle Handlungen wie das Reparieren, Gärtnern oder Tauschen auf, inszenieren sie im öffentlichen Raum und politisieren sie als Handlungen für eine nachhaltige Gesellschaft (s. detaillierter Abschn. 4.5). Oftmals sind Netzwerke zwischen solchen unterschiedlichen konsumkritischen Projekten auszumachen, sodass sich eine breitere konsumkritische Bewegung entwickelt. Ob auch eine solche konsumkritische Bewegung einen Werte- und Gesellschaftswandel erwirken kann, bleibt zu beobachten. 
Medien spielen für diese konsumkritische Bewegung v. a. eine Rolle für die Vernetzung der Mitglieder, die Mobilisierung und Artikulation. Die Fallstudien zeigen aber auch, dass Medientechnologien selbst Objekt der Praktiken der Aktivist*innen sozialer Bewegungen sind.

Open Access Dieses Kapitel wird unter der Creative Commons Namensnennung 4.0 International Lizenz (http://creativecommons.org/licenses/by/4.0/deed.de) veröffentlicht, welche die Nutzung, Vervielfältigung, Bearbeitung, Verbreitung und Wiedergabe in jeglichem Medium und Format erlaubt, sofern Sie den/die ursprünglichen Autor(en) und die Quelle ordnungsgemäß nennen, einen Link zur Creative Commons Lizenz beifügen und angeben, ob Änderungen vorgenommen wurden.

Die in diesem Kapitel enthaltenen Bilder und sonstiges Drittmaterial unterliegen ebenfalls der genannten Creative Commons Lizenz, sofern sich aus der Abbildungslegende nichts anderes ergibt. Sofern das betreffende Material nicht unter der genannten Creative Commons Lizenz steht und die betreffende Handlung nicht nach gesetzlichen Vorschriften erlaubt ist, ist für die oben aufgeführten Weiterverwendungen des Materials die Einwilligung des jeweiligen Rechteinhabers einzuholen.

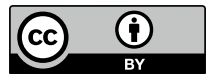

